\title{
Experimentelle Aufmerksamkeitsuntersuchungen an normalen und hirnverletzten Soldaten.
}

\author{
Von \\ Dr. Friedrich v. Rohden (Landesheilanstalt Nietleben bei Halle), \\ zur Zeit Kriegsassistenzarzt.
}

(Eingegangen am 30. Dezember 1918.)

Einleitung.

Die vorliegende Arbeit ist aus Untersuchungen hervorgegangen, die in den beiden letzten Jahren an hirnverletzten und normalen Soldaten im psychologischen Laboratorium des Sonderlazaretts für Hirnverletzte an der Landesheilanstalt Nietleben (Direktor: Stabsarzt Professor Dr. Pfeifer) und in dem der Universität Halle (Direktor: Geheimer Rat Professor Dr. Ziehen) angestellt wurden.

Aufmerksamkeitsuntersuchungen bilden einen kleinen, aber nicht unwesentlichen Teil der dem psychologischen Laboratorium eines Hirnverletztenlazaretts gestellten Aufgaben. Wenn wir im psychologischen Experiment auch nur irgendeine Frage des Seelenlebens untersuchen wollen, so tritt uns als erste Forderung die entgegen, daß unsere Versuchspersonen ihre Aufmerksamkeit mit möglichst intensiver und gleichmäßiger Konzentration betätigen. Die Aufmerksamkeit ist die formale Voraussetzung und Vorbedingung jeder intellektueller Leistung. Ohne große Aufmerksamkeit keine genaue Wahrnehmung und Beobachtung, kein sicheres Behalten und kein intensives Denken. Daher kann die Wertung jeder Intelligenzprüfung und jedes psychologischen Experiments nur dann Anspruch auf Gültigkeit erheben, wenn der Aufmerksamkeitszustand der Versuchsperson keine unbekannte Größe ist. Fällt eine psychologische Prüfung schlecht aus, so darf nicht ohne weiteres auf einen Defekt geschlossen werden. Man wird sich vielmehr in erster Linie die Frage vorzulegen haben, ob das mangelhafte Ergebnis nicht durch Aufmerksamkeitsstörungen bedingt ist, vorausgesetzt, daß andere Fehlerquellen, wie die erhebliche Ausdehnung der normalen Schwankungsbreite auch nach der negativen Seite oder der Einfluß von Bewußtseins- und Affektsstörungen ausgeschlossen werden können. Eine Aufmerksamkeitsprüfung wird also nicht zu umgehen sein. Erst ihr Ausfall liefert uns einen Maßstab zur richtigen Beurteilung der Versuchsergebnisse. Jeder Hirnverletzte wird daher bei uns zuerst einer gründlichen Aufmerksamkeitsprüfung unterzogen. 
Bei der weitgehenden Meinungsverschiedenheit über das Wesen der Aufmerksamkeit bedarf es zunächst einer kurzen Verständigung über die Bedeutung, die im folgenden dem Begriff der Aufmerksamkeit beigelegt werden soll. Nach Ziehen ist die Aufmerksamkeit das Resultat eines Selektionsprozesses. Und zwar vollzieht sich beim Akt des Aufmerkens eine Auswahl unter einer Anzahl gleichzeitig gegebener Empfindungen. Es siegt diejenige Empfindung, die den stärksten assoziativen Impuls hat, d. h. eine Empfindung, die infolge ihrer Intensität, ihres Gefühlstons, ihres Kontrastes und ihrer Assimilierbarkeit den anderen Empfindungen überlegen ist. Die siegende Empfindung, an die sich die Ideenassoziation anschließt, befindet sich im Zustande der Aufmerksamkeit.

Es kann hier nicht unsere Aufgabe sein, theoretisch Stellung zu nehmen zur Berechtigung dieser oder irgendeiner der zahlreichen anderen Auffassungen vom Wesen der Aufmerksamkeit. Unsere experimentellen Aufmerksamkeitsuntersuchungen verfolgen lediglich den praktischen Zweck, eine sichere Grundlage zu gewinnen für die Beurteilung der Intelligenzprüfung und des psychologischen Experiments bei hirnverletzten und normalen Soldaten. Vom Standpunkt der intellektuellen Auffassung der Aufmerksamkeit würde sich die hier zu beantwortende Fragestellung etwa folgendermaßen formulieren lassen: Wie vollzieht sich die Auswah] der Aufmerksamkeit unter mehreren gleichzeitig gegebenen Reizen ?

Ziehen unterscheidet eine sensorielle und eine intellektuelle Aufmerksamkeit, je nachdem sie anf Empfindungen oder Vorstellungen gerichtet ist. Die vorliegenden Untersuchungen beschränken sich auf die Prüfung der sensoriellen Aufmerksamkeit, und zwar lediglich auf op. tischem Gebiet. Hierbei richten wir unser Augenmerk:

I. Auf den Umfang der Aufmerksamkeit.

II. Auf die Vigilität nud Tenazität der Aufmerksam. keit.

\section{I.}

\section{Tachistoskopische Untersuchung des Aufmerksamkeitsumfanges.}

d. Psychologische Vorbemerkungen.

Zu den formalen Eigenschaften des Aufmerksamkeitszustandes gehört der sogenannte Umfang der A ufmerksamkeit. Wir verstehen darunter die An. zahl der momentan dargebotenen Objekte, die gleichzeitig von der Aufmerksam. keit erfaßt werden können. Als Maß des Aufmerksamkeitsumfanges gilt die Zahl eben dieser simultan erfaßbaren Elemente.

Die Frage, wieviel Objekte gleichzeitig von der Aufmerksamkeit umspannt werden können, hat die psychologische Experimentalforschung vielfach beschäf. tigt. Daß nur eine begrenzte Zahl von Gegenständen uns gleich zeitig klar und deutlich gegeben sein kann, diese Erkenntnis ist begreiflicherweise nicht eine Errungensehaft erst der letzten Jahrzehnte. Aber eine exakte Beantwortung des Frage, wieviel Empfindungen bei momentaner Exposition im Maximum auf ein- 
mal aufgefaßt werden können, hat man wohl erst in neuerer Zeit versucht. Man hat sich zu diesem Zweck der tachistoskopischen Methode bedient, von der Voraussetzung ausgehend, da $B$ das, was im Zeitraum von wenigen Tausendstel Sekunden erfaßt und bis zu Protokollabgabe festgehalten werden kann, zur Messung des Aufmerksamkeitsumfangs verwendbar sein müsse (Dürr).

Das Tachistoskop ist eine Vorrichtung, die eine Einwirkung von optischen Reizen auf das Auge der Versuchsperson während einer kurzen meßbaren Zeit unter konstanten Bedingungen ermöglicht. Die Expositionszeit muß dabei so kurz gewählt werden, da $B$ Augenbewegungen und Aufmerksamkeitswanderungen ausgeschlossen sind. Wird diese Bedingung nicht erfüllt, so haben wir es nicht mit einem, sondern mit mehreren aufeinanderfolgenden Akten der Aufmerksamkeit zu tun, also nicht mit einer simultanen, sondern mit einer sukzessiven Auffassung der Objekte. Die Folge davon wäre, daß eine größere Anzahl von Einzelelementen festgehalten werden könnte als bei einer Expositionszeit, die Augenbewegungen und Aufmerksamkeitswanderungen ausschließt. Wenn auch über die Expositionszeit, die diesen Voraussetzungen genügt, völlige Übereinstimmung noch nicht erzielt ist, so scheint doch so viel festzustehen, da $\beta$ bei einer Zeit unter $100 \sigma$ die Darbietung der optischen Eindrücke gleichzeitig und in eine $m$ Augenblick erfolgt. Dabei entspricht $1 \sigma$ einer $1 / 1000$ Sekunde.

Als optische Reizobjekte benutzt man entweder Punkte, Striche und geometrische Figuren oder Zahlen, Buchstaben, Worte, Sätze, Farben, Bilder. Die Anzahl der bei kürzester Darbietung gleichzeitig erkannten optischen Reize wird man also nach unserer Definition als Maß des Aufmerksamkeitsumfangs anzusehen haben.

Es sind eine ganze Reihe von A ufmerksamkeitsapparaten angegeben und im Gebrauch. Als am einfachsten, aber auch am ungenauesten haben sich Apparate mit photographischem Momentverschluß erwiesen. Die guten Tachistoskope arbeiten entweder mit einer Fallvorrichtung oder mit einer rotierenden Scheibe. In allen Fällen wird das vorher verdeckte Objekt durch eine kleine Spalte für den Bruchteil einer Sekunde dem Auge der Versuchsperson sichtbar. Die Expositionszeit läßt sich durch elektrische Messung bestimmen.

Der erste, der die Wundtsche Fragestellung nach dem Bestand an simultanen optischen Vorstellungen analysierte, war Cattel. Seine grundlegenden und vielfach bestätigten Untersuchungen hatten ergeben, da $\beta 4$ bis 6 unverbunden nebeneinander gestellte Reize, wie Linien, Zahlen, Buchstaben, eben noch bei einer Expositionszeit von $10 \sigma$ richtig erkannt und wiedergegeben werden können. Da die Auffassung einer größeren Anzahl flüchtig exponierter Reize im allgemeinen nicht möglich ist, so nimmt man seither im Anschluß an die $W$ und tsche Deutung dieses Befundes vielfach an, daß der Umfang der A ufmerksamkeit 4 bis 6 unverbundene Einheiten umfassen kann, wobei die kleinere dieser Zahlen für relativ ungeübte, die größere für geübte Beobachter gilt (W undt, Ziehen u. a.).

Ähnliche Beobachtungen auf anderen Gebieten machen es wahrscheinlich, daß es sich bei diesem Grenzwert nicht um eine bloße Eigenschaft des einzelnen Sinnesgebiets, sondern um eine Konstante der A ufmerksamkeit selbst handelt. Auch mit dem Tastsinn kann man nämlich eben noch 6 in passenden Distanzen einwirkende, punktuelle Druckreize unterscheiden, wogegen eine größere Zahl nicht mehr in eine einheitliche Vorstellung zusammengefaßt werden kann. Es ist daher offenbar nicht zufällig, daB die Punktschrift der Blinden bei der Maximalzahl von 6 Punkten für ein Buchstabenzeichen stehengeblieben ist (Wundt). - Ferner ist Quandt der Nachweis gelungen, daß der Umfang der Aufmerksamkeit beim Gehörsinn denselben Bedingungen unterliegt wie beim Tast- und Gesichtssinn; denn auch hier konnten von den Versuchspersonen im Maximum 6 einfache Gehörseindrücke simultan perzipiert werden. 
Auf Grund dieser Ergebnisse hat man von einer Konstanz des A uf merksamkeitsumfangs für alle Sinnesgebiete gesprochen. Daß dieses Gesetz von der Konstanz des Aufmerksamkeitsumfangs unter pathologischen Bedingungen Ausnahmen erleidet, zeigen die Untersuchungen an Hirnverletzten. Es scheint jedoch in bestimmten Fällen auch unter physiologischen Verhältnissen keine Geltung zu haben. Die Zahl von 4 bis 6 Einheiten als optimale Aufmerksamkeitsleistung war von Cattel gefunden worden für Punkte, Striche, Zahlen und Buchstaben, die ohne besondere Anordnung in gleichen Abständen und in horizontaler Reihe nebeneinandergestellt waren, ein Ergebnis, das von allen Nachuntersuchern bestätigt werden konnte. Indes blieb es auch Cattel nicht verborgen, daß unter bestimmten Versuchsbedingungen die Zahl der gleichzeitig perzipierten Elemente nicht unwesentlich stieg. Er konnte nämlich zeigen, daß man dreimal soviel Buchstaben auffaßt, wenn sie Wörter bilden, als wenn dies nicht der Fall ist. Auch dieser Befund hat sich in Nachuntersuchungen als richtig herausgestellt. Bei Buchstaben beträgt die Zahl der simultan erfaßbaren Elemente für den Erwachsenen im Durcchnitt nur dann höchstens 6, wenn es sich um Konsonanten handelt, die in nicht alphabetischer Reihenfolge sinnlos aneinandergereiht sind. Bringt man jedoch in geeignetem Wechsel Vokale unter die Konsonanten, so daß3 eine gewisse Gliederung des sinnlosen Buchstabenkomplexes entsteht, so steigt die Zahl gleichzeitig erkennbarer Buchstaben bis auf 10. Ebenso werden auch gruppierte und gegliederte Punkte, Striche und geometrische Figuren richtiger beurteilt als ungegliederte (Freeman). Das gleiche gilt für symmetrisch angeordnete Zahlen (Me u mann). Es ergibt sich also, daß jede Gruppierung, Gliederung und Symmetrie die Auffassung erleichtert. Geht man nun von den sinnlosen Silbenverbindungen zu sinnvollen Worten über, so nimmt der Aufmerksamkeitśsumfang scheinbar abermals zu. Der Erwachsene erkennt dann im tachistoskopischen Versuch Worte, die aus 15 bis 20 und mehr Buchstaben bestehen. Bei geläufigen Sätzen und Sprichworten erreicht der Aufmerksamkeitsumfang sein Maximum (Zeitler). - Man kann also sagen, daß eine Steigerung des Aufmerksamkeitsumfangs mit zunehmender Ordnung und steigendem Sinn erfolgt, und zwar so, daß der Aufmerksamkeitsumfang von den sinnlosen Buchstabenkomplexen bis zu den sinnvollen Satzgebilden sich von cinem Minimum zn einem Maximum bewegt.

Auf die Erklärung dieses psychologischen Tatbestandes kann hier nicht näher eingegangen werden. Daß es sich jedoch nur um scheinbare Ausnahmen des Gesetzes von der Konstanz des Aufmerksamkeitsumfanges handelt, ergibt sich schon aus folgender Überlegung: Sieht man nämlich mit Wirth die Einzelobjekte, die festgehalten und wiedergegeben werden, nicht in den einzelnen Buchstaben, sondern in kurzen Worten und geläufigen Silben, mit anderen Worten, faßt man geläufige Silben und Worte als Einheit auf, so besteht kein prinzipieller Unterschied zwischen beiden Komplexen. Hier werden im Maximum 4 bis 6 Silben, dort im Maximum 4 bis 6 Buchsta be n erkannt. Der Aufmerksamkeitsumfang umfaßt also hier ebensoviel Silben wie dort Buchstaben. In beiden Fällen wird der an sich konstante Umfang sozusagen in verschiedenen Einheiten gemessen, wie wenn z. B. eine eindeutig bestimmte räumliche Ausdehnung einmal in Metern, das andere Mal in Fuß ausgedrückt wird.

\section{B. Versuchsanordnung.}

Die eigenen Untersuchungen wurden an zwei verschiedenen Apparaten angestellt, dem Wundtschen Falltachistoskop und dem von Netschajeff angegebenen Apparat. Die Konstruktion und Anwendungsweise des Wundtschen Tachistoskops kann als bekannt vorausgesetzt werden. Weniger gebräuchlich 
dürfte der Netschajeffsche Apparat sein, der nach dem Prinzip der rotierenden Scheibe konstruiert ist. Der Apparat besteht aus einem aufrecht gestellten Holzbrett mit einer $7 \mathrm{~cm}$ langen und $5 \mathrm{~cm}$ breiten Öffnung. Auf der Rückseite des Brettes befindet sich eine runde Blechscheibe, an der zwei gegeneinander verschiebliche Scheibenflügel angebracht sind. Vermittels einem dieser Flügel bleibt die Brettöffnung für gewöhnlich verschlossen. Die Flügel werden nun durch eine Schraubenvorrichtung in der Weise gegeneinander verschoben, daß zwischen ihnen ein variierbarer, sektorenförmiger spalt entsteht. Setzt man nun die Scheibe durch ein Gewicht in rotierende Bewegung, so wird das hinter dem Flügel befindliche Objekt für die Versuchsperson in dem Augenblick sichtbar, wo die Flügelspalte vor der Holzöffnung vorbeigleitet. Durch Vergrößcrung oder Verkleinerung der Spalte und durch Veränderung der Rotationsgeschwindigkeit der Flügel ist die Expositionszeit innerhalb weiter Grenzen variierbar.

In der Form, wie das Netschajeffsche Tachistoskop von der Firma Zimmermann-Leipzig in den Handel gebracht wird, fehlt allerdings eine Vorrichtung zur Bestimmung der Expositionszeit. Da von Netschajeff nirgends die Frage der Zeitmessung berührt wird und Angaben über Expositionszeiten fehlen, so war die Konstruktion einer Zeitmessungsvorrichtung erforderlich, um den Apparat für wissenschaftliche Zwecke überhaupt erst brauchbar zu machen. Die Vorrichtung, die nach den Angaben von Ziehen und mir von der Firma PolikeitHalle ausgeführt, wurde, bedient sich zur Zeitmessung des Prinzips von Stromschluß und Stromöffnung. Beim Beginn der Expositionszeit wird ein Strom eingeschaltet, der das Uhrwerk eines mit dem Tachistoskop rerbundenen Chronoskops in Bewegung setzt. Im Augenblick, wo das exponierte Objekt verschwindet, wird der Chronoskopstrom unterbrochen. Mit dieser Verbesserung arbeitet der Netschajeffsche Apparat zur Zufriedenheit. Er hat gegenüber dem Wundtschen Tachistoskop eine Reihe von Vorzügen, die ihn für Versuche im Hirnverletztenlazarett geeigneter erscheinen lassen als das weit subtilere und kostspielerische Falltachistoskop.

Dabei erfüllt er alle Bedingungen, die nach $W$ undt an ein gutes Tachistoskop gestellt werden müssen: 1. Die Exposition des Reizes ist gleichzeitig und so kurz, daß Augenbewegungen und Wanderungen der Aufmerksamkeit von einem Teil des Objektes zum anderen ausgeschlossen werden können. 2. Die Einwirkungsdauer des Lichtreizes ist räumlich so beschränkt und zugleich durch die Anbringung eines Fixationspunktes vor der Exposition so bestimmt, da $\boldsymbol{\beta}$ das Objekt im wesentlichen in den Bereich des direkten Sehens fällt und alle Einzelheiten annähernd gleich scharf gesehen werden können. 3. Die Versuche mit dem Netsch a jeffschen Apparat sind bei normaler Tagesbeleuchtung des Versuchsraumes durchzuführen, so daß alle störenden Wirkungen auf die Netzhautadaption verwieden werden können, wie sie bei tachistoskopisehen Apparaten vorkommen, bei denen plötzliche Erhellungen und Verdunklungen des Gesichtsfeldes stattfinden. 4. Die Anordnung einer Fixationsmarke, ferner die Möglichkeit der Selbstauslösung der Exposition und schließlich die relative Geräuschlosigkeit, mit der sich die Exposition des Objektes vollzieht, gewährleisten das Vorliegen der günstigsten Aufmerksamkeitsbedingungen beim Beobachtungsakt.

Als optische Reizobjekte dienten ein- bis sechsstellige Zahlen- und Buchstabengruppen, deren Auswahl und Zusammensetzung unter zwei Gesichtspunkten erfolgte: Erstens wurde eine möglichst große Mannigfaltigkeit sowohl der Komplexe an und für sich wie auch ihrer einzelnen Bestandteile angestrebt. Außerdem mußten die Zahlen so gewählt werden, daß sie zu assoziativen Verknüpfungen möglichst keine Veranlassung gaben. Zahlenverbindungen wie 1871 oder 1918 durften also nicht verwandt werden. Bei Konstruktion der Buchstabenreize war die den assoziativen Faktor ausschließende Sinnlosigkeit dadurch zu 
erzielen, daß unter Vermeidung ron Vokalen und großen Anfangsbuchstaben bestimmte Konsonanten in der Weise aneinandergereiht wurden, daß die entstehenden Komplexe keine Anklänge an geläufige Wortbilder enthielten. Anderseits durfte die Erkennung nicht unnötig erschwert werden. Es mußte daher auf ungewöhnlichere Buchstaben und auf solche verzichtet werden, die zur Verwechslung Anlaß geben konnten. Gleichzcitig waren die formalen Eigentümlichkeiten, welche die Auffassung der Objekte beeinflussen, so gleichförmig wie möglich zu machen. Beispielsweise wurde auf möglichst gleiche Zahl und Verteilung der mittel-, ober- und unterzeiligen Konsonanten gesehen. I'm schließlich auch noch die Gleichheit der Objekte in bezug auf die Anzahl der exponierten Einzelreize zu wahren, setzten sich die Buchstabenreihen ebenso wie die Zahlenreihen aus zehn rerschiedenen Elementen zusammen, nämlich aus den Zahlen 0 bis 9 und den Konsonanten b, d, f, g, k, l, p, r, s und t. Was GröBe und Form der benutzten Typen betrifft, so mag hier die Bemerkung genügen, da 3 die Reizkarten mit einer Kontinental-Antiqua-Schreibmaschine, Schriftgröße Korpus, hergestellt sind.

Die Entfernung des Auges von der Reizkarte wurde so gewählt, daß sie innerhalb der Grenzen des deutlichsten Schens lag. In Vorversuchen war der Versuchsperson Gelegenheit gegeben, die richtige Akkommodation herauszufinden und die Aufmerksamkeit räumlich und zeitlich zweckmäßig auf den Fixationspunkt einzustellen, der vor der Mitte des zu exponierenden Objektş in geeigneter Weise angebracht war. Auf die Bedeutung des Fixierpunktes und auf die Frage, ob eine genaue Fixation nicht unter Umständen störend wirkt und den Aufmerksamkeitsumfang herabsetzt, wird an anderer stelle näher einzugehen scin.

Als wesentlicher Vorzug des Wundtschen und Netschajeffschen Tachistoskops gilt die Möglichkeit, die Versuche bei natürlichem Tageslicht anzustellen. Auf diese Weise können die bei künstlicher Beleuchtung nicht zu vermeidenden großen Helligkeitsunterschiede und deren störenden Wirkungen auf die Netzhautadaptation umgangen werden. Sichumann hat gezeigt, daß bei Tageslicht der Beleuchtungsfaktor von geringer Bedeutung ist. Das Resultat ist innerhalb weiter Grenzen von der Helligkeit der Beleuchtung unabhängig. Es soll z. B. keinen wesentlichen Unterschied ausmachen, ob der Himmel klar oder leicht hewölkt ist, wenn nur die Objekte rom Fensterlicht direkt getroffen werden. Dementsprechend wurde der Apparat so aufgestellt, aaß das volle Tageslicht auf das Expositionsfeld fiel. Der Apparat war dabei etwa $2 \mathrm{~m}$ rom Fenster entfernt.

Um das Vorliegen des Aufmerksamkeitsmaximums im Moment der Exposition zu gewährleisten, war es notwendig, durch Signalgebung die Versuchsperson auf die nachfolgende Exposition des Objektes vorzubereiten. Es ist von verschiedenen Autoren der Vorschlag gemacht worden, die Auslösung der Exposition der Versuchsperson selbst zu iiberlassen (Freeman, Finzi). Letzterer bemerkt, daß diese Anordnung in allen Fällen als eine wesentliche Unterstützung der Aufmerksamkeitsspannung betrachtet wurde. Beim Wundtschen Apparat begegnet eine solche Selbstauslösung der Exposition manchen Schwierigkeiten, in erster Linie wegen der Abhängigkeit der Fallgeschwindigkeit von der Technik des Loslassens des Fallgewichtes. Dagegen ist beim Netschajeffschen Tachistoskop die Selbstauslösung möglich, ohne daß die Expositionszeit dadurch beeinflußt wird. T̈ber den Ausfall dieser Versuchsanordnung wird weiter unten zu berichten sein.

Die Expositionszeit war so zu wählen, daß jedes der dargebotenen Elemente des Komplexes bei normaler Aufmerksamkeitsspannung als selbständige Einheit deutlich hervortrat. Anderseits mußte auch die Grundbedingung aller tachistoskopischen Versuche erfüllt werden: Gleichzeitige und momentane Darbietung des Reizkomplexes bei Vermeidung von Augenbewegungen und Aufmerk- 
samkeitswanderungen (vgl. S. 227). Die ganz kurzen Expositionszeiten bis zu $10 \sigma$ wie sie von Cattel, Messmer und Zeitler vorgeschlagen wurden, waren hier nicht zu gebrauchen, weil diese Minimalzeiten große Übung und mehrfache Wiederholung der Versuche voraussetzen. Vorversuche ergaben nun, daß bei unserm Versuchsmaterial im allgemeinen eine Expositionszeit von 15-30 $\sigma$ die physiologische Anpassung an den Reiz und dadurch einen scharfen Eindruck des Objekts ermöglichte.

Schließlich noch einige Bemerkungen zu der viel umstrittenen Frage, ob das Objekt nur einmal zu exponieren sei, oder ob die Darbietungen sich so oft zu wiederholen haben, bis vollständig richtige Erkennung stattfindet. Cattel hatte bei seinen grundlegenden Versuchen den zweiten Weg gewählt. Seine Werte für den Aufmerksamkeitsumfang sind also "Schlußergebnisse“. Wenn bis zur fünften Exposition nichts oder nicht viel erkannt wurde, nahm er an, daß eine weitere Wiederholung nutzlos sei. Es sind schon früher besonders von Zeitler gegen diese Versuchsanordnung Bedenken erhoben worden. Zeitler vertritt die Auffassung, daß der Idealfall eines Versuchs die einmalige Exposition eines Objektes sei, da jede folgende Darbietung unter Bedingungen stattfindet, welche die Exaktheit der Beobachtung um so mehr beeinträchtigt, je öfter das Objekt exponiert wird. Dieser Einwand ist zweifellos berechtigt. Hat die Versuchsperson bei der ersten Exposition das Objekt nur teilweise erkannt, so wird sie bei den folgenden Darbietungen ihre Aufmerksamkeit nicht auf den Fixierpunkt, sondern zweifellos auf benachbarte, noch unbekannte Regionen richten, um die Lücke in der Auffassung auszufüllen und das Fehlende zu ergänzen. Auf diese Weise kann unter Umständen eine künstliche Erweiterung des Aufmerksamkeitsumfangs zustande kommen. Auch Wundt bemerkt in seiner Kritik tachistoskopischer Versuche, daß Wiederholung der Exposition den gleichen Frfolg habe wie Verlängerung der einmaligen Expositionszeit. Es wird allerdings von Zeitler eingeräumt, daß seine Einwände nur theoretischer Natur seien und keine praktische Bedeutung hätten. Denn zu Fehlschlüssen wird diese Versuchsanordnung zweifellos nur dann Veranlassung geben, wenn dem Vergleich der Aufmerksamkeitsleistungen die Ergebnisse verschiedener Expositionen in willkürlicher Weise zugrunde gelegt werden. Wenn jedoch das Resultat jeder Exposition zu Protokoll genommen und für sich beurteilt wird, so ist gegen diese Versuchsanordnung um so weniger etwas einzuwenden, als wir hierdurch nachträglich einen Einblick in zahlreiche individuelle Eigentümlichkeiten, namentlich bei der Auffassung von Worten erhalten (Meumann). Dementsprechend wird von Freeman und Me umann die Wiederholung der Exposition bis zur vollständigen Erkennung des Objektes bevorzugt. Bei dieser Sachlage schien es nicht ohne Interesse, an unseren Hirnverletzten beide Versuchsanordnungen durchzuproben und die Ergebnisse vergleichsweise nebeneinanderzustellen.

Die Versuche am W u nd t schen Tachistoskope gestalteten sich nun in der Weise, daß jedes Objekt nur einmal exponiert wurde. Um einen vergleichbaren Durchschnittswert zu erhalten, der von zufälligen Aufmerksamkeitsschwankungen und unberechenbaren inneren und äußeren Störungen möglichst unabhängig ist, werden von jedem ein- bis sechsstellige Zahlen- und Buchstabenobjekt fünf verschiedene Proben dargeboten. Der Versuch beginnt also mit der Exposition von fünf einstelligen Zahlen, hierauf kommen fünf zweistellige Zahlen an die Reihe usw. Die Steigerung des Umfangs der optischen Reize wird so lange fortgesetzt, als von den fünf Proben mindestens eine richtig wiedergegeben wird. Frkennt die Versuchsperson keine der fünf verschiedenen Reizkarten mit gleicher Stellenzahl, so wird der Versuch abgebrochen, da Vorversuche gezeigt haben, daß der optimale Aufmerksamkeitsumfang damit erreicht ist.

Unter ganz gleichen Bedingungen stand die erste Versuchsreihe am Netscha. 
jeffschen Apparat. Bei der zweiten Netschajeffschen Reihe wurde in Anlehnung an die Cattelschen Versuche in der Weise verfahren, daß sich die Dar. bietung jedes einzelnen Objektes so lange wiederholte, bis es erkannt wurde. War bei der fünften Exposition die Erkennung noch nicht erfolgt, so konnte auf weitere Wiederholungen verzichtet werden.

\section{Versuchspersonen.}

Die Versuche wurden an 100 Soldaten angestellt. Davon hatten $80 \mathrm{Hirn}$ verletzungen, 10 äußere Kopfverletzungen ohne Beteiligung des Gehirns und 10 Verletzungen an Rumpf und Gliedmaßen ohne Betelligung des Gehirns und Kopfes. Der Einfachheit halber sollen im folgenden die Vertreter der ersten Gruppe kurz als „Hirnverletzte“ bezeichnet werden, die der zweiten Gruppe als „Kopfverletzte", die der dritten als "Normale".

Was zunächst die Gruppe der Hirnverletzten betrifft, so handelt es sich um Soldaten, bei denen eine Verletzung des Gehirns mit Sicherheit anzunehmen ist. In den meisten Fällen war die Hirnzertrümmerung bei der Trepanation festgestellt worden. Wo eine solche nicht stattgefunden hatte, ließen klinische Reiz- und Ausfallssymptome auf Defekte der Hirnsubstanz schließen. Die Ausdehnung der verletzten Hirnpartie ist natürlich schwer zu bestimmen. Kann auch teilweise nur von oberflächlieher Läsion der Hirnrinde aie Rede sein, so weisen doch auch viele Versuchspersonen Hirnsubstanzdefekte aut, die, soweit plastische Operationen noch nicht erfolgt sind, zu äußerlich sichtbaren, zum Teil tiefgreifenden Schrumpfungsprozessen geführt haben. Mit Ausnahme des Kleinhirns sind Verletzungen sämtlicher Hirnteile vertreten. Bei der bekannten Inkongruenz zwischen äußerer Kopfwunde und innerer Hirnverletzung war für die Bestimmung des geschädigten Hirnteils nicht in erster Linie die Topographie der Schußwunde, als vielmehr der klinische Symptomenkomplex maßgebend. Die Wundbehandlung war bei Vornahme der Aufmerksamkeitsprüfung in allen Fällen seit mindestens drei Monaten abgeschlossen, die Verletzung selbst lag 4 Monate bis 4 Jahre, durchschnittlich $1^{1 / 4} \mathrm{Jahr}$ zurück. Wir haben es also mit residuären Zuständen zu tun, bei denen fieberhafte Allgemeinerscheinungen und reaktive Fernwirkungen seitens einer Wunde auszuschließen sind. - Das Alter der Versuchspersonen schwankt zwischen 20 und $40 \mathrm{Jahren.} \mathrm{Die} \mathrm{über-}$ wiegende Mehrheit, etwa $80 \%$, steht zwischen dem 20. und 30 . Lebensjahre. Der Rest ist über 30 Jahre alt. - An Ber ufen sind vertreten: 9 Gymnasiasten, Studenten und Volksschullehrer, 11 Kaufleute, 12 Landwirte, 23 Handwerker sowie 25 Fabrikarbeiter, Bergleute und ungelernte Arbeiter. Außer den 9 Erstgenannten haben sämtliche Versuchspersonen lediglich Volksschulbildung genossen.

Unsere $z$ weite Gruppe von Versuchspersonen, die der Kopfverletzten, umfaßt solche Soldaten, bei denen das Trauma zwar auch den Kopf getroffen hat, ohne jedoch eine äußerlich sichtbare oder durch Ausfallssymptome nachweisbare Schädigung des Gehirns verursacht zu haben. Sie befinden sich lediglich wegen allgemeiner Hirnerscheinungen - Kopfschmerzen, Schwindelgefühl, Herabsetzung der körperlichen und geistigen Leistungsfähigkeit, abnorme Erregbarkeit usw. - in Sonderlazarettbehandlung.

Eine dritte Gruppe bilden schließlich 10 Soldaten, die lediglich periphere Extremitäten- oder Organverletzungen aufweisen und insofern als normal bezeichnet werden können, als sie weder kopf- noch hirnverletzt sind. Versuchspersonen waren z. T. die Militärkrankenwärter unseres Hirnverletztenlazaretts, z. T. stammten sie aus dem Hilfslazarett Diakonissenhaus, wo sie noch in chirurgischer Behandlung waren. Ihre Auswahl erfolgte lediglich unter dem Gesichtspunkt, daß sie in bezug auf Alter, Beruf und Schulbildung mit den Hirnverletzten im großen und ganzen auf gleiche Stufe gestellt werden konnten. 


\section{Ergebnisse.}

Die Ergebnisse stützen sich auf fünf verschiedene Versuchsreihen, die sich folgendermaßen gliedern:

Reihe I: Wundtsches Tachistoskop. Zahlen- und Buchstabenversuche. Einmalige Exposition. Expositionszeit $30 \%$.

Reihe II: Netschajeffsches Tachistoskop. Das übrige wie in Reihe I.

Reihe III a und IIIb: Netschajeffsches Tachistoskop. Zahlen- und Buchstabenversuche. Einmalige Exposition (IIIa) und mehrmalige Exposition (III b). Expositionszeit $15 \sigma$.

Reihe IVa und IVb: Nestschajeffsches Tachistoskop. Buchstabenversuche mit Ablenkung. Einmalige Exposition (IVa), mehrmalige Exposition (IVb). Expositionszeit $15 \sigma$.

Reihe Va und Vb: Netschajeffsches Tachistoskop. Wortversuche. Das äbrige wie in Reihe IVa und IVb.

Alle Reihen mit Ausnahme der zweiten sind übereinstimmend an den gleichen 71 Versuchspersonen durchgeführt. Die Untersuchung der übrigen 29 Versuchspersonen beschränkt sich auf Reihe II.

\section{Gesamtïbersicht.}

Zunächst soll in Tabelle I eine Gesamtübersicht gegeben werden, und zwar erstens über Name, Alter und Beruf der 80 Hirnverletzten, 10 Kopfverletzten und 10 Normalen, zweitens über den erzielten Aufmerksamkeitsumfang, drittens über den Ort der Hirnverletzung und viertens über die hauptsächlichsten somatischen Symptome. Maßgebend für die Reihenfolge der Versuchspersonen waren die aus den beiden ersten Versuchsreihen gewonnenen Umfangswerte, wobei das arithmetische Mittel aus den Zahlen- und Buchstabenversuchen der Rangordnung zugrunde gelegt wurde. Die Anordnung der Tabelle im einzelnen entspricht der obigen Versuchseinteilung. Die Ziffern sind Maximalwerte und bedeuten die Anzahl der gleichzeitig erfaßten Zahlen und Buchstaben. In den Rubriken $\mathrm{Va}$ und $\mathrm{Vb}$ bezeichnen die Ziffern die Buchstabenzahl des längsten erkannten Wortes. In der Rubrik ,Optimale Exposition" sind den Umfangswerten kleine Zahlen angehängt, aus denen zu entnehmen ist, bei welcher Exposition die Erkennung stattfand. Was die Benennung der verletzten Hirnteile betrifft, so wird unterschieden zwischen Frontalhirn $(\mathbf{F})$, Zentralhirn, das der vorderen und hinteren Zentralwindung entspricht (Z), Parietalhirn (P), Occipitalhirn $(\mathrm{O})$ und Temporalhirn $(\mathrm{T})$. Die römischen Ziffern weisen auf die ungefähre Lage des Substanzdefekts innerhalb des verletzten Hirnteils hin. Beispielsweise bedeutet r F I: Verletzung des rechten Gyrus frontalis I; 1 Z II/III: Verletzung des zweiten und dritten Drittels der linken vorderen und hinteren Zentralwindung. Handelt es sich um ausgedehntere Zerstörungen, so sind alle beteiligten Hirnteile verzeichnet, wobei das vorwiegend verletzte Rindengebiet durch fehlende Einklammerung besonders kenntlich gemacht ist. 
Tabelle I.

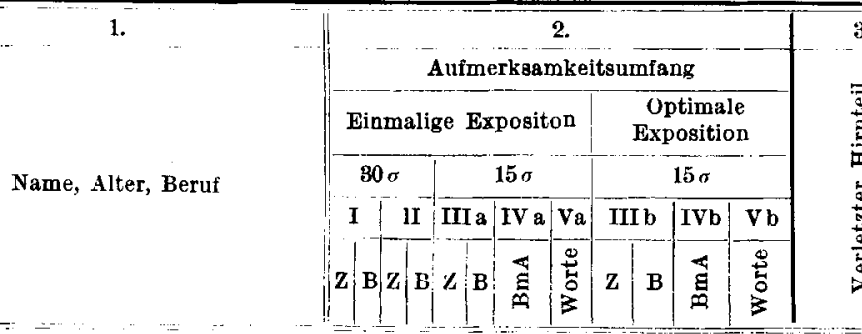

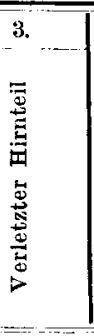

4.

I. Hirnverletzte.

1. Ho., Ernst, 25: Stud. phil. $\| 5 \mid 6$

2. Wo., Paul, 20; Masch.-Arb.

3. Bö., Max, 21; Realschüler

4. Schu., Robert, 20; Maurer 64

5. Ka., Georg, 32 ; Lehrer. . 55

6. So., Wilh., 27; Bahnarb. . 55

7. Nei., Franz, 31 ; Lehrer. . 55

8. Mi., Karl, 25; Kontorist

$5 \longdiv { 5 }$

9. Schr., Ernst, 24; Schriftsetzer ........ . 54

10. Thu., Karl, 22; Maurer. . 45

11. Bi., Franz, 21; Fabrikarbeiter 54

12. Li., Kurt, 34 ; Lehrer. . . $6 \mid 3$

13. Ap., Walter, 34 ; Drogist . 54

14. Bu., Otto, 24 ; Fleischer . $5|3|$ \begin{tabular}{l|l|l|l|l|l|l|l|l|}
5 & 6 & 2 & 18 & $6_{5}$ & $6_{1}$ & $6_{5}$ & $18_{1}$
\end{tabular}

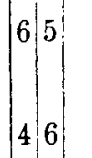

46

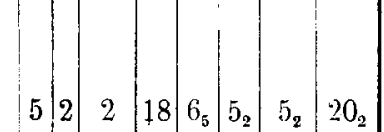

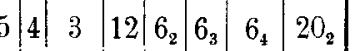

$\begin{array}{lllllllll}4 & 4 & 2 & 18 & 6_{2} & 6_{3} & 6_{5} & 20_{3}\end{array}$

r Z I/II

$1 \mathbf{Z}$ II

I F II

( $\mathrm{Z}$ II)

r F I

I Z I II

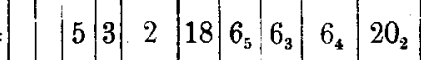

\begin{tabular}{l|lll|l|l|l|l}
4 & 5 & 4 & 15 & $5_{3}$ & $5_{1}$ & $5_{5}$ & $20_{2}$
\end{tabular}

l F III
(1 Z I)

MF I

r F I

\begin{tabular}{l|lllllll|l|l}
4 & 3 & 1 & 17 & $4_{1}$ & $4_{2}$ & $1_{1}$ & $18_{3}$ & 1
\end{tabular}

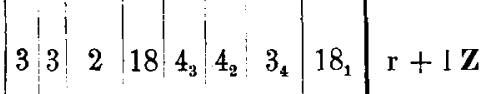
\begin{tabular}{l|lll|l|l|l|l|l}
5 & 4 & 2 & 11 & $6_{4}$ & $4_{1}$ & $4_{4}$ & $18_{2}$ & r Z
\end{tabular} r. Facialis- u. Hypoglossusparese; Reste motorischer Aphasie.

Symptome epilept. Anfälle mit Bewußtseinsverlust, $3-4$ mal monatlich.

1. Facialis- u. Handparese. Sensib.-Störung an 1 . Mund u. Fingern, 1. Tastlähmung.

r. leichte Facialisparese. Halbseitige Sensib.-Störungen $r$.

neurasthenische Allgemeinerscheinungen.

leichte r. Hemiparese mit Sensib.-Störungen.

schwere 1. Hemiparese nit Sensib.-Störungen; epilept. Anfälle.

leichte r. Schwäche mit Sensib.-Störungen; epilept. Anfälle.

r. Beinschwäche. Halbseitige Sensib.-Störungen, außer Kopf.

Kopfschmerzen; Schwindelgefühl.

leichte allgem. Hirnerscheinungen.

mot. Aphasie; Reste von Agraphie u. Alexie, epilept. Anfälle.

Lähmung beider Arme u. Beine; Verlust des r. Auges; epilept. Anfälle.

1. Hemiparese mit Sensib.Störungen. 
Tabelle I (Fortsetzung).

Name, Alter, Beruf

\begin{tabular}{|c|c|c|c|c|c|c|c|c|}
\hline \multicolumn{9}{|c|}{2} \\
\hline \multicolumn{9}{|c|}{ Aufmerksamkeitsumfang } \\
\hline \multicolumn{5}{|c|}{ Einmalige Exposition } & \multicolumn{4}{|c|}{$\begin{array}{c}\text { Optimale } \\
\text { Exposition }\end{array}$} \\
\hline \multicolumn{2}{|r|}{$30 \%$} & \multicolumn{3}{|c|}{$\overline{15 \sigma}$} & \multicolumn{4}{|c|}{$15 \pi$} \\
\hline & II & III a & IV a & $\overline{\mathrm{Va}}$ & III & & IV b & $\mathbf{v b}$ \\
\hline & $\mathbf{B} \mathbf{z}$ & 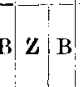 & $\underset{B}{\mathbb{B}}$ & $\begin{array}{l}0 \\
\pm \\
0 \\
0\end{array}$ & $\mathrm{Z}$ & B & वृ & $\begin{array}{l}\stackrel{\$}{5} \\
\text { B }\end{array}$ \\
\hline
\end{tabular}

1.

\begin{tabular}{ll|ll|l}
9 & $5_{2}$ & $3_{1}$ & 2 & 17
\end{tabular}

15. Gu., Karl, 23; Hausdiener

\begin{tabular}{l|l|l|l|l|l|l|l}
4 & 3 & 2 & 9 & $5_{2}$ & $3_{1}$ & 2 & 17 \\
\hline
\end{tabular}

16. Sta, Willy, 19; Landw.-

Arbeiter .....

\section{3}

17. Ha., Gustav, 20; Landwirt 44

18. Na., Oswin, 29; Bergmann 44

19. Be., Karl, 30; Bergmann .

20. Kl., James, 22; Kontorist 4 3

21. Tr., Wilhelhm, 36; Dachdecker . . . . . . 34

22. Pe., Karl, 37; Maurer.

23. Fr., Kurt, 23; Schriftsetzer

24. Be., Emil, 27; Kutscher .

25. Je., Leo., 22; Kaufmann . 43

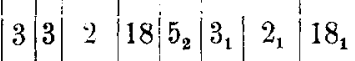

26. Schö., Alfr., 22; Kaufnann 43

27. Bä., Alwin, 23; Landwirt. 4 3 \begin{tabular}{llll|l|l|l|l}
3 & 3 & 2 & 18 & $5_{5}$ & $3_{1}$ & $6_{2}$ & $18_{1}$
\end{tabular} $\begin{array}{llllllllll}3 & 3 & 2 & 18 & 5_{8} & 4_{5} & 2 & 18_{1}\end{array}$

28. Bo., Heinr., 22; Bergmann 4 33

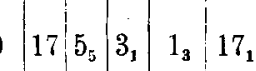

29. Ju., Reinhard, 21; Bureaugehilfe....... $\left.4\right|^{3}$

30. Fe., Albert, 25 $4|3|$

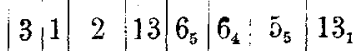

$\begin{array}{llllllllll}3 & 0 & 0 & 10 & 5_{4} & 2_{5} & 0 & 10_{1}\end{array}$
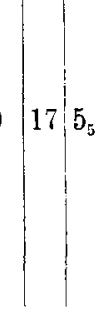

4.

I Z II

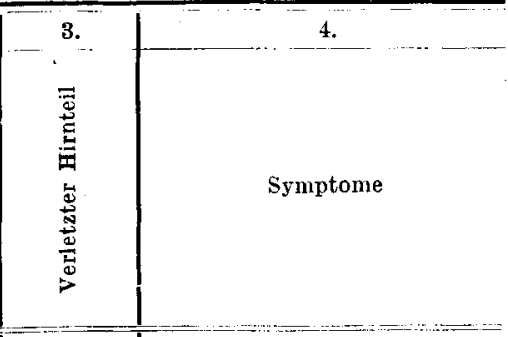

leichte r. Armparese; epilept. Krampfanfälle.

r Z II leichte 1. Armparese mit Sensib.-Störung.

$1 \mathbf{Z}$ I r. Beinschwäche u. r. halb(r F I) seitige Sensib.-Störung.

I Z r. Hemiparese mit Sensib.Störungen.

r Z geringe 1. Hemiparese mit Sensib. - Störungen; epilept. Anfälle.

1. Facialisparese; 1. halbseitige Sensib.-Störung; epilept. Anfälle.

r F I allgem. Hirnerscheinungen.

1 Z III Reste von mot. Aphasie; r. Sensib.-Störungen.

r F I l. Hemiparese mit Sensib.( $\mathrm{Z}$ Z) Störungen; Verlust des r. Auges.

r F I homolaterale (r.) Schwäche (r Z I/II) von Fuß u. Hand mit Sensib.-Störungen.

I Z I r. Sensib.-Störung; Reste (I T) von sensor. Aphasie; geheilte hysterische Abasie u. Astasie.

Parese beider Beine u. des $\mathrm{r}$. Arms; epilept. Anfälle.

I Z II leichte Schwäche der $r$.

(M F) Hand; allgem. epilept. Krampfanfälle; sensor. Jacksonsche Anfälle.

r Z l. Hemiparese mit Sensib.Störungen.

r. Hemiparese mit Sensib.Störungen.

r Z II Parese u.Sensib. der 1. Hand. 
Ta belle 1 (Fortsetzung).

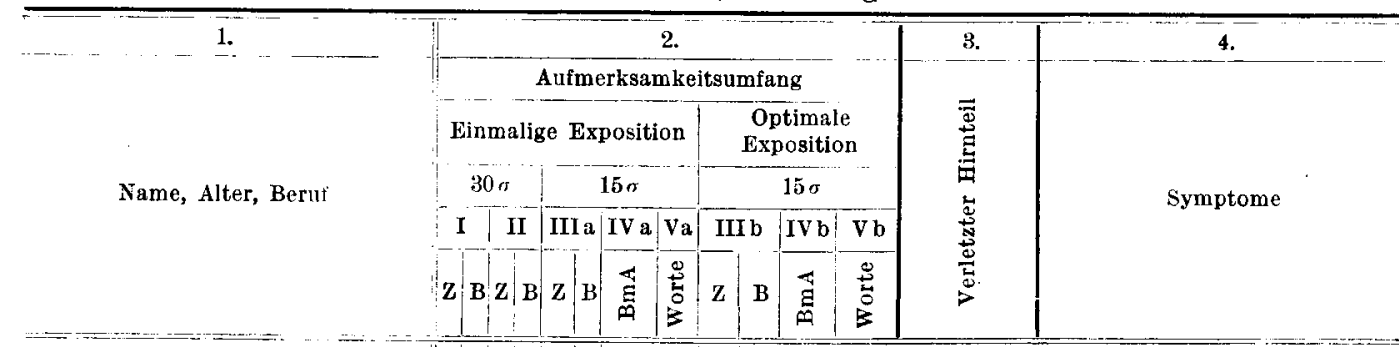

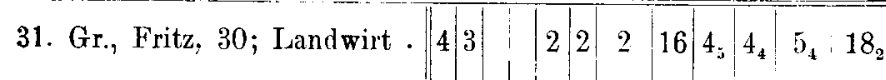

32. He., Gottfried, 20; Gymnasiast . . . . . . 33

33. Ba., Otto, 28; Bahnarbeiter 4,2

34. Asch., Kurt, 26; Bahnarb. 42

35. Kö., Karl, 21; Dreher . . $4 \mid 2$

36. Hei., Kurt, 22; Landwirt 33

37. Ho., Wilh., 32 ; Zigarrenarb. 33

38. Rei., Karl, 22 ; Landw.-Arb. $\begin{array}{ll}3 & 3\end{array}$

39. Kie., Thilo, 25; Schmied $\left.4\right|_{2}$

40. Ho., Willy, 21; Trainer . 333

41. Lö., Alban, 20; Fabrikarb. 33

42. Ko., Walter, 20 ; Hausdiener $3{ }_{2}$

43. La., Otto, 28; Fabrikarb. 32

44. Ö., Franz, 22; Bäcker .

32

45. Schm., Fritz, 24; Bäcker.
$1 \mathrm{P}$

r. Sensib.-Störung, Ataxie, Lagegefühlsstörung u. Tastlähmung; geheilte Alexie u. Agraphie; epilept. Anfälle.

r Z

\begin{tabular}{ll|lll|l:l:l}
4 & 4 & 3 & 18 & $6_{3}$ & $6_{4}$ & $6_{4}$ & $20_{4}$
\end{tabular} \begin{tabular}{l|l|l|l|l|l|l|l}
4 & 3 & 1 & 17 & $6_{5}$ & $3_{1}$ & $3_{2}$ & $18_{2}$
\end{tabular} r Z I

$\begin{array}{lllllllllll}4 & 3 & 1 & 12 & 5_{2} & 3_{1} & 2_{2} & 18_{2} & \mathbf{r}+1 \mathbf{Z I}\end{array}$

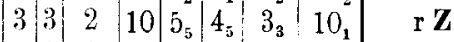

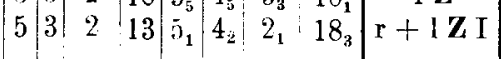

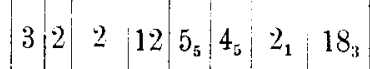

$1 Z$

1. Sensib.-Störung u. geringe Schwäche.

Schwäche u. Sensib.-Störung am 1. FuB.

r. Sensib.-Störung,

1. Sensib.-Störung.

1. Hemiplegie mit Sensib.Störungen u. r. Beinparese.

r. Hemiplegie; Reste von mot. Aphasie.

1. Arm- u. Beinparese mit Sensib.-Störungen.

leichte Parese des I. Fußes mit Sensib. - Störung; r. halbseitige Sensib. - Störung; l. Ataxie; r. Lagegefühlsstörung.

r P l. Hemiplegie mit Sensib.

(r Z) Störung, Ataxie; Tastlähmung, Lagegefühlsstörung.

lP epilept. Krämpfe; leichte Gesichtsfeldeinschränkung nach $\mathbf{r}$.

r P

(r Z)

1. Hemiplegie mit Sensib. Störung, Ataxie, Tastlähmung, Lagegefühlsstörung.

l Z r. mot, u. sensible J a ckson sche Anfälle.

$1 \mathbf{Z}$ leichte r. Hemiparese mit Sensib.-Störung; Reste von mot. Aphasie. 
Tabelle 1 (Fortsetzung).

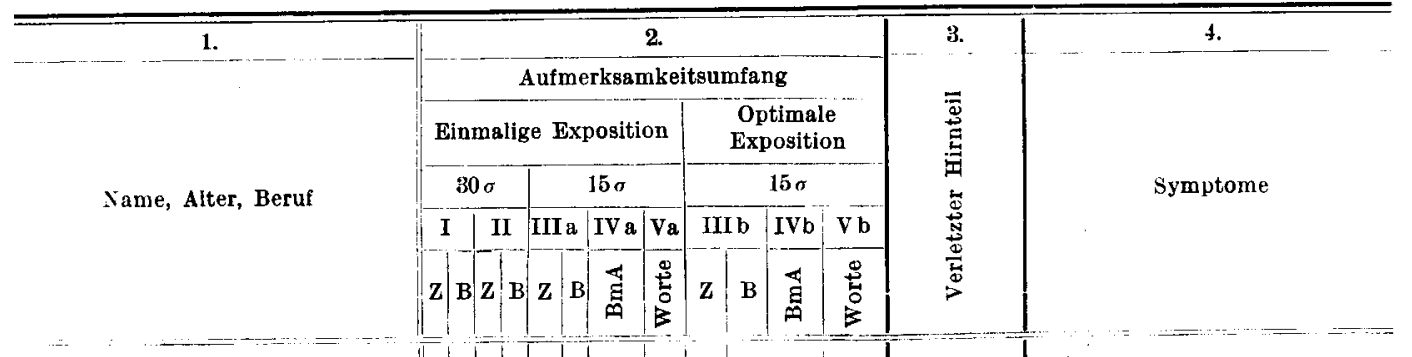

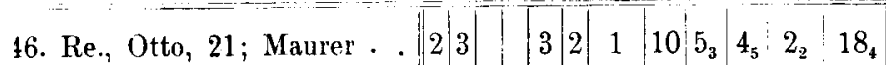

17. Kö., Elwin. 22; Bergmann 32

48. Ja., Friedrich, 39 ; Land wirt

49. Hein., Hugo, 38; Landwirt

50. Heid., Wilh., 24; Schiffer 22

51. Sa., Karl, 24; Fabrikarb. 22

52. Kr., Artur, 20; Sehmied . 22

53. Ge., Ilerm., 22 ; Fabrikarb. 22

54. Schä., Herm., 21 ; Landwirt 22

55. Na.. Erich, 22 ; Lehrer. . 22

56. Li., Friedr., 33; akt. Uffz.

$\begin{array}{rrrrrrrrr}2 & 0 & 0 & 3 & 3 & 0 & 0 & 5 \\ 3 & 1 & 0 & 10 & 4_{2} & 2 & 2_{3} & 18_{5}\end{array}$

\begin{tabular}{|l|l|l|l|l|ll|l}
4 & 3 & 1 & 17 & $5_{3}$ & $3_{1}$ & $4_{4}$ & $18_{2}$
\end{tabular}

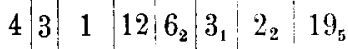

\begin{tabular}{l|llll:llll}
3 & 2 & 2 & 3 & $3_{1}$ & $4_{3}$ & 3 & 3 & 3
\end{tabular}

\begin{tabular}{l|lllllllll}
2 & 4 & 2 & 10 & $5_{5}$ & $5_{5}$ & $5_{5}$ & $13_{3}$
\end{tabular}

57. Zi., Wladisl., 33; Kaufuann

22

58. Ka., Bruno, 35; 1)rogist . $\left.1\right|_{2}$

\begin{tabular}{l|l|l|l}
2 & 1 & 0 & 18
\end{tabular}

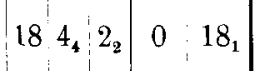

59. Wo., Herm., 36; Landw.-

Arb. . . . . . . . 21
rP

$r \mathbf{P}$

I P

(I Z)

r $\mathbf{P}$

$\mathbf{r} \mathbf{P}$
$(\mathbf{r ~ Z})$

$1 \mathbf{P}$

(I Z)

$\mathbf{r}+1 \mathbf{P}$

$\mathbf{r}+1 \mathbf{P}$

$1 \mathrm{Z}$

r $\mathbf{Z}$

(r T)

$\mathbf{r} \mathbf{T}$

$1 \mathbf{P}$

(1 Z)

I P

(1 Z)

r T
1. Hemiplegie nit Sensib. Störung, Lagegefühlsstörung, Tastlähmung.

r. Hemiparese mit Sensib.Störung; mot. Aphasie, Ataxie, Tastlähmung, Lagegefühlsstörung.

r. Sensib.-Störung.

1. Sensib.-Störung an Finger u. Fuß.

r. Hemiparese u. Reste von mot. Aphasie.

1. Sensib.-Störung.

r. Taubheit; Schwindelanfälle.

r. Hemiparese mit Sensib.Störungen; epilept. Anfälle; Ataxie, Lagegefühlsstörung, Tastlähmung.

1. Sensib.-Störung.

Sensib.-Störungen am l. Arm u. Bein; Ataxie u. Tastlähmung.

leichte r. Hemiparese mit Sensib.-Stürungen; Aphasiereste ; r. Ataxie, Tastlähmung u. Lagegefühlsstörung.

Schwäche des l. Armes mit 1. halbseitiger Sensib.Störung; hysterisches Kopfschütteln.

r. Hemiplegie mit Sensib.Störung; Ataxie u. Lagegefühlsstürung; epilept. Anfälle.

allgem. Hirnerscheinungen; Schwindelanfälle. 
Tabelle 1 (Fortsetzung).

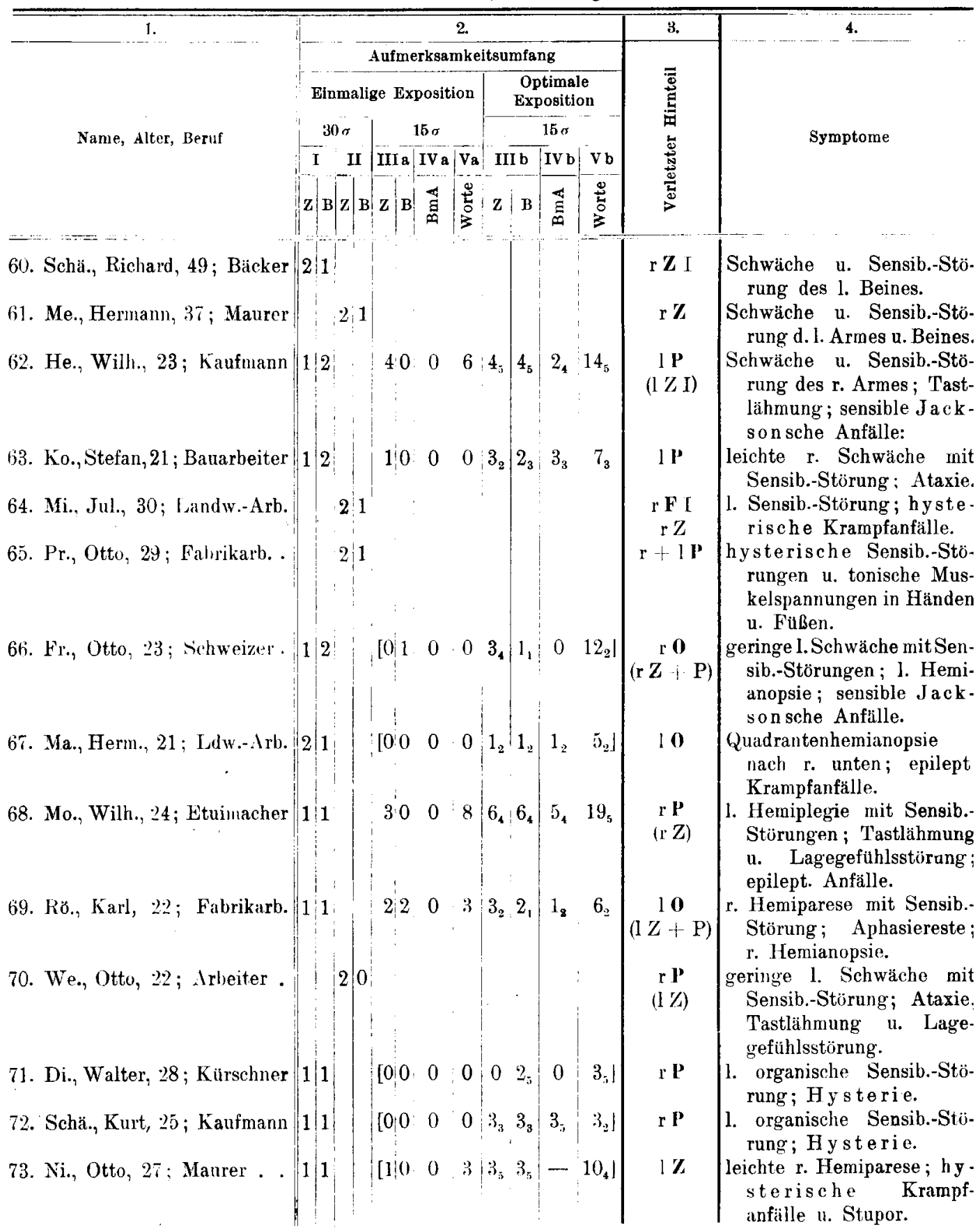


Tabelle 1 (Fortsetzung).

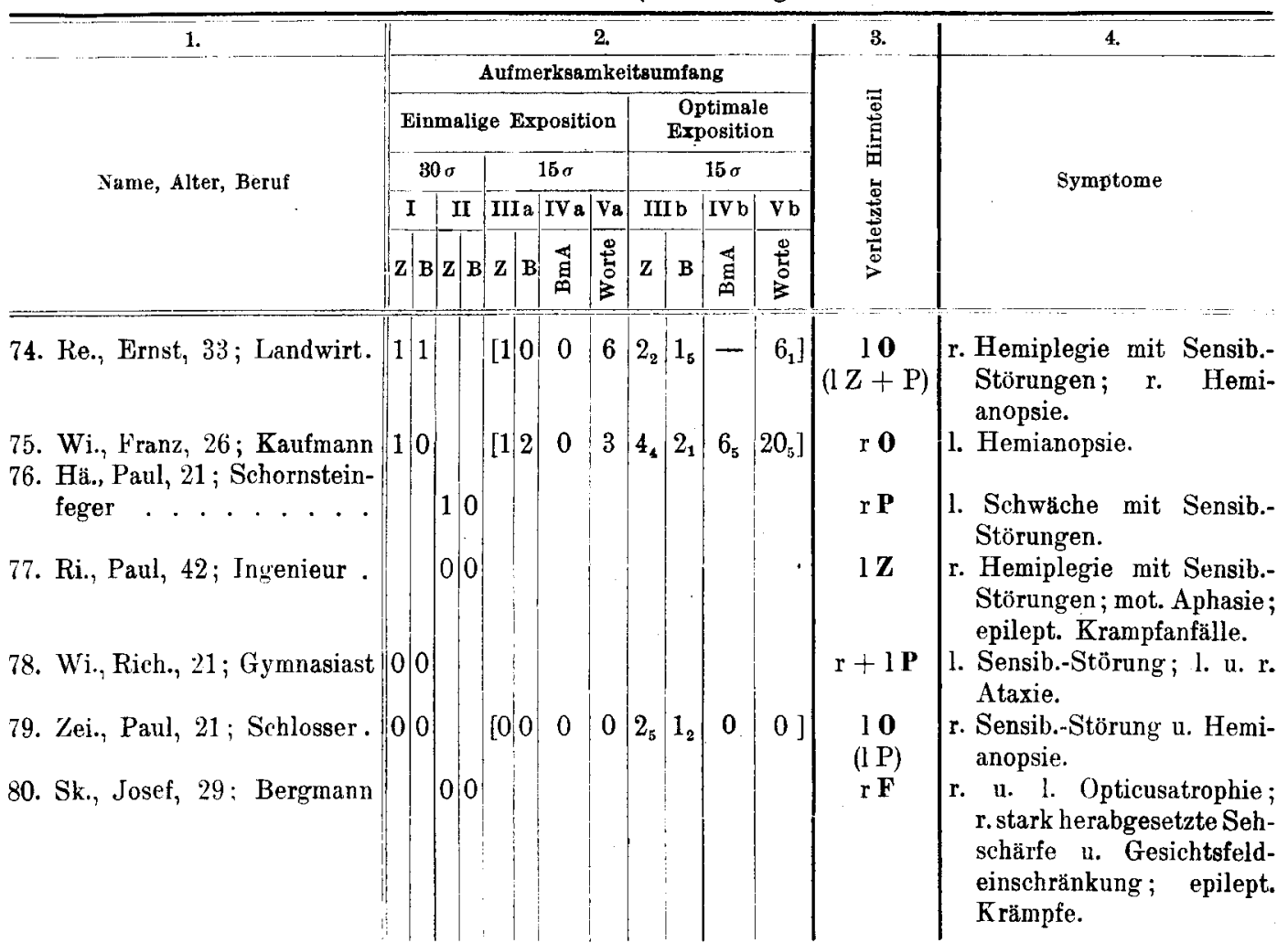

II. Kopfverletzte.

1. Ra., Alb., 26 ; Schuhmacher

\begin{tabular}{ll|l|l|l|l} 
2. Ku., Eduard, 24; Schlosser & & 4 & 6 & & \\
3. Th., Wilhelm, 31; Arbeiter & 4 & 5 & & 4 & 2 \\
\hline
\end{tabular}

4. Wi., Otto, 25; Tischler . 44

5. Di., Wilhelm, 35; Tischler $\left.4\right|^{3}$

6. Eu., Josef, 22; Bergmann 4

7. Bö., Friedrich, 22; Schmied 43

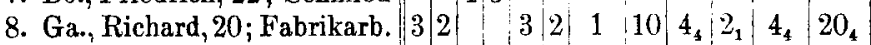

9. Wa.,Fritz, 20; Pinselmacher $\mid 32$

10. Hei., Herm., 33 ; Stellmach. ${ }_{2} / 2$

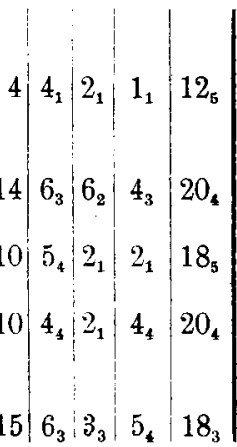

allgem. Hirnerscheinungen. allgem. Hirnerscheinungen. allgem. Hirnerscheinungen. r. Hörstörung u. allgem. Hirnerscheinungen. epilept. Dämmerzustände u. Krampfanfälle.

allgem. Hirnerscheinungen. allgem. Hirnerscheinungan. allgem. Hirnerscheinungen. hyster. Sensib.- u. Sprachstörung.

allgem. Hirnerscheinungen.

III. Normale.

1. Ke., Fritz, 27; Masseur . 45

2. Be., Kurt, 20; Schuhmacher 63

3. Fr., Otto, 34; Kürschner. 53

$\mid$\begin{tabular}{l|l|l|l|l|l|l|l|l}
4 & 2 & 1 & 18 & $4_{1}$ & $2_{1}$ & $3_{2}$ & $20_{3}$ \\
4 & 3 & 2 & 10 & $5_{2}$ & $4_{5}$ & $5_{4}$ & $20_{5}$ & - \\
4 & 2 & 2 & 10 & $4_{1}$ & $3_{2}$ & $2_{1}$ & $20_{5}$ & -
\end{tabular}


Tabelle 1 (Fortsetzung).

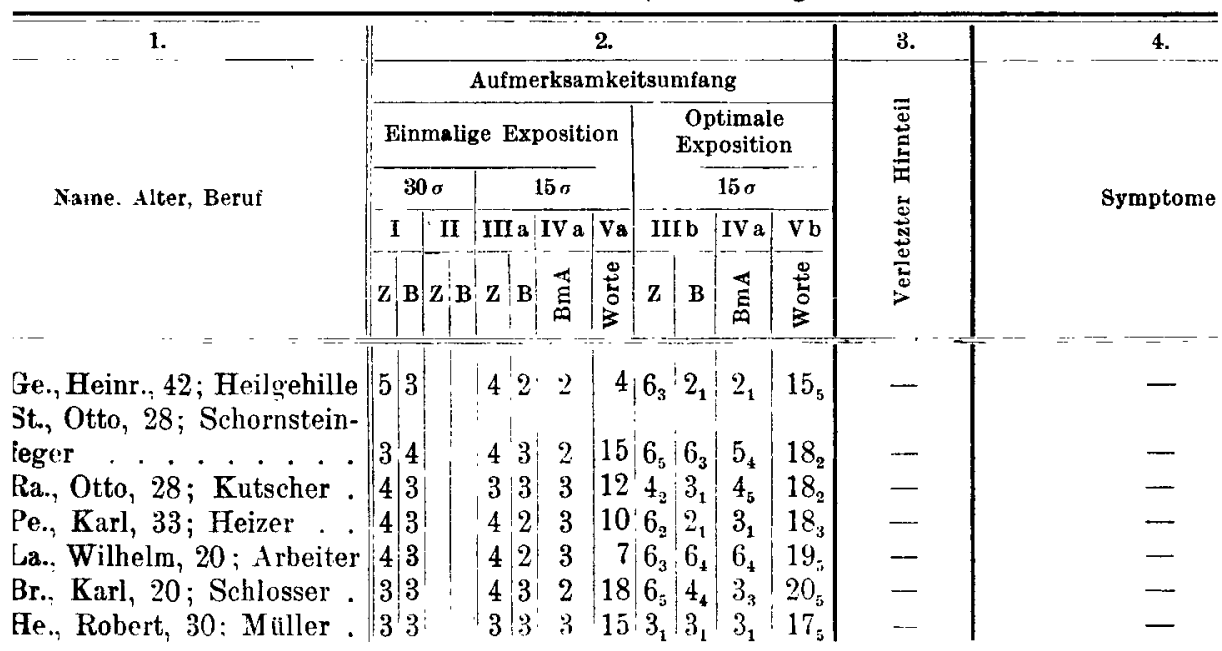

Bevor wir zur Besprechung dieser Versuchsergebnisse übergehen, bedarf es noch einer einschränkenden Vorbemerkung. Es ist ohne weiteres klar, daß sich aus dem Ausfall der tachistoskopischen Versuche nur dann vergleichende Schlüsse auf den Aufmerksamkeitsumfang ziehen lassen, wenn die Leistungen des peripheren und zentralen Sehorgans hei allen Versuchspersonen sich innerhalb normaler Grenzen bewegen und keine Unterschiede aufweisen. Handelt es sich beispielsweise um Fälle, wo mehr oder weniger große Teile der Netzhaut, sei es durch periphere, sei es durch zentrale Schädigungen funktionslos geworden sind, so wird man die schlechten Ergebnisse der tachistoskopischen Versuche nicht auf Aufmerksamkeitsstörungen, sondern auf die Funktionsdefekte des optischen Systems zurückzuführen haben. Die bei solchen Versuchspersonen gefundenen Werte sind also nicht maßgebend für den Aufmerksamkeitsumfang, weshalb sie als unvergleichbar mit den übrigen Resultaten auszuscheiden haben. Es werden also in allen folgenden Berechnungen die 7 Hirnverletzten mit Sehstörungen gesondert zu behandeh sein. Ferner müssen zunächst unberücksichtigt bleiben 6 weitere Versuchspersonen, deren organisch bedingtes Hirnleiden von hysterischen Symptomen überlagert ist. Es hat sich nämlich herausgestellt, daß sich die Aufmerksamkeitsleistungen dieser Hirnverletzten quantitativ und qualitativ in einer Weise von denen der übrigen abheben. daß das Gesamtresultat zu Ungunsten der nicht hysterischen Versuchspersonen beeinträchtigt würde, wollte man die Aufmerksamkeitsleistungen der Hysteriker auf gleiche Stufe stellen mit denen der übrigen Hirnverletzten. Nach Ausschaltung der Versuchspersonen mit Sehstörungen und hysterischen Symptomen bleiben übrig 67 Hirnverletzte. 
bei denen die Untersuchungen nach einheitlichen Gesichtspunkten durchgeführt werden konnten, so daß die Vorbedingungen für eine vergleichende Utbersicht hier gegeben sind.

\section{Versuche bei einmaliger Exposition.}

Fragen wir uns zuerst, wieviel unverbundene Elemente von den Hirnverletzten im tachistoskopischen Versuch bei der ersten Exposition gleichzeitig erkannt werden. Der Beantwortung dieser Frage legen wir die Ergebnisse der beiden ersten Versuchsreihen zugrunde, die unter völlig gleichen Bedingungen mit dem $W$ undtschen und Netschajeffschen Apparat angestellt sind. Da ist zunächst festzustellen, daß 5 von unseren 67 Hirnverletzten bis zu 6 Einheiten erkennen und damit einen Aufmerksamkeitsumfang erreichen, welcher der durchschnittlichen Höchstleistung geübter Versuchspersonen entspricht. Und zwar erfassen sechsstellige Zahlen je ein stirnhirnverletzter 20 jähriger Maschinenarbeiter (Nr. 2) und Maurer (Nr. 4) sowie ein 34 jähriger Volksschullehrer (Nr. 12) mit schwerer motorischer Aphasie und häufigen epileptischen Krämpfen. Sechsstellige Konsonantenreihen erkannten ein 25 jähriger Student der Philologie (Nr. 1), ebenfalls mit motorischer Aphasie und halbseitigen Motilitäts- und Sensibilitätsstörungen, sowie ein 21 jähriger Realschüler (Nr. 3) mit leichten Ausfallserscheinungen seitens der rechten Centroparietalregion. 5 Zahlen werden von 11 Hirnverletzten erkannt, 5 Buchstaben dagegen nur von 6 . Schon aus diesen beiden Beispielen geht hervor, daß sinnlose Konsonantenverbindungen an die Aufmerksamkeit größere Anforderungen stellen als Zahlenreihen, eine Beobachtung, die mit verschwindend geringen Ausnahmen für alle Versuchspersonen gilt. Berechnet man die Zahl derjenigen Hirnverletzten, die innerhalb des für Normalversuche gültigen Aufmerksamkeitsumfangs von 4-6 Einheiten bleiben, so ergibt sich, daß bei den Zahlenversuchen von 67 Versuchspersonen 33 das Normalmaß erreichen, bei den Buchstabenversuchen dagegen nur 17. Mit anderen Worten: Bei den Zahlenversuchen gelangt etwa die Hälfte der Hirnverletzten bis zum Durchschnittswert des normalen Aufmerksamkeitsumfangs, bei den Buchstabenversuchen nur der vierte Teil.

Vergleichen wir hiermit den Ausfall der Aufmerksamkeitsproben an unseren normalen Soldaten! Von 10 Versuchspersonen erkennt hier nur einer eine sechsstellige Zahl. Immerhin wären das im Verhältnis doppelt soviel als bei den Hirnverletzten. Dagegen fällt bei den Normalen die Erkennung einer sechsstelligen Buchstabenverbindung aus. Abgesehen hiervon kommt die Uberlegenheit der Gesunden über die Hirnverletzten in zwei Befunden zum Ausdruck: 1. Bei keinem der Normalen sinkt der Aufmerksamkeitsumfang unter 3 Einheiten, bei Hirnverletzten dagegen in mehr als einem Drittel der Fälle. 2. Die relative Zahl derjenigen Ver- 
suchspersonen, die das physiologische Durchschnittsmaß des Aufmerksamkeitsumfangs, also 4 Einheiten erreichen, ist bei Normalen größer als bei Hirnverletzten. Der Unterschied ist allerdings auffallend gering. Er beträgt für Zahlenversuche $49 \%$ bei Hirnverletzten, gegenüber $70 \%$ bei Normalen; für Buchstabenversuche $25 \%$ bei Hirnverletzten, gegenüber nur $20 \%$ bei Normalen. Faßt man das Resultat der Zahlen- und Buchstabenversuche in einen Wert zusammen, so würden nur $37 \%$ unserer hirnverletzten und nur 45\% der normalen Soldaten über einen Aufmerksamkeitsumfang verfügen, der den physiologischen Durchschnittswerten entspricht.

Dieses Ergebnis ist in doppelter Beziehung bemerkenswert. Daß die Hirnverletzten schlechte Aufmerksamkeitsleistungen zeigen würden, war von vornherein anzunehmen. Wie aber ist es zu erklären, daß ein beträchtlicher Teil auch unserer nor malen Versuchspersonen die untere Grenze des physiologischen Aufmerksamkeitsumfangs nicht erreicht? Einer Aufklärung bedarf ferner der auffallend geringe Unterschied in der Leistungsfähigkeit der normalen und himverletzten Soldaten, wie er in den obigen Verhältniszahlen scheinbar zum Ausdruck kommt.

Man wird nun allerdings nicht vergessen dürfen, daß die Versuche, aus denen das Gesetz von der Konstanz des Aufmerksamkeitsumfangs abgeleitet wurde, größtenteils an Versuchspersonen angestellt sind, die zum mindesten über eine größere Ubung in psychologischer Beobachtung verfügten als unsere Soldaten. Es würde daher ein falsches und für unsere Versuchspersonen allzu ungünstiges Bild geben, wollte man den Laboratoriumsmaßstab auch an ihre Aufmerksamkeitsleistung anlegen. Aufschluß über das, was bei meinem Versuchsmateral noch innerhalb der physiologischen Grenzen liegt, kann nur der Ausfall der Kontrollversuche an normalen Soldaten geben. Angesichts der erheblichen Ausdehnung der normalen Schwankungsbreite rechtfertigt sich dieses Verfahren ohne weiteres. Wir hatten bereits festgestellt, daß keiner der Normalen weniger als 3 Einheiten erkennt. Hier hätten wir also die untere Grenze des normalen Aufmerksamkeitsumfangs anzunehmen und nicht bei 4 Einheiten. Wir können also sagen: Eine Aufmerksamkeitsstörung liegt vor, wenn 3 unverbundene Einheiten nicht mehr gleichzeitig erkannt werden. Es scheint zwar auf den ersten Blick bedeutungslos, ob die untere Normalgrenze bei 3 oder 4 Einheiten angenommen wird. Indessen lehren alle Erfahrungen auf tachistoskopischem Gebiet, daß die Zunahme des Aufmerksamkeitsumfangs auch nur um eine einzige Stelle schon eine beträchtliche Steigerung der Leistung bedeutet.

Was schließlich den geringen zahlenmäßigen Unterschied im Aufmerksamkeitsumfang der beiden Versuchsgruppen betrifft, auf den aus 
unsern Durehschnittswerten von $37 \%$ für Hirnverletzte gegenüber $45 \%$ für Normale scheinbar geschlossen werden muß, so findet diese zunächst auffallende Erscheinung ihre Erklärung in der Ungleichwertigkeit unseres Hirnverletztenmaterials. Es ist nämlich zu bedenken, daß die untersuchten Hirnverletzten, selbst nach Ausschaltung der Versuchspersonen mit Sehstörungen und hysterischen Symptomen, ein klinisch keineswegs einheitliches Versuchsmaterial darstellen. Neben Soldaten mit oberflächlicher Schädigung der Hirnrinde haben wir es doch auch mit solchen zu tun, bei denen große Rindengebiete zerstört oder ausgeschaltet sind. Außerdem betrifft die Verletzung nicht nur sog. stumme Hirnteile, sondern in der Mehrzahl der Fälle hochwertige somatische oder psychische Funktionszentren, die in mehr oder weniger hohem Grade der Zerstörung anheimgefallen sind. Eine Berechnungsart, die diese Differenzen unberücksichtigt läßt, würde die tatsächlichen Verhältnisse verschleiern, indem sie die schlechten Aufmerksamkeitsleistungen auf Kosten der guten ausgleicht. Um in die individuellen Eigentümlichkeiten der Aufmerksamkeitsstörungen tiefer einzudringen, wird sich also wohl eine weitere Differenzierung des Untersuchungsmaterials nicht umgehen lassen. Es fragt sich nur, unter welchen Gesichtspunkten dies zu erfolgen hat.

Daß der Grad der Hirnzertrümmerung in den meisten Fällen nicht ausschlaggebend für den Ausfall der Aufmerksamkeitsleistung ist, zeigte sich sehr bald. Fanden sich doch Versuchspersonen mit ausgedehnten Zerstörungen beider Hemisphären, die bessere Resultate aufwiesen als solche, bei denen ein Streifschuß beispielsweise in der Parietalgegend lediglich unbedeutende Sensibilitätsstörungen hinterlassen hatte. Auch die Verletzung hochwertiger psychischer Rindengebiete wie des Sprechzentrums, erwies sich im allgemeinen von auffallend geringer Bedeutung für die Güte der tachistoskopischen Leistung. Eine Zusammenstellung der Resultate von 8 Hirnverletzten mit gebesserter oder noch bestehender motorischer Aphasie ergab nur mit ei ner Ausnahme einen dem Durchschnittswert nicht entsprechenden Aufmerksamkeitsumfang. Ähnliche Verhältnisse lagen bei 13 Versuchspersonen mit epileptischen Anfällen vor. Wo die Aufmerksamkeitsleistungen der Epileptiker unternormal waren, kamen gewisse schädigende Momente hinzu, von denen gleich zu reden sein wird. Ebensowenig ließ sich bezüglich des Ausfalls der Aufmerksamkeitsuntersuchungen eine höhere Wertigkeit der linken Hemisphäre gegenüber der rechten feststellen.

Schließlich wurde eine Gruppierung der Versuchspersonen nach dem verletzten Hirnteil vorgenommen. Hierbei ergab sich nun eine ausgesprochene UUberlegenheit der Stirnhirnverletzten gegenüber den Versuchspersonen mit Rindendefekten in der Centroparietalregion. Indes erwies sich auch diese $Z$ weiteilung noch nicht als ansreichend. Während 
die ersteren über ziemlich gleichartige Aufmerksamkeitsleistungen verfügen, ist dies bei den Scheitelhirnverletzten durchaus nicht der Fall. Neben hervorragend gutem Aufmerksamkeitsumfang erscheinen hier vielfach äußerst schwere Störungen. Bei näherem Zusehen stellte sich heraus, daß die Versuchspersonen mit den schlechtesten Aufmerksamkeitsleistungen sich durch eine Reihe bemerkenswerter klinischer Befunde von den anderen deutlich abheben: Einmal hatte hier das Trauma nur zum Teil oder überhaupt nicht die Gegend der vorderen und hinteren Zentralwindung getroffen, sondern mehr das eigentliche Scheitelhirn, und zweitens war in der Mehrzahl der Fälle bei diesen Hirnverletzten eine auffallende Übereinstimmung charakteristischer Symptome nachzuweisen, nämlich Lagegefühlsstörungen, Tastlähmung und Ataxie, also ein Symptomenkomplex, der nach $O$ p penheim auf Verletzung gerade des Scheitellappens hinweist. Handelte es sich dagegen um Versuchspersonen, bei denen diese Scheitelhirnsymptome nicht vorlagen, sondern in der Hauptsache motorische und sensible Ausfallserscheinungen von seiten des Zentralhims, so lag der durchschnittliche Aufmerksamkeitsumfang wesentlich höher. Ihre Aufmerksamkeitsleistungen näherten sich mehr dem Typus der Stirnhirnverletzten, während der Aufmerksamkeitsumfang der Scheitelhirnverletzten bis zu den niedrigsten beobachteten Werten absank.

Hiernach hätten wir zu unterscheiden zwischen Versuchspersonen mit vorwiegender Verletzung: 1. des Stirnhirns, 2. des Zentralhirns, 3. des Scheitelhirns, 4. des Schläfenhirns. Die Versuche bei Soldaten mit reiner Occipitalhirnverletzung müssen auch in diesem $\mathrm{Zu}$ sammenhang aus den früher genannten Gründen unberücksichtigt bleiben. Zu dieser Klassifizierung sei noch bemerkt, daß bei Ausdehnung der Verletzung über größere Rindengebiete als maßgebend für die Gruppeneinteilung derjenige Hirnteil angesehen wurde, dessen Funktion sich nach den Ausfallssymptomen als vorwiegend gestört erwies. Unter dieser Voraussetzung ließ sich eine zwanglose Gruppierung der einzelnen Fälle durchführen.

Wie gestalten sich nun unter diesen Gesichtspunkten die Verhältnisse für unsere 4 Hirnverletztengruppen? Die Versuchsergebnisse sollen zunächst an der Hand der Tabelle II besprochen werden.

In der Tabelle sind die Ergebnisse der Versuchsreihe I und II für Normale, Kopfverletzte und Hirnverletzte vergleichsweise nebeneinandergestellt. Gesondert hiervon werden die Aufmerksamkeitsleistungen der Versuchspersonen mit hysterischen Symptomen und Sehstörungen behandelt. Schließlich wird noch eine übersichtliche Zusammenstellung der 4 Hirnverletztengruppen gegeben. Im einzelnen sei zum Verständnis der Tabelle noch folgendes bemerkt: Die Ziffern $6-0$ in der ersten horizontalen Reihe bedeuten den Umfang der Aufmerksamkeit. Wie groß 
der Aufmerksamkeitsumfang ist, den die Versuchspersonen bei den Zahlenund Buchstabenversuchen erreichen und wieviel Versuchspersonen auf jeden einzelnen Aufmerksamkeitsumfang kommen, geht aus der zweiten und dritten Horizontalen hervor. In der vierten und fünften Reihe wird durch Quersummenbildung ein Uberblick gewonnen über die Zahl der Versuchspersonen, die in jeder Gruppe oberhalb und unterhalb der Grenze des normalen Aufmerksamkeitsumfangs stehen. Die Werte in der letzten Horizontalen stellen reine Verhältniszahlen dar und entsprechen dem arithmetischen Mittel der beiden vorhergehenden Reihen.

Aus der Tabelle ist nun folgendes zu entnehmen: Die untersuchten 10 Stirnhirnverletzten kennzeichnen sich dadurch, daß ihr Aufmerksamkeitsumfang völlig innerhalb der normalen Schwankungsbreite bleibt. In keinem Fall sinkt er unter 3 ; in der Hälfte der Fälle wird sogar die obere Grenze mit 5 und 6 Einheiten erreicht. Mithin übertreffen die Stirnhirnverletzten die tachistoskopische Aufmerksamkeitsleistung der normalen Soldaten. Und dabei

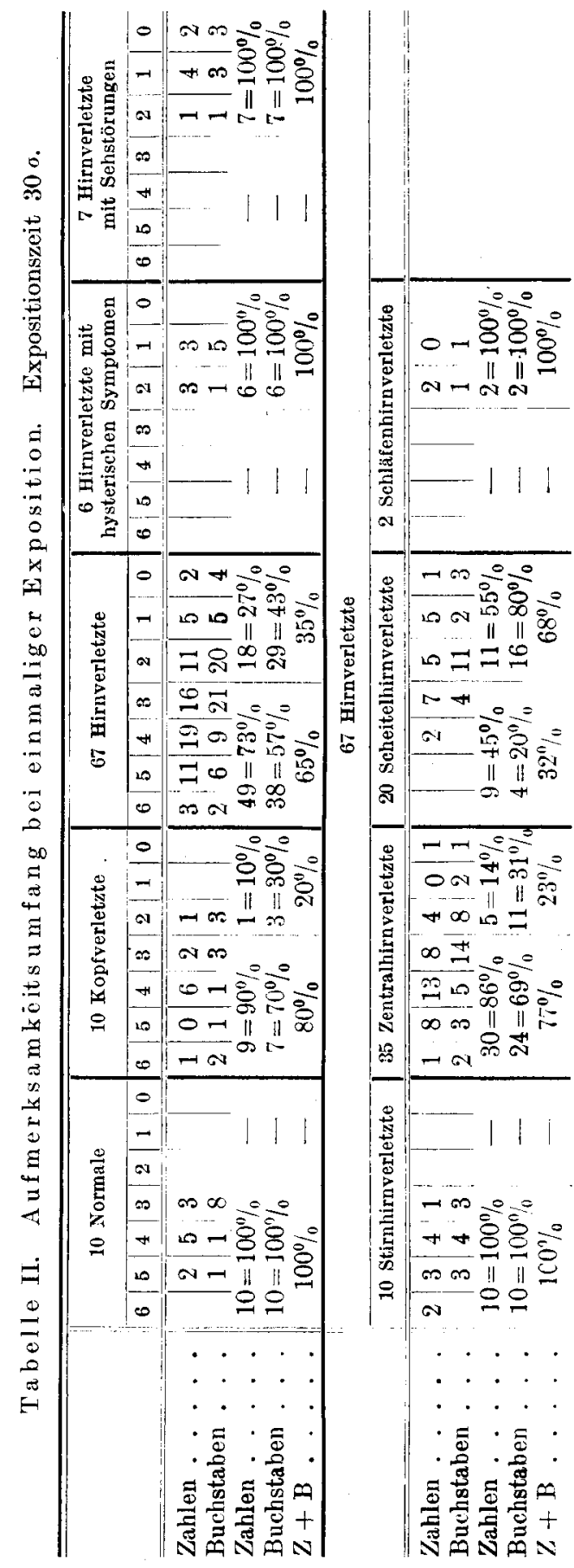


handelt es sich z. T. um erhebliche Zerstörung von Stirnhirnsubstanz. Besondere Erwähnung verdient ein 22 jähriger Kontorist (Nr. 20), der trotz Durchschusses durch beide Stirnhirne und vereinzelter epileptischer Anfälle vierstellige Zahlen- und Buchstabenobjekte bei der ersten Exposition erkennt. Auch die Aufmerksamkeitsresultate der 3.) Ze ntralhirnver letzte $n$ bewegen sich größtenteils noch im Rahmen des Normalen, und zwar auch dann, wenn motorische Aphasie und Epilepsie in Verbindung mit mehr oder weniger schweren Ausfallserscheinungen seitens der vorderen und hinteren Zentralwindung vorliegen. Bei den Zahlenversuchen ist die Amnäherung an den Aufmerksamkeitstyp der Stirnhirnverletzten ganz deutlich ausgeprägt: 30 Versuchspersonen erkennen 3-6stellige Zahlen, nur 5 bringen es auf nicht mehr als 2 Einheiten. Wesentlich geringer ist schon die Leistung bei den Buchstabenversuchen. Hier stehen den 24 Hirnverletzten mit normalem Aufmerksamkeitsumfang 11 gegenüber, die nicht mehr die untere Aufmerksamkeitsgrenze erreichen. Ganz anders dagegen verhalten sich die 20 Versuchspersonen mit ausschließlicher oder vorwiegender Verletzung des Scheitelhir ns. Nur 9 von ihnen gelangen bei den Zahlenversuchen bis zur unteren Normalgrenze, bei den Buchstabenversuchen sogar nur 4. Der Rest erkennt nur ein- bis zweistellige Objekte oder überhaupt nichts. Über die Bedeutung der Te mporal region für den Ausfall der Aufmerksamkeitsuntersuchungen kann angesichts von nur 2 Fällen reiner Schläfenhirnverletzung bisher noch nichts gesagt werden.

Für unsere drei Hauptgruppen wäre das Ergebnis also folgendes: Einen normalen A ufmerksamkeitsumfang haben sämtliche untersuchten Frontalhirnverletzten, drei Viertel der unters uchtenZentralhirnverletzten und nurein Drittelder untersuchten Parietalhirnverletzten. Fügen wir noch hinzu, daß die tachistoskopische Aufmerksamkeitsleistung zum Teil bis Null sinkt, wenn wir es mit Verletzung des Occipitalhirns zu tun haben, so hätten wir folgenden Tathestand: Bei Substanzdefekten des Stirnhirns sind Einschränkungen des A ufmerksamkeits umfangs bisher nicht nachzuweisen. Sie treten erst a uf bei Rindenherden i m Gebiet der Zentralwindungen. In dem Maße, als der Ort der Schädigung sich dem Occipitalpol nähert, nimmt der A ufmerksamkeitsumfang ab. Den Nullpunkt erreicht er bei Verletzung der zentralen Sehregion. Dieses Resultat konnte durch eine ganze Reihe von Parallelversuchen gestützt und vertieft werden. Es stehen uns im ganzen 5 in sich geschlossene Versuchsreihen zur Verfügung, die alle zum gleichen Ergebnis führen.

Wir gingen in unseren Berechnungen von der experimentell festgestellten Tatsache aus, daß sämtliche untersuchten Normalen sowohl bei Zahlen als auch bei Buchstabenversuchen mindestens 3 Einheiten 
erkennen. Faßt man nun, wie es in Tabelle II geschieht, die Hirnverletzten wieder zu eirier einheitlichen Gruppe zusammen und vergleicht sie mit den Kopfverletzten und Normalen, so stellt sich heraus, daß über ein Drittel der Hirnverletzten die untere Grenze des normalen Aufmerksamkeitsumfangs nicht erreicht. Im Vergleich hiermit erweisen sich die Kopfverletzten zwar auch in ihren tachistoskopischen Leistungen geschädigt, jedoch in weit geringerem Maße als die Hirnverletzten. Bei den Buchstabenversuchen sind es unter 10 Kopfverletzten 3, bei den Zahlenversuchen sogar nur einer, der unternormale Aufmerksamkeitswerte zeigt. Die Kopfverletzten nehmen also eine Mittelstellung ein zwischen den Normalen und Hirnverletzten.

Das wesentliche Ergebnis unserer bisherigen Untersuchungen wäre also kurz zusammengefaßt folgendes:

1. Unter der Voraussetzung, daß die Erkennung von 3 unverbundenen Einheiten noch im Rahmen des Physiologischen liegt, haben einen normalen Aufmerksamkeitsumfang sämtliche untersuchten normalen Soldaten, $80 \%$ Kopfverletzte und $65 \%$ Hirnverletzte.

2. Für den Ausfall der tachistoskopischen Aufmerksamkeitsprüfung ist der Ort der Rindenläsion von ausschlaggebender Bedeutung. Kei ne Herabsetzung des Aufmerksamkeitsumfangs zeigen nur die Stirnhirnverletzten, sehr schwere Aufmerksamkeitsstörungen die Scheitelhirnverletzten. Eine Mittelstellung nehmen die Zentralhirnverletzten ein, die nicht nur in dieser Beziehung den Kopfverletzten entsprechen, sondern auch in der Prozentzahl der Versuchspersonen mit normalem Aufmerksamkeitsumfang. Bei den Kopfverletzten waren es $80 \%$, hier sind es $77 \%$.

Die bisherigen Zahlen und Berechnungen stützen sich lediglich auf die beiden ersten Versuchsreihen I und II, die mit dem Wundtschen und Netschajeffschen Tachistoskop unter gleichen Versuchsbedingungen bei einer Expositionszeit von $30 \sigma$ angestellt wurden. In beiden Reihen hatten wir es zu tun mit einer einmaligen Exposition der Reizobjekte. Als Kontrollversuche wären hier zunächst heranzuziehen die Ergebnisse der dritten Versuchsreihe IIIb, bei der die Darbietung der Zahlen- und Buchstabenkomplexe solange wiederholt wurde, bis Erkennung stattfand, im ganzen jedoch nicht über fünfmal. Gleichzeitig war hier die Expositionszeit auf die Hälfte, also auf $15 \sigma$ reduziert, ohne daß die übrigen Versuchsbedingungen irgendwelche Änderung erfuhren. Diese Parallelversuche sind geeignet, auf zwei Fragen Antwort zu geben:

1. Beeinflußt die Verkürzung der Expositionszeit die tachistoskopische Aufmerksamkeitsleistung und nach welcher Richtung?

2. Besteht zwischen dem Aufmerksamkeitsumfang bei einmaliger und bei optimaler Exposition eine gesetzmäßige Beziehung? 
Bei Beantwortung der ersten Frage stützen wir uns einerseits auf die aus den beiden ersten Versuchsreihen ( $\mathrm{I}$ und II) gewonnenen Aufmerksamkeitsresultate, andererseits auf die Umfangswerte, die sich aus der ersten Exposition der Kontrollversuchsreihe (IIIa) ergeben.

\section{Versuche bei Verkürzung der Expositionszeit.}

Als Vergleichsmaterial stehen uns hier die Untersuchungen an 65 Soldaten zur Verfügung. Davon sind 50 hirnverletzt, 5 kopfverletzt und 10 normal. Im folgenden sollen aus den bereits wiederholt genannten Gründen 3 Hirnverletzte mit hysterischen Erscheinungen sowie $5 \mathrm{mit}$ Sehstörungen zunächst unberücksichtigt bleiben. Außerdem empfiehlt sich wegen ihrer geringen Zahl die Zurückstellung der 2 Schläfenhirnverletzten. Es blieben dann übrig: 4 Stirnhirnverletzte, 22 Zentralhirnverletzte und 14 Scheitelhirnverletzte, im ganzen 40 hirnverletzte Versuchspersonen.

Tabelle III. Aufmerksamkeitsumfang bei verschiedener Expositionszeit. (Einmalige Exposition.)

\begin{tabular}{|c|c|c|c|c|c|c|c|c|c|c|c|}
\hline & & \multicolumn{6}{|c|}{10 Normale } & \multicolumn{3}{|c|}{5 Kopfverletzte } & 40 Hirnverle \\
\hline & & 6 & 5 & 4 & 3 & $2: 1$ & 0 & 5 & $\mathbf{3}$ & $2: 1$ & \begin{tabular}{l:l|l|ll}
6 & 5 & 4 & 3 & 2 \\
\end{tabular} \\
\hline $\begin{array}{c}\text { Expositions- } \\
\text { zeit } 30 \sigma \\
\text { (Reihe I u. II) }\end{array}$ & $\begin{array}{c}Z \\
B \\
Z+B \\
Z+B\end{array}$ & 15 & \begin{tabular}{|l|}
2 \\
1 \\
0 \\
100
\end{tabular} & $\begin{array}{r}5 \\
1 \\
8 \% \\
8 \\
0\end{array}$ & $\begin{array}{l}3 \\
8 \\
5 \%\end{array}$ & & & $\begin{array}{r}1 \\
10 \% \\
70\end{array}$ & \begin{tabular}{l:l|}
3 & 1 \\
0 & 2 \\
$90 \%$ & $9 \%$ \\
\end{tabular} & $\begin{array}{l}1 \\
2 \\
30 \%\end{array}$ & 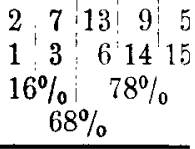 \\
\hline $\begin{array}{c}\text { Expositions- } \\
\text { zeit } 15 \text { o } \\
\text { (Reihe IIIa) }\end{array}$ & $\begin{array}{c}Z \\
B \\
Z+B \\
Z+B\end{array}$ & & $\begin{array}{l}0 \\
10 \\
75^{\circ}\end{array}$ & $\begin{array}{r}7 \\
9 \\
9 \\
9\end{array}$ & 5 & $\left.\right|_{25} ^{5}$ & & & $\begin{array}{l}1 \\
1 \mid \\
100 \% \\
100\end{array}$ & \begin{tabular}{l|l}
2 & \\
4 & \\
0 & \\
$60 \%$ &
\end{tabular} & 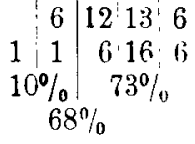 \\
\hline
\end{tabular}

Der Vergleich ist zahlenmäßig in den Tabellen III und IV durchgeführt, deren Anordnung in einzelnen Punkten von der in Tabelle II gewählten abweicht. Die beiden ersten horizontalen Reihen sind unverändert geblieben und geben Auskunft über die Anzahl der auf die einzelnen Umfangswerte entfallenden Versuchspersonen. In der dritten Reihe ist eine Dreiteilung vorgenommen, aus der $\mathrm{zu}$ entnehmen ist in welcher Weise sich Maximal-, Durchschnitts- und Minimalleistungen auf die Gesamtzahl der Versuchspersonen verteilen. Dabei soll unter Maximalleistung die Erkennung von 5 oder 6 Einheiten verstanden werden, unter Durchschnittsleistung ein Aufmerksamkeitsumfang von 2-4 Einheiten, unter Minimalleistung ein Aufmerksamkeitsumfang von null oder einer Einheit. Die vierte Reihe entspricht wieder der Eintei. lung in Tabelle II und läßt das Verhältnis der Versuchspersonen mit normalem und unternormalem Aufmerksamkeitsumfang erkennen. 
Dieses Verhältnis wird nun, wie die Gegenüberstellung der Aufmerksamkeitsleistungen bei einer Expositionszeit von 30 und $15 \sigma$ zeigt, durch die Verkürzung der Exposition bei der Gruppe der Normalen und Kopfverletzten in ungünstigem Sinne beeinflußt und zwar so, daß die Zahl der Versuchspersonen, die 3-6 Einheiten erkennen, bei den Normalen von 100 auf $75 \%$, bei den Kopfverletzten von 70 auf $40 \%$ sinkt. Demgegenüber muß es zunächst auffallen, daß die Zahl der Hirnverletzten mit normalem Aufmerksamkeitsumfang durch Verkürzung der Expositionszeit anscheinend nicht herabgedrückt wird. In beiden Versuchsreihen erhalten wir die gleiche Verhältniszahl, nämlich $68 \%$. Bei näherem Zusehen ergibt sich jedoch, daß von einer absoluten Gleichheit nicht die Rede sein kann. Vielmehr verringert sich die Anzahl der Versuchspersonen, die den maximalen Aufmerksamkeitsumfang erreichen, bei verkürzter Expositionszeit fast um die Hälfte, während die Zahl der Hirnverletzten mit Minimalleistungen sich verdreifacht.

elle IV. Aufmerksamkeitsumfang bei verschiedener Expositionszeit (einmalige Exposition).

\begin{tabular}{|c|c|c|c|c|c|c|c|c|c|c|c|c|}
\hline & & $4 \mathrm{Sti}$ & irnhirnvè & Èrlet & tzte & 22 Zer & ntralhirn & nverletzte & 14 Sch & eitelhirn & nver & rletzte \\
\hline & & 5 & $4 \longdiv { 3 }$ & 2 & $1 \mid 0$ & \begin{tabular}{l|l|l|}
6 & 5
\end{tabular} & 4 & $2 \longdiv { 1 }$ & \begin{tabular}{l|l}
6 & 5
\end{tabular} & 43 & 2 & $1 \mid 0$ \\
\hline $\begin{array}{l}\text { positions- } \\
\text { zeit } 30 \% \\
\text { leihe I a. II) }\end{array}$ & $\begin{array}{c}Z \\
B \\
Z+B \\
Z+B\end{array}$ & 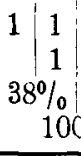 & \begin{tabular}{c|c}
2 & \\
2 & 1 \\
$62 \%$ \\
$0 \%$
\end{tabular} & & - & \begin{tabular}{r|r|}
1 & 6 \\
1 & 2 \\
$23 \%$ \\
$\quad 84$ \\
\end{tabular} & \begin{tabular}{|c|c|}
9 & 5 \\
3 & 10 \\
$77 \%$ \\
$\%$
\end{tabular} & \begin{tabular}{|l|l}
1 & \\
6 & \\
& $16 \%$ \\
\end{tabular} & $\frac{1}{-}$ & \begin{tabular}{|l|l|}
2 & 4 \\
1 & 3 \\
$82 \%$ \\
$\%$
\end{tabular} & $\begin{array}{l}4 \\
9 \\
0\end{array}$ & $\begin{array}{c}4 \\
1 \\
18 \% \\
64 \% \\
\end{array}$ \\
\hline $\begin{array}{l}\text { positions- } \\
\text { zeit } 15 \sigma \\
\text { Reihe IIIa) }\end{array}$ & $\begin{array}{c}Z \\
B \\
Z+B \\
Z+B\end{array}$ & $\begin{array}{r}2 \\
1 \\
38 \% \\
88^{\circ}\end{array}$ & $\begin{array}{r:r}2 & \\
1 & 1 \\
62 \% & 6\end{array}$ & 1 & $\frac{i}{2 \%}$ & $\begin{array}{r} \\
14 \\
1 \mid \\
11 \% \\
11 \% \\
88\end{array}$ & \begin{tabular}{|c|c|}
8 & 9 \\
4 & 13
\end{tabular} \mid & \begin{tabular}{l|l|l|}
1 & & \\
2 & 1 & 1 \\
& & $5 \%$ \\
0 & $5 \%$
\end{tabular} & $\frac{1}{32}$ & \begin{tabular}{|c|c|}
2 & 4 \\
1 & 2 \\
$61 \%$ & \\
61
\end{tabular} & $\begin{array}{l}5 \\
3 \\
0 \\
1\end{array}$ & $\begin{array}{l:l}1 & 2 \\
2 & 6 \\
39 \% \\
68 \%\end{array}$ \\
\hline
\end{tabular}

Die Differenzierung der Hirnverletzten nach dem Ort der corticalen Störung zeigt die Beeinflussung des Aufmerksamkeitsumfangs durch Verkürzung der Expositionszeit noch deutlicher: Einerseits Abnahme der Versuchspersonen mit maximalen Umfangswerten, andererseits $\mathrm{Zu}$ nahme der Hirnverletzten mit minimalen Aufmerksamkeitsleistungen. Beispielsweise steigt bei den Scheitelhirnverletzten die relative Zahl derjenigen Versuchspersonen, die überhaupt nichts oder nur eingliedrige Objekte erkennen, von 18 auf $39 \%$. Bei den Stirnhirnverletzten kommt die Verschlechterung der Leistung bei der kürzeren Expositionszeit zwar auch zum Ausdruck, jedoch wegen der geringen Versuchszahl weniger eindeutig. Im übrigen bestätigt die Tabelle von neuem einwandfrei die Unterlegenheit der Scheitelhirnverletzten gegenüber den Zentralund Stirnhirnverletzten. 


\section{Versuche bei Wiederholung der Exposition.}

Hiermit ist jedoch das Ergebnis der dritten Versuchsreihe noch nicht erschöpft. Unseren Berechnungen haben wir bisher nur den bei erster Exposition erreichten Aufmerksamkeitsumfang zugrunde gelegt (Versuchsreihe III a). Wie gestalten sich nun die Verhältnisse bei Wie derholung der Exposition (Versuchsreihe IIIb)? Besteht zwischen dem Aufmerksamkeitsumfang bei einmaliger und bei optimaler Darbietung irgendwelche Beziehung? Dabei soll unter optimaler Exposition diejenige verstanden werden, bei welcher der größte Aufmerksamkeitsumfang erreicht wird. Dies braucht nicht in jedem Fall die letzte oder fünfte Exposition zu sein. Je nach Umfang und Schwierigkeit der dargebotenen Objekte erfolgt die Erkennung unter Umständen auch schon bei der ersten oder einer der folgenden Expositionen. In welcher Weise sich die Umfangswerte bei Wiederholung der Exposition verändern, zeigen Tabelle $\mathrm{V}$ und $\mathrm{VI}$.

Tabelle V. Anfmerksamkeitsumfang bei einmaliger und optimal Exposition. Expositionszeit $15 \sigma$.

\begin{tabular}{|c|c|c|c|c|c|c|c|c|c|c|c|c|c|c|}
\hline \multirow[b]{3}{*}{$\begin{array}{l}\text { Einmalige } \\
\text { Exposition } \\
\text { (Reihe IIIay }\end{array}$} & \multirow[b]{3}{*}{$\mid \begin{array}{c} \\
Z \\
B \\
Z+B \\
Z+B\end{array}$} & \multicolumn{3}{|c|}{10 Normale } & \multicolumn{5}{|c|}{5 Kopfverletzte } & \multicolumn{5}{|c|}{40 Hiruverletz1 } \\
\hline & & \begin{tabular}{l|l|l}
6 & 5 & 4 \\
\end{tabular} & 4 & \begin{tabular}{l|l|l}
2 & 1 & 0
\end{tabular} & 6 & $4|3|$ & 21 & 1 & 0 & 6 & 5 & 4 & 3 & 2 \\
\hline & & \begin{tabular}{r:r|r}
1 & 0 & 7 \\
$\vdots$ & \\
$5 \%$ & \\
$75 \%$ & \\
&
\end{tabular} & $\begin{array}{l}7\left|\begin{array}{c}2 \\
5 \\
95 \%\end{array}\right| \\
\end{array}$ & $\begin{array}{c:c} & \\
5 & \\
0 & 25 \% \\
\end{array}$ & & $\mid \begin{array}{c:c}1 & 2 \\
1 & 0 \\
100 \% \\
10 \%\end{array}$ & $\begin{array}{l}2 \\
4 \\
10\end{array}$ & $0 \%$ & & & $\begin{array}{c}6 \\
1 \\
0 \\
68^{\circ} \\
\end{array}$ & & $\begin{array}{l}13 \\
16 \\
3 \%\end{array}$ & \begin{tabular}{|l}
6 \\
6 \\
0 \\
3 \\
\end{tabular} \\
\hline $\begin{array}{c}\text { Optimale } \\
\text { Exposition } \\
\text { (Reihe IIIb) }\end{array}$ & $\begin{array}{c}Z \\
B \\
Z+B \\
Z+B\end{array}$ & \begin{tabular}{l|l|l}
5 & 1 & 3 \\
2 & 0 & 2 \\
$40 \%$ & \\
$45 \%$
\end{tabular} & $\begin{array}{l}3\left|\begin{array}{l}1 \\
3\end{array}\right| \\
60 \%\end{array}$ & \begin{tabular}{|c|c}
3 & 1 \\
0 & $15 \%$
\end{tabular} & \begin{tabular}{r|r}
2 & 1 \\
1 & 0 \\
$40^{\circ} \%$ \\
$\quad 7$
\end{tabular} & \begin{tabular}{l|l}
2 & \\
0 & 1 \\
& $60 \%$ \\
$\%$
\end{tabular} & 3 & & & & $\begin{array}{c}15 \\
3 \\
0 \% \\
87^{0}\end{array}$ & & $\begin{array}{c}2 \\
10 \\
0 \%\end{array}$ & $\begin{array}{l}2 \\
7 \\
0 \\
1\end{array}$ \\
\hline
\end{tabular}

Hier ist also für alle drei Gruppen eine zum Teil nicht unbeträchtliche Steigerung des Aufmerksamkeitsumfangs bei optimaler Exposition festzustellen. Der Leistungszuwachs ist um so größer, je geringer die Umfangswerte bei einmaliger Exposition waren. Als Resultat dieser graduell verschiedenen Umfangssteigerung stellt sich eine bemerkenswerte thereinstimmung in den Aufmerksamkeitsleistungen der Himverletzten und Normalen ein. In beiden Gruppen erreichen 85 resp. $87 \%$ der Untersuchten einen normalen Aufmerksamkeitsumfang. Die Kopfverletzten bleiben dagegen mit $70 \%$ etwas im Rückstand. Allerdings haben die letzteren in bezug auf die Maximalwerte den größten Leistungszuwachs bei optimaler Exposition zu verzeichnen. Während nämlich bei einmaliger Exposition keiner der 5 Kopfverletzten 5 oder 6 Einheiten erkannte, sind es jetzt 3 bei den Zahlenversuchen und 1 bei den Buchstabenversuchen. Verhältnismäßig weniger steigt die Versuchsper- 
sonenzahl mit maximalen Umfangswerten bei den Normalen, am weniggten bei den Hirnverletzten. Die Folge davon ist, daß bei optimaler Exposition die Ubereinstimmung der Gruppen sich in den Maximalwerten - $40 \%$ für Normale und Kopfverletzte, $49 \%$ für Hirnverletzle noch auffallender ausprägt als bei den obenerwähnten Normalwerten, die noch zwischen 70 und $87 \%$ schwankten. Mit andern Worten: Die Wiederholung der Exposition ist imstande, die anfänglichen Differenzen in den tachistoskopischen Aufmerksamkeitsleistungen der Normalen, Kopfverletzten und Hirnverletzten so weit auszugleichen, $\mathrm{da} B$ die letzteren in ihrem Aufmerksamkeitsumfang gegenüber den beiden andern Gruppen nicht mehr zurückstehen.

Tabelle VT. Aufmerksamkeitumfang bei einmaliger und optimaler Exposition. Expositionszeit 15 a.

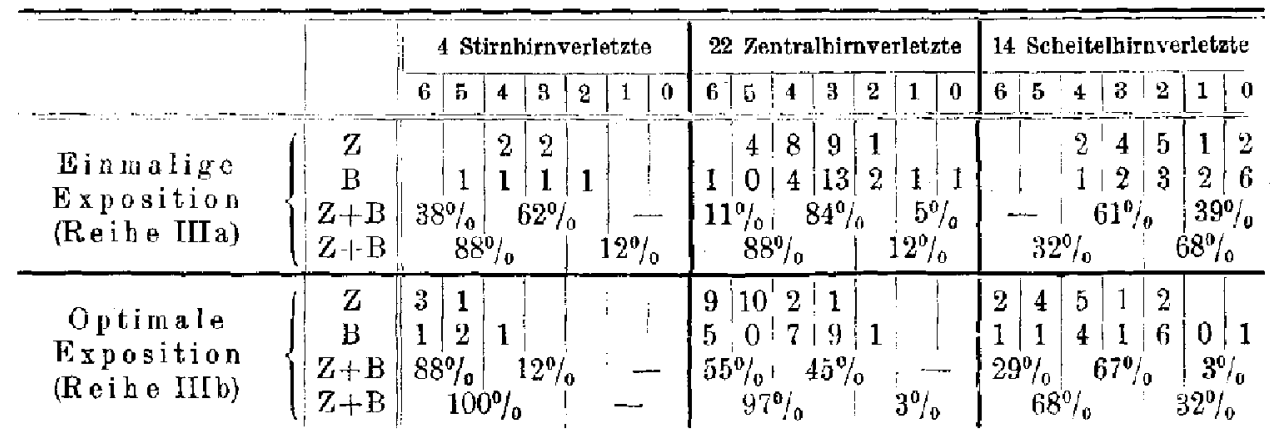

Auch hier sehen wir wiecter ebenso wie in der vorhergehenden Tabelle, daß die Wiederholung der Exposition um so wirksamer ist, je schlechter die Aufmerksamkeitsleistung bei einmaliger Exposition war. Während beispielsweise in der Stirnhirnverletztengruppe die Zahl der Versuchspersonen mit maximalem Aufmerksamkeitsumfang um etwas mehr als das Doppelte zunimmt, vergrößert sich diese Zahl bei den Zentralhirnverletzten um das Fünffache. Bei den Seheitelhirnverletzten ist die Steigerung am erheblichsten, nämlich von 0 auf $29 \%$, wogegen die Versuchspersonenzahl mit minimalem Aufmerksamkeitsumfang von $39 \%$ auf $3 \%$ sinkt. Trotz dieser Verschiebung der Werto bleibt die Überlegenheit der Stirnhirnverletzten gegenüber den andern gewahrt, wenn auch der Unterschied infolge der versehiedenen Wirkung der Expositionswiederholung sich zagunsten der Scheitelhirnverletzten einigermaßen ausgoglichen hat.

\section{Ablenkungstersuche.}

Eine vierte Versuchsreihe stelit sich die Aufgabe, den EinfluB der Ablenkung auf die Aufmerksamkeitsleistung zu studieren. Zu diesem Zwecke wutrden die Versuche mit ähnlich konstruierten sinnlosen Buch- 
stabenverbindungen angestellt, wie sie bei den Normalversuchen verwandt worden waren. In der Umgebung der Buchstaben sind regellose Striche und Figuren in der Weise angeordnet, daß sie den Blick der Versuchspersonen auf sich ziehen. Im übrigen haben Versuchsanordnung und Expositionszeit keine Änderung erfahren. Die Versuche gliedern sich in 2 Reihen, je nachdem es sich um das Ergebnis einmaliger oder optimaler Exposition handelt. Dem entsprechen die Tabellen VII und VIII. Um den Einfluß der Ablenkung auf den Aufmerksamkeitsumfang deutlich hervortreten zu lassen, werden in beiden Tabellen die Ergebnisse der Buchstabenversuche mit und ohne Ablenkung vergleichsweise gegenübergestellt.

Tabelle VII. Aufmerksamkeitsumfang bei Buchstabenversuchen mit und ohne Ablenkung. Einmalige Exposition. Expositionszeit $15 \sigma$. Reihe IVa.

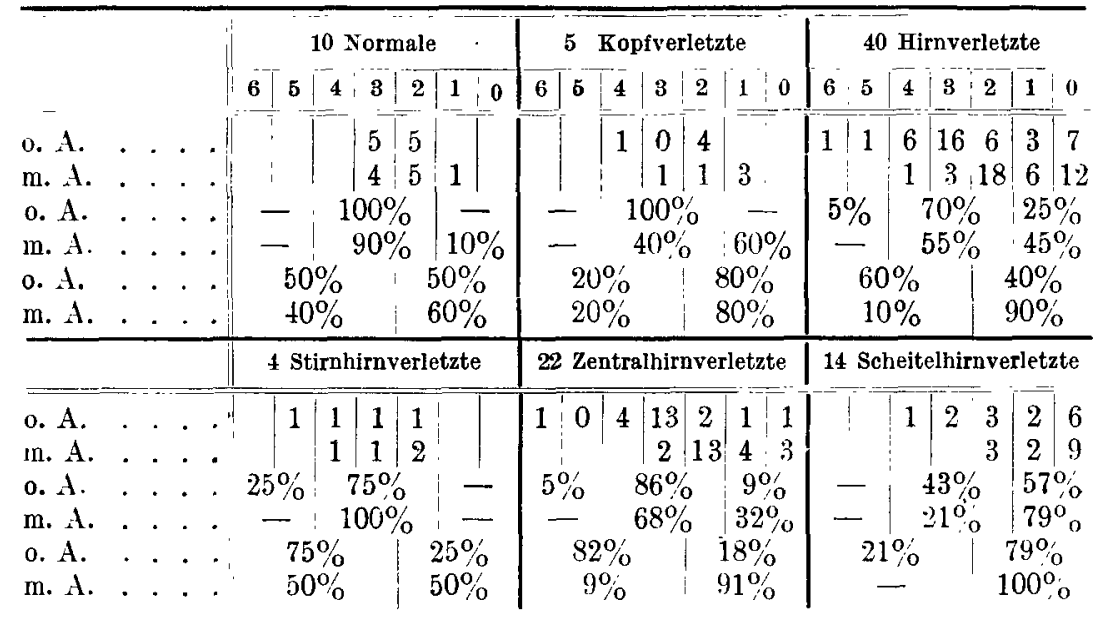

Da zeigt sich nun, daß bei Normalen und Kopfverletzten der Ablenkungsfaktor kaum imstande ist, den Aufmerksamkeitsumfang herabzudrücken. Es findet nur eine ganz geringe Verschiebung der Werte nach unten hin statt, und zwar derart, daß bei den Ablenkungsversuchen in beschränkter Zahl Minimalwerte auftreten, die bei fehlender Ablenkung nicht vorhanden waren. Diesem schädigenden Einfluß der Ablenkung unterliegen die Kopfverletzten mehr als die Normalen. Eine wesentlich eingreifendere Rolle spielt die Ablenkung bei den Hirnverletzten. Während nämlich bei den Buchstabenversuchen ohne Ablenkung etwas mehr als die Hälfte der Hirnverletzten einen normalen Aufmerksamkeitsumfang aufweist, sinkt jetzt die Zahl auf $1 / 10$. Maximalwerte werden überhaupt nicht mehr erreicht; statt dessen kommen die meisten Hirnverletzten nicht mehr über einen Aufmerksamkeitsumfang von 1-2 Ein- 
heiten hinaus, und 12 Versuchspersonen erkennen überhaupt nichts. Von diesen kommen 9 auf Scheitelhirnverletzte, der Rest auf Zentralhirnverletzte. Kein einziger der Scheitelhirnverletzten erreicht die untere Grenze des normalen Aufmerksamkeitsumfangs, während dies bei den Buchstabenversuchen ohne Ablenkung noch bei $21 \%$ der Untersuchten der Fall war. Dagegen verfügt die Hälfte der Stirnhirnverletzten trotz der Ablenkung über einen normalen Aufmerksamkeitsumfang und übertrifft mit dieser Leistung nicht nur die Kopfverletzten sondern auch die Normalen.

Tabelle VIII. Aufmerksamkeitsumfang bei Buchstaben. versuchen mit und ohne Ablenkung. Optimale Exposition. Expositionszeit $15 \sigma$. Reihe IV b.

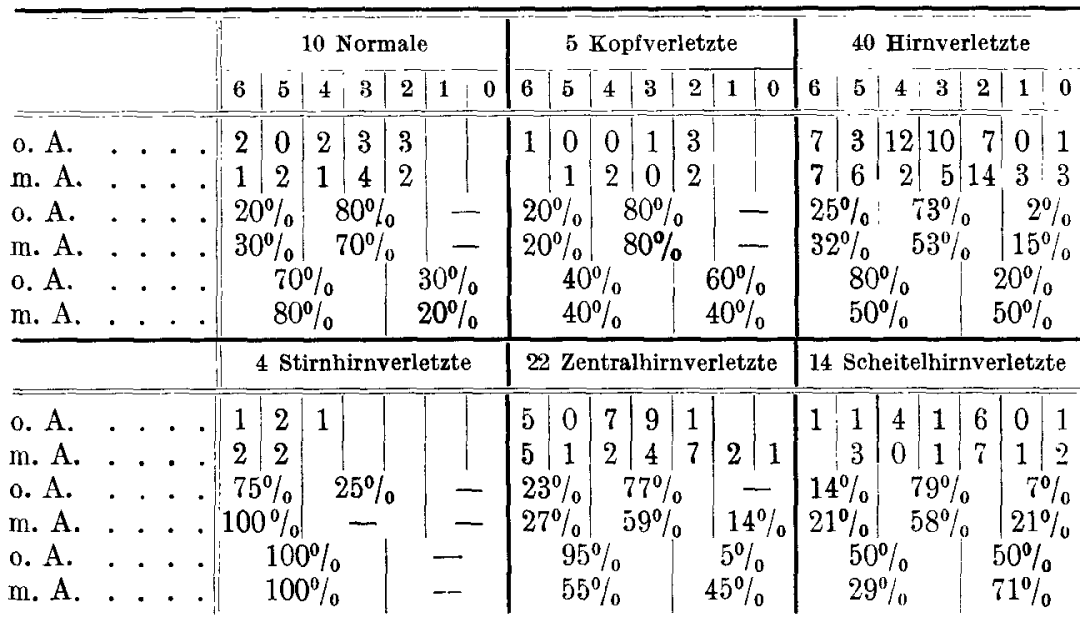

Was die Stimhirnverletzten bei einmaliger Exposition erreichen, nämlich in $50 \%$ der Fälle einen normalen Aufmerksamkeitsumfang, leistet der Durchschnitt aller Hirnverletzten, wie Tabelle VIII zeigt, erst bei optimaler Exposition. Wiesen bei einmaliger Exposition nur $10 \%$ der untersuchten Hirnverletzten einen normalen Befund auf, so sind es jetzt gerade die Hälfte. Die Wiederholung der Exposition ist also sehr wirksam. Ähnliches beobachten wir bei Normalen und Kopfverletzten. Hier werden dank der mehrmaligen Exposition auffallenderweise sogar höbere Aufmerksamkeitswerte erreicht, als bei Buchstaben versuchen ohne Ablenkung. Man kann also sagen: Die negative Wirkung, die der Ablenkungsfaktor auf den Aufmerksamkeitsumfang ausübt, wird durch Wiederholung der Exposition nicht nur ausgeschaltet, sondern, soweit es sich nicht um Hirnverletzte handelt, sogar überkompensiert.

Der Aufmerksamkeitsumfang ist also bei dieser Versuchsanordnung zwei entgegengesetzt wirkenden Einflüssen ausgesetzt, der hemmenden 
oder negativen Ablenkungswirkung und der fördernden oder positiven Wiederholungswirkung. Un so bemerkenswerter ist die Feststellung, daß trotzdem der Unterschied in den Aufmerksamkeitsleistungen zwischen den 3 Hirnverletztengruppen so gut wie unbeeinflußt bleibt, und zwar auch dann, wemn selbst der dritte Faktor, die Expositionszeit, eine Änderung erfährt. Wir fanden anfangs, daß bei einer Darbietungszeit von $30 \%$, bei einmaliger Exposition und fehlender Ablenkung einen normalen Aufmerksamkeitsumfang erreichen: sämtliche Stirnhirnverletzte, $77 \%$ der Zentralhirnverletzten und 32\% der Scheitelhirnverletzten. Jetzt zeigt sich, daß bei einer Darbietungszeit von $15 \sigma$, bei optimaler Exposition und gleichzeitiger Ablenkung, also unter völlig veränderten Versuchsbedingungen, das gegenseitige Verhältnis der Gruppen in bezug auf ihre tachistoskopischen Aufmerksamkeitsleistungen sich kaum geändert hat: 100\% Stirnhirnverletzten mit normalem Aufmerksamkeitsumfang stehen hier $55 \%$ Zentralhirnverletzte und $29 \%$ Scheitelhirnverletzte gegenüber. Die Aufmerksamkeitsleistungen der Irei Hirnverletztengruppen entsprechen also in beiden Fällen etwa dem Verhältnis $3: 2: 1$. Hiermit hätten wir eine weitere einwandfreie Bestätigung gewonnen für die GesetzmäBigkeit der funktionell verschiedenen Wertigkeit der Hirnrinde für die optisch-sensorielle Aufmerksamkeit.

\section{Wortversuche.}

Es wurde in den psychologischen Vorbemerkungen (vgl. S. 224f.) auseinandergesetzt, daß eine Steigerung des Aufmerksamkeitsumfangs statt findet, wenn man statt sinnloser, unzusammenhängender Reizobjekte siunvoll geordnete Buchstabenkomplexe und Worte tachistoskopisch exponiert. Cattel, Erdmann und Dodge, Zeitler u. a. haben gezeigt, daß unter denselben Versuchsbedingungen, unter denen im Maximum nur 5-6 sinnlos aneinander gereihte Buchstaben gelesen wurden, die Erkennung von Worten bis zu 25 Buchstaben möglich war. Natürlich kann es sich in diesem Fall nicht um die gleichzeitige klare Erfassung jedes einzelnen der 25 Buchstaben handeln. Vielmehr wird man nach Ebbinghaus ein langes Wort nur deshalb erkennen, weil man von dem Wort ein einheitliches und charakteristisches Bild erhält und nun aus früheren Erfahrungen weiß, aus was für Buchstaben dieses Wort besteht. Ist die Vorstellung von Wirth richtig, daß3 man in sinnvollen Worten ebensoviel geläufige Silbe $\mathbf{n}$ erkennt, wie in sinnlosen Komplexen einzelne Buchstabe $\mathrm{n}$, so wäre bei den Worten der Aufmerksamkeitsumfang nicht durch die Zahl der erkannten Buchstaben, sondern durch die Zahl der erkannten Silben auszudrücken.

Von dieser Utberlegung ausgehend, wählten wir für unsere Wortversuche 18 sinnvolle Worte, die entsprechend den $1-6$ stelligen Zahlenund Buchstabenverbindungen aus $1-6$ Silben mit durchschnittlich je 
3-4 Buchstaben bestanden. Das kürzeste Wort setzte sich aus 3 Buchstaben zusammen - ,gut" -, das längste Wort aus 6 Silben mit 20 Buchstaben - .,innerwirtschaftliche". Jedes Wort wurde mit dem Netschajeffschen Tachistoskop bei einer Expositionszeit von $15 \sigma$ so oft exponiert, bis es erkannt wurde, jedoch nicht über fünfmal. Die Ergebnisse der ersten und der optimalen Exposition sind in den Tabellen IX und $\mathrm{X}$ zusammengestellt. Die Anordnung brauchte gegenüber der bisher üblichen nicht geändert zu werden; nur wird hier der Aufmerksamkeitsumfang nicht in Buchstaben-, sondern in Silbeneinheiten gemessen. Die jeweilige Buchstabenzahl der Worte ist unter der Silbenzahl vermerkt.

Tabelle IX. Aufmerksamkeitsumfang bei Wortversuchen. Einmalige und mehrmalige Exposition. Expositionszeit 15 o.

\begin{tabular}{|c|c|c|c|c|c|c|c|c|c|c|c|c|c|c|c|}
\hline & & $0 \mathrm{Nc}$ & male & & & & Kopfverl & rlet & & & & Hir & rnver & rletzt & \\
\hline & \begin{tabular}{|l|l|l}
6 & 5
\end{tabular} & 3 & 2 & 1 & 0 & 5 & $4|3|$ & 2 & 1 & 6 & 5 & 4 & 3 & 2 & $1 \mid 0$ \\
\hline & {$\left[\begin{array}{ll}a & = \\
1 & 1 \\
\infty & 0\end{array}\right]$} & $\prod_{0}$ & b & $\mid 01$ & 10 & \begin{tabular}{|c|c|}
8 & 0 \\
1 & 1 \\
0 & 0 \\
\end{tabular} & $\left|\begin{array}{c|c}-1 & =1 \\
1 & 1 \\
2 & 0\end{array}\right|$ & 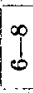 & $\mid 0$ & & $\stackrel{1}{1}$ & & $\begin{array}{l}7 \\
1 \\
0\end{array}$ & & of $=$ \\
\hline $\begin{array}{l}\text { Einmalige } \\
\text { Exposition } \\
\text { (Reihe Va) }\end{array}$ & \begin{tabular}{r|r|}
2 & 2 \\
$40^{\circ} \%$ \\
$\quad 80^{\circ}$
\end{tabular} & \begin{tabular}{l|l}
1 & 3 \\
$50 \%$ & \\
5 &
\end{tabular} & & $\begin{array}{l}1 \\
10 \\
20 \%\end{array}$ & $\%$ & $\begin{array}{r}-1 \\
20 \% \\
80^{\circ}\end{array}$ & $\begin{array}{c}1 \\
12 \\
60 \% \\
\%\end{array}$ & 0 & $\begin{array}{l}1 \\
20 \% \\
20 \%\end{array}$ & & $\begin{array}{r}7 \\
2 \% \\
80\end{array}$ & 6 & $\begin{array}{r}9 \\
48 \%\end{array}$ & & $\begin{array}{l}2 \% 2 \\
10 \% \\
20 \%\end{array}$ \\
\hline $\begin{array}{l}\text { Optil } \\
\text { expos } \\
\text { (Reihe }\end{array}$ & $\mid$\begin{tabular}{r|r}
7 & 3 \\
$100 \%$ \\
$100 \%$
\end{tabular} & $\%$ & & - & & \begin{tabular}{r|r}
4 & 0 \\
$80 \%$ \\
100
\end{tabular} & $\begin{array}{l}1 ! \\
20 \% \\
0 \%\end{array}$ & & $1-$ & & $2 \%$ & & $\begin{array}{r}5 \\
25 \% \\
\end{array}$ & & $\begin{array}{l}1 \% \\
3 \% \\
\%\end{array}$ \\
\hline
\end{tabular}

Während aus den bisherigen Versuchen hervorging, daß die Kopfverletzten hinsichtlich ihrer Aufmerksamkeitsleistung im allgemeinen eine Mittelstellung einnehmen zwischen Normalen und Hirnverletzten, ist diese Gruppenbeziehung bei den Wortversuchen nicht nachzuweisen. Tabelle IX zeigt vielmehr eine auffallende Utbereinstimmung der Gruppenresultate. Wenn man als untere Grenze des normalen Aufmerksamkeitsumfangs die Erkennung von dreisilbigen Worten mit 9-11 Buchstaben ansieht, so haben $80 \%$ der Versuchspersonen in jeder Gruppe einen normalen Aufmerksàmkeitsumfang. Auch das Verhältnis der maximalen zu den mittleren und minimalen Durchschnittswerten hat sich kaum verschoben. Ähnliches gilt für die durchschnittliche Höchstleistung: sie liegt für Normale und Kopfverletzte nicht höher als wie für Hirnverletzte, nämlich bei einem Wort mit 11 Buchstaben. Bei Wiederholung der Exposition tritt dieses Gleichheitsverhältnis allerdings nicht mehr so ausgesprochen in Erscheinung. Hier sind wieder die Normalen an der Spitze, indem bei ihnen sowohl die mittleren als auch die minimalen Werte ausfallen. Bei den Kopfverletzten fehlen nur die Minimalwerte. während bei den Hirnverletzten auch diese wieder auftreten. 
Tabelle X. Aufmerksamkeitsumfang bei Wortversuchen. Einmalige und mehrmalige Exposition. Expositionszeit 15 б.

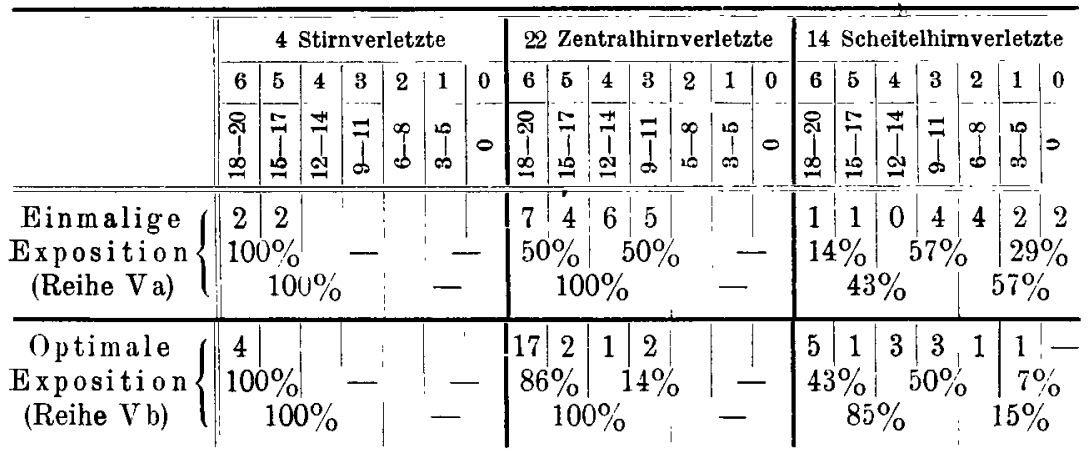

Geht man nun, wie es in Tabelle X geschieht, noch einen Schritt weiter und nimmt die Differenzierung der Hirnverletzten nach dem Ort der corticalen Schädigung vor, so ergibt sich, daß von einer Gleichheit der Hirnverletzten untereinander keineswegs die Rede sein kann. Das Gesetz von der verschiedenen Wertigkeit der Hirnrinde für den AufmerksamkeitsprozeB auf optischem Gebiet findet auch hier seine Bestätigung. Während von den untersuchten Stirnhirnverletzten alle ohne Ausnahme schon bei einmaliger Exposition Worte nicht unter 5 Silben resp. 15 Buchstaben erkennen, sind es von den Zentralhirnverletzten nur noch die Hälfte und von den Scheitelhirnverletzten nur etwas mehr als der zehnte Teil. Dafür erkennt fast ein Drittel der letzteren überhaupt nichts oder nur einsilbige Worte. Die Zentralhirnverletzten liefern als schlechteste Leistung Worte mit 9 Buchstaben, Stirnhirnverletzte solche mit 15 Buchstaben. Berechnet man wieder die Durchschnittsleistung, so stehen die Stirnhirnverletzten an der Spitze mit Worten mit 17 Buchstaben, dann folgen die Zentralhirnverletzten mit 14, am Schluß die Scheitelhirnverletzten mit 9 Buchstaben. Auch die Wiederholung der Exposition ändert nichts an diesem Verhältnis.

\section{Versuche an Hirnverletzten mit hysterischen Symptomen.}

Wir hatten von Anfang an bei Besprechung der Aufmerksamkeitsversuche zwei Gruppen von Versuchspersonen auf Grund ihrer auffallend schlechten Leistungen ausscheiden müssen: In dem einen Fall handelte es sich um Hirnverletzte, deren minderwertiger Aufmerksamkeitsumfang nicht auf Störungen der Aufmerksamkeit, sondern auf Störungen des peripheren oder zentralen Sehorgans zurückzuführen waren. In einer zweiten Gruppe hatten wir alle jene Soldaten vereinigt, die neben unzweifelhafter Hirnverletzung Symptome von Hysterie aufwiesen. Von ihnen soll jetzt zum Schluß die Rede sein. 
Wir haben es hier zu tun mit 6 Hirnverletzten mit hysterischen Sensibilitäts- und Motilitätsstörungen -2 von ihnen waren ausgesprochene Zitterer -, sowie hysterischer Zerstreutheit, Dämmerzuständen und Krampfanfällen. Sie unterscheiden sich von anderen Hirnverletzten dadurch, daß sie im tachistoskopischen Versuch entweder nichts oder nur einstellige, ausnahmsweise auch zweistellige Objekte erkennen (vgl. S.243, Tabelle II). Keiner von ihnen erreicht bei einmaliger Exposition die untere Grenze des normalen Aufmerksamkeitsumfangs. Mehr als 3 Einheiten werden auch bei optimaler Exposition nicht erfaßt. Bezeichnend ist ferner, $\mathrm{da} B$ sie bei den Ablenkungsversuchen vollständig versagen, indem keines der Objekte erkannt wird, zum Teil selbst nicht nach fünfmal wiederholter Darbietung und erheblicher Verlängerung der Expositionszeit. Dementsprechend wirkt auch die Expositionsverkürzung sehr ungünstig auf den Aufmerksamkeitsumfang ein. Hiernach .wäre also festzustellen, daß die psychogene Komponente bei Hirnverletzten zu einem in quantitativer und qualitativer Beziehung wohl charakterisierten Aufmerksamkeitstypus führt, der unter Umständen von differentialdiagnostischer Bedeutung ist. Besonders bei der Differentialdiagnose zwischen Simulation, Hysterie und Epilepsie haben uns die tachistoskopischen Aufmerksamkeitsuntersuchungen gute Dienste geleistet.

Zwei in dieser Beziehung interessante Fälle mögen kurz gestreift werden. Ein 35jähriger Tischler (Nr. 5 der Kopfverletzten) wurde wegen gehäuft auftretender hysterischer Anfälle dem Lazarett überwiesen. Der Mann kam mit einer langen Liste von 60 sorgfältig datierten Anfällen an und machte auch in seinem ganzen Auftreten einen durchaus hysterischen Eindruck. Da die Anfälle auf entsprechend energisches Zureden anfangs prompt ausblieben, trugen wir kein Bedenken, uns der gestellten Diagnose anzuschließen, zumal da lediglich eine unbedeutende Kopfhautverletzung ohne nachweisbare Läsion des Schädeldaches, geschweige des Gehirns vorzuliegen schien. Die ersten Zweifel an der Richtigkeit der Diagnose tauchten auf nach der experimentellen Aufmerksamkeitsuntersuchung, deren Ergebnis absolut nicht mit den für Hysterie charakteristischen Befunden in Einklang zu bringen war. Erkannte er doch bei der ersten Exposition vierstellige Zahlen- und Buchstabenreihen, bei der zweiten Exposition sogar sechsstellige Objekte. Dieser bisher bei Hysterikern noch nicht beobachtete Aufmerksamkeitsumfang blieb solange ungeklärt, bis der Mann eine Reihe von Anfällen bekam, deren epileptischer Charakter offenkundig war.

Jetzt das Gegenbeispiel: Bei einem 27 jährigen Maurer (Nr. 73), der in einem Dämmerzustand bei uns eingeliefert wurde, konnten klinische Untersuchung und Beobachtung ebenfalls nicht mit Sicherheit entscheiden, ob eine epileptische oder hysterische Grundlage vorlag. Bei 
ihm ergab die experimentelle Aufmerksamkeitsuntersuchung derartig typische hysterische Ausfallserscheinungen, daß seitdem an der Diagnose nicht mehr gezweifelt werden konnte.

\section{E. Schlußfolgerungen.}

Unsere Untersuchungen haben gezeigt, da $\beta$ unter pathologischen Verhältnissen das Gesetz von der Konstanz des Aufmerksamkeitsumfangs keine Gültigkeit hat. Schon Kraskowski konnte als Ergebnis seiner Normalversuche den Satz aufstellen: ,Es gibt keine Umfangskonstante. Die Umfangsgrenze ist nicht absolut konstant, sondern von den jeweiligen Auffassungsbedingungen ahhängig." Neben der Individualität und dem Grade der Úbung der Versuchspersonen hatte er dem Spannungszustand der Aufmerksamkeit die entscheidende Bedeutung für die Größe des Aufmerksamkeitsumfangs beigenessen. Demgegenüber haben unsere Untersuchungen eine weitgehende Abhängigkeit der Umfangsgröße von der Unversehrtheit ganz bestimmter Rindengebiete feststellen können. Wir sahen, daß der Aufmerksamkeitsumfang von einem Maximum auf ein Minimum in dem Maße sinkt, als der Ort der Schädigung sich vom Stimhirn entfernt und sich dem Occipitalpol nähert. Indes ist der Faktor der Hirnverletzung nicht der einzige, der den Ausfall tachistoskopischer Aufmerksamkeitsleistungen beeinflußt. Bei Beantwortung der Frage, von welchen Bedingungen der Aufmerksamkeitsumfang abhängig ist, werden wir zweckmäßigerweise zu unterscheiden haben zwischen objektiven und subjektiven Faktoren. Unter ersteren soll hier alles das verstanden werden, was im Zusammenhang zu bringen ist mit den objektiven Bedingungen der Versuchsanordnung. Die subjektiven Faktoren sind zu suchen in der Beschaffenheit des physiologischen und psychischen Zustandes der Versuchsperson.

In Úbereinstimmung mit normalpsychologischen Versuchsergebnissen war uns in unseren Versuchen die Tatsache entgegengetreten, daß die Größe des Aufmerksamkeitsumfangs in hohem Maße bedingt ist durch die Art der optischen Reize. Für den Ausfall der Versuche hatte es sich als keineswegs gleichgültig herausgestellt, ob Buchstaben, Zahlen oder Worte exponiert wurden. Die Steigerung der Schwierigkeit des Erkennens beim Übergang von Zahlen- zu Buchstabenversuchen wurde auch von fast allen Soldaten empfunden und oft auch spontan geäußert Dort, wo ausnahmsweise Buchstaben leichter aufgefaßt wurden als Zahlen -- es handelt sich um 10 unter 80 Fällen -, geben die Versuchs. personen übereinstimmend an, daß sie bei den Buchstabenversuchen. die den Zahlenversuchen folgten, mehr țbung gehabt hätten. Auf diese Ưbungsfähigkeit wird noch zurückzukommen sein. In der Mehrzahl der Fälle jedoch stellte die Erkennung von sinnlosen Buchstabenkomplexen an die Aufmerksamkeit größere Anforderungen als die der Zahlenreize. 
Die Ursache dieser Erscheinung mag zum Teil darin zu suchen sein, daß Zahlen wenig Anlaß zu Verwechslungen gehen (Finzi). Das Hauptgewicht möchte ich jedoch auf die Erklärungsversuche der Hirnverletzten selbst legen. Hiernach wäre die Steigerung des Aufmerksamkeitsumfangs bei Zahlenversuchen in der Hauptsache darauf zurückzuführen, daß die einzelnen Ziffern sofort zu einer Zahl zusammengefaßt werden, die ,Sinn" hat, was bei regelloser Konsonantenfolge nicht möglich ist. In dem Maße nun, als die Sinnlosigkeit der Reizobjekte abnimmt, tritt konsequenterweise eine Steigerung des Aufmerksamkeitsumfangs ein, die ihr Maximum bei sinnvollen Worten erreicht.

Neben der Beschaffenheit der Reize kommen noch eine Reihe anderer objektiver Versuchsbedingungen in Frage, die nicht ohne Einfluß auf die Größe des Aufmerksamkeitsumfangs sind. Auf ihre Abhängigkeit von der Expositionszeit, wovon an anderer Stelle ausführlich die Rede war, soll in diesem Zusammenhang nur andeutungsweise hingewiesen werden, ebenso wie auf die fördernde Wiederholungswirkung und die hemmende Ablenkungswirkung (vgl. S. 249 ff.). Dagegen bedarf die Frage noch der Erörterung, in welcher Beziehung der Fixationspunkt und die Selbstauslösung der Exposition zur Größe der tachistoskopischen Aufmerksamkeitsleistung steht.

Wir haben es hier mit Versuchsanordnungen zu tun, die das Vorhandensein des Aufmerksamkeitsmaximums im Augenblick der Exposition gewährleisten sollen. Nun hat sich aber herausgestellt, daß mit der Wahrung der Konstanz dieser objektiven Versuchsbedingungen keineswegs in jedem Fall auch die günstigsten Aufmerksamkeitsbedingungen notwendigerweise verbunden zu sein brauchen. Die Instruktion für alle Versuchspersonen lautete dem Sinne nach: „Genau auf den Fixierpunkt sehen! Dahinter erscheint das Objekt." Nachträglich konnte man sich nun davon überzeugen, daß diese Vorschrift durchaus nicht immer streng eingehalten wurde. Die einen erklärten ohne weiteres, daß sie den Fixierpunkt scharf ins Auge gefaßt und hierbei auch mehr erkannt hätten, als wenn sie den Blick vom Fixierpunkt abweichen ließen. Im Gegensatz hierzu wurde von anderen Versuchspersonen die genaue Befolgung der Instruktion als störend empfunden. Vielmehr erkannten sie die Objekte am besten bei gleichmäßiger Verteilung der Aufmerksamkeit über das gesamte Sehfeld.

Diese Erfahrungen stimmen überein mit Angaben aus der Literatur. Während Zeitler noch annahm, daß die genaue oder mangelhafte Einstellung auf den Fixierpunkt für den Ausfall der Versuche von großer Bedeutung sei, konnte Freeman zeigen, daß das Vorhandensein des Fixierpunkts keinen durchgängigen Unterschied in der Genauigkeit der Auffassung bedingt. Es leuchtet ohne weiteres ein, daß ein Zentralpunkt dann störend wirken kann, wenn die exponierten Objekte eine 
größere Ausdehnung haben. Die genaue Einstellung auf den Fixierpunkt gestattet dann nicht bei der kurzen Expositionszeit, die Aufmerksamkeitswanderungen ausschließt, gleichzeitig auch entferntere Teile des Objekts aufzufassen. Dementsprechend verlangt auch Wirth als günstigste Vorbedingung für einen großen Aufmerksamkeitsumfang eine konstante ursprüngliche Verteilung der Aufmerksamkeit um den Fixationspunkt. Es läßt sich in der Tat aus unseren Versuchen nachweisen, daß dort, wo es sich um kleine Objekte handelt, die starre Fixation genügt. Wo jedoch größere Umfangsleistungen verlangt werden, da tritt die schweifende Aufmerksamkeit in ihr Recht. Wenn wir nun feststellen können, daß nur etwa die Hälfte der Versuchspersonen diese Verteilung der Aufmerksamkeit um den Fixierpunkt als günstigste Vorbedingung des tachistoskopischen Sehens empfindet, während beim Rest genau das Gegenteil der Fall ist, so weisen diese Verhältnisse offenbar auf das Vorliegen verschiedener Aufmerksamkeitsty pen hin.

$\mathrm{Zu}$ gleichen Schlußfolgerungen gelangt man, wenn man die Frage der Selbstauslösung der Exposition einer kritischen Prüfung unterzieht. Deuchler war der Meinung, daß der Auffassungsakt sich unter den günstigsten Bedingungen vollziehe, wenn die Anwendung einer Fixationsmarke mit der Ermöglichung einer selbständigen Auslösung der Exposition verknüpft würde. Auch Finzi hatte seinen Versuchspersonen dia Exposition des Reizes selbst überlassen, eine Anordnung, die nach seiner Angabe von allen als eine wesentliche Unterstützung der Aufmerksamkeit betrachtet wurde. Indes lassen unsere Erfahrungen an Hirnverletzten die Zweckmäßigkeit dieser Versuchsanordnung keineswegs in allen Fällen gesichert erscheinen. Denn von den in Frage kommenden 22 Versuchspersonen sahen nur 7 in der selbständigen Exposition eine Versuchsbedingung, die zur Erzielung des Aufmerksamkeitsmaximums beitrug. Die überwiegende Mehrzahl empfand die durch die Selbstauslösung der Exposition verlangte Mehrarbeit als störend und ablenkend und erzielte tatsächlich auch bessere Aufmerksamkeitsleistungen, wenn die Exposition dem Versuchsleiter überlassen wurde. Hier ist nun eine bemerkenswerte Beziehung zu beobachten zwischen der genauen Einstellung auf die Fixationsmarke und der Ermöglichung der Selbstauslösung der Exposition: Fast sämtliche Versuchspersonen, die in der selbständigen Exposition eine willkommene Unterstützung sehen, verteilen ihre Aufmerksamkeit um den Fixierpunkt, während unter den Versuchspersonen, die starr fixieren, fast keiner ist, dessen Aufmerksamkeit bei Selbstauslösung an Umfang zunimmt.

Es läßt sich also nicht von vornherein sagen, welche Versuchsanordnung die optimalen Aufmerksamkeitsbedingungen für jede einzelne Versuchsperson darstellt. Wir haben es hier in der Tat mit individuell 
verschiedenen Aufmerksamkeitstypen zu tun. Der eine Typus charakterisiert sich dadurch, daß er seine Aufmerksamkeit nur auf einen Punkt konzentrieren kann. Die Folge davon ist, daß ihm im tachistoskopischen Versuch alles entgeht, was etwas weiter über das Gebiet der Fixationsmarke hinausreicht. Die Aufmerksamkeit befindet sich hier in einem abnorm starken Spannungszustand, der jede anderweitige Betätigung, wie beispielsweise die Selbstauslösung der Exposition, als ablenkendes Moment empfindet. Demgegenüber erzielen die Vertreter des zweiten Aufmerksamkeitstypus bessere Leistungen, da sie imstande sind, ihre Aufmerksamkeit auf ein umfangreicheres Gebiet zu verteilen, um dam im günstigsten Augenblick die Exposition des Objekts selbständig vorzunehmen.

Diese verschiedenen Arten entsprechen offenbar Messmers und Me umanns fixierendem und fluktuierendem Aufmerksamkeitstypus. Nach ihnen haben die Versuchspersonen mit fixierender Aufmerksamkeit zwar einen kleineren Aufmerksamkeitsumfang; sie geben jedoch nur das an, was sie ganz genau gesehen haben und verzichten auf alles Raten und Vermuten. Ǔber einen relativ größeren Aufmerksankeitsumfang verfügen die Versuchspersonen mit einem mehr schweifenden Charakter der Aufmerksamkeit, der sich mit einer subjektiven Interpretationstendenz (Mess mer) verbindet, $d . h$. mit der Neigung, Fehlendes und undeutlich Gesehenes zu erraten oder zu ergänzen. Mit unseren Beobachtungen würde auch die Feststellung Kraskowskis übereinstimmen, wonach nicht eine gespannte, aktive Aufmerksamkeit, sondern gerade eine schweifende, passive, dem Eindruck sich hingebende, möglichst gleich verteilte und normal gespannte Aufmerksamkeit die besten Bedingungen für einen großen Aufmerksamkeitsumfang bietet. Mit anderen Worten: Der Aufmerksamkeitsumfang nimmt mit der Abnahme der Spannung zu oder, wie Ebbinghaus es ausdrückt: ,Jede Steigerung der Konzentration ist mit einer Verengerung cles Aufmerksamkeitsumfangs verbunden."

Hiermit ist jedoch die Bedeutung des psychischen Gesamtzustandes für den Ausfall der tachistoskopischen Aufmerksamkeitsuntersuchungen noch nicht erschöpft. Es soll in diesem Zusammenhang ganz abgesehen werden von der einschneidenden Wirkung psychopathologischer $\mathrm{Zu}$ stände, wie wir sie bei unseren hysterischen Hirnverletzten kennengelernt haben. Dagegen hätten wir noch zum Schluß auf die Abhängigkeit des Aufmerksamkeitsumfangs von der individuellen Begabung hinzuweisen.

Nach Meumann kann ein geringer Aufmerksamkeitsumfang bedingt sein einerseits durch große, anderseits durch mangelhafte Intensität der Konzentration. Das letztere ist zum Teil in ausgesprochenem Maße der Fall bei Kindern, auch wenn ihre Begabung an und für sich 
normal ist. Mess mer und l'ree man haben gezeigt, daß der Umfang rer Aufmerksamkeit bei normal begabten Schulkindern um 1--2 Einheiten kleiner ist, als bei Erwachsenen, ohne jedoch auch bei kürzester Exposition unter 3 Winheiten zu sinken. Dagegen können mangelhaft begabte und schwachsinnige Kinder oft nicht mehr als zwei Elemente gleichzeitig auffassen (Meumann). Aufmerksamkeit und Intelligenz stehen eben in inniger Wechselbeziehung. Die Meinungen gehen zwar auseinander, ob rlie Aufmerksamkeit zur Intelligenz zu rechnen sei oder nicht. Während einerseits ein Zweifel darüber wohl nicht bestehen kann, laß die intellektuellen Leistungen in hohem Grade vom Aufmerksamkeitszustand abhängen, lehren doch andererseits Erfahrungen besonders auf psychiatrischem Gebiet, daß schwere Aufmerksamkeitsstörungen auch bei sehr intelligenten Personen vorkommen können, während bei manchen unzweifelhaft Schwachsinnigen Aufmerksamkeitsstörungen fehlen (Ziehen). Auch über rlie Beziehung des Aufmerksamkeits u mfangs zur Begabung sind die Ansichten noch geteilt. Freeman konnte eine Uthereinstimnung zwischen Schulbegabung und Richtigkeit des Urteils beim tachistoskopischenVersuch, wenigstens für Kinder, nicht feststellen. Demgegenüber vertritt Me u man $n$ die Auffassung, daß zwar schwachbegabte Kinder einen geringen Aufmerksamkeitsumfang und auffallende Ungenauigkeit in der Wiedergabe dargebotener Eindrücke zeigen, da $\Omega_{3}$ jedoch bei Erwachsenen die Unterschiede des Begabungsgrades sich nicht wesentlich im Aufmerksamkeitsumfang ausprägen.

Bei dieser Sachlage war von voruherein anzunehmen, da $B$ bei unsern hirnverletzten Versuchspersonen die Abhängigkeit des Aufmerksam keitsumfangs vom Begabungsgrade nur eine untergeordnete Rolle spielen würde, vorausgesetzt, daß eine solche neben der überragenden Bedeutung der örtlichen Rindenschädigung für das Versuchsresultat überhaupt noch in Erscheinung trat. Als ungeeignet für die Untersuchung der Beziehungen zwischen Begabung und Aufmerksamkeitsumfang erwiesen sich denn auch die Scheitelhirnverletzten, weil hier die Wirksamkeit des Begabungsfaktors beim Zustandekommen der Aufmerksamkeitsleistung gänzlich durch den schädigenden Einfluß der Hirnverletzung verwischt war. Mehr erwartet werden konnte von der Untersuchung jener Hirnverletzten, deren Aufmerksamkeitsumfang durch die Rindenläsion überhaupt nicht oder wenigstens nur in geringem Maßstah beeinträchtigt war. In folgendem soll nun der Beurteilung des Begabungsgrades zugrmide gelegt werlen, einerseits die schulmäßige Einschätzung der Begabung, wie sie aus dem für jeden Hirnverletzten vorliegenden Schulzeugnis zn entnehmen war, anderseits das Ergebnis der hier vorgenommenen Intelligenzprüfung.

Bei Untersuchung der Stirnhirnverletzten stellte sich nun heraus, da $\beta$ von 6 Versuchspersonen, die Zahlen- und Buchstabenverbin- 
dungen mit 5 und 6 Einheiten erkannten, 5 eine gute und nur einer eine mittelmäßige Begabung hatten. Von den übrigen 4 Stirnhirnverletzten mit einem Aufmerksamkeitsumfang von 3 und 4 Einheiten sind 2 gut und je einer mittelmäßig und schwach begabt. In Verhältniszahlen ausgedrückt, würde von Stirnhirnverletzten mit maximalen Umfangswerten $83 \%$ gut und keiner schlecht begabt sein. Von den Stirnhirnverletzten mit mittlere n Umfangswerten waren dagegen nur $50 \%$ gut und 25\% schlecht begabt, mit andern Worten: Je besser begabt, desto größer der Aufmerksamkeitsumfang. Bestätigt wird dieses Ergebnis durch den Ausfall der Versuche bei Zentralhirnverletzten.

Von 10 Versuchspersonen mit maximalen Umfangswerten sind 7 gut, 3 mittelmäßig begabt; von 17 Versuchspersonen mit mittleren Umfangswerten sind 2 gut, 14 mittelmäßig, einer schlecht begabt; von 8 Versuchspersonen mit minimalen Umfangswerten ist einer gut, 5 mittelmäßig, 2 schlecht begabt.

Also: ein maximaler Aufmerksamkeitsumfang wird von $70 \%$ gut begabten und $30 \%$ mittelmäßig begabten Zentralhirnverletzten erreicht. Ein minimaler Aufmerksamkeitsumfang dagegen von $12 \%$ gut Begabten, $63 \%$ mittelmäßig und $25 \%$ schlecht Begabten.

Noch ausgeprägter tritt die Abhängigkeit der tachistoskopischen Aufmerksamkeitsleistung von der Begabung bei unseren nicht hirnverletzten Versuchspersonen in Erscheinung. Zahleumäßig läßt sich dies am besten für die Gruppe der Kopf verletzten nachweisen:

6 Einheiten erkennen 2 Kopfverletzte - beide sind gut begabt; 4 und 5 Einheiten erkennen 5 Kopf verletzte - alle 5 sind mittelmäßig begabt; 2 und 3 Einheiten erkennen 3 Kopfverletzte - alle 3 sind schlecht begabt.

Unsere Versuche lassen also keinen Zweifel über den Charakter der Beziehung zwischen Begabung und Aufmerksamkeitsumfang. Es dürfte sich daher wohl in Zukunft empfehlen, die Begabung der Versuchspersonen bei jeder experimentellen Prüfung des Aufmerksamkeitsumfangs als einen nicht zu unterschätzenden Faktor in Rechnung zu ziehen.

Schließlich wäre noch unter den subjektiven Faktoren, die geeignet sind, den Aufmerksamkeitsumfang in positivem oder negativem Sinne zu beeinflussen, eine Eigenschaft zu nennen, die in innerem Zusammenhang mit der individuellen Begabung steht, die Ubungsfähigkeit. Me u ma nn ist zwar der Meinung, daß der Unfang der Aufmerksamkeit beinahe eine von Haus aus gegebene Fähigkeit ist, die von der angebo. renen Begabung abhängt, jedoch durch Ưbung fast nichts zu gewinnen vermag. Dem widersprechen jedoch zahlreiche experimentelle Erfahrungen. Schon Cattel hatte nachgewiesen, daß individuelle Unterschiede bei tachistoskopischer Darbietung zusammenhangloser Buch- 
staben auf dem Grade der Utbung beruhen. Auch bei Kindern fand Messmer, daß der Aufmerksamkeitsumfang mit zunehmender Ubung wächst. Allerdings soll nach Finzi die UUbung mehr die Zuverlässigkeit der Auffassung als ihren Umfang steigern. Kraskowski endlich mißt dem Spannungszustand der Aufmerksamkeit eine größere Bedeutung für den Aufmerksamkeitsumfang bei als dem Utbungsgrad und der Individualität der Versuchsperson.

Was unsere eigenen Versuche zur Frage der Úbungsfähigkeit angeht. so war bereits Gelegenheit, darauf hinzuweisen, daß in einzelnen Fällen bei Buchstabenversuchen ein größerer Aufmerksamkeitsumfang erzielt wurde, als bei Zahlenversuchen, trotzdem letztere im allgemeinen geringere Anforderungen an die Aufmerksamkeit stellen als die Buchstaben. Die Versuchspersonen, bei denen dies der Fall war, gaben als Grund für diese auffallende Erscheinung übereinstimmend an, daß sie bei den Buchstabenversuchen mehr Ưbung gehabt hätten als bei Zahlenversuchen. Angesichts der Tatsache, daß die Buchstaben jedesmal nach den Zahlen exponiert wurden, hat cliese Erklärung manches für sich. Auffallend bleibt dabei nur, daß nicht bei mehr als etwa $12 \%$ der Hirnverletzten die Feststellung des ('bungszuwachses subjektiv oder objektiv möglich war. Die Ursache hierfür ist offenbar im Utberwiegen cler Ermüdung über den Übungszuwachs bei den Buchstabenversuchen zu suchen. Da indessen über diese Frage spezielle Untersuchungen zwar nicht mit der tachistoskopischen Methode, wohl aber mit der Bourdonschen Probe angestellt sind, soll hierüber weiter unten herichtet werden.

Ủberblickt man nun die verschiedenen, den Aufmerksamkeitsumfang bestimmenden Faktoren im Zusammenhang, so lassen sich zwei große Gruppen unterscheiden, die in entgegengesetzter Richtung ihre Wirkung ausüben: Die eĩne Gruppe hat einen die tachistoskopische Aufmerksamkeitsleistung he m menden Charakter, die andere eine förder nde Wirkung. Innerhalb jeder Gruppe ist wieder eine graduelle Abstufung der einzelnen positiven und negativen Faktoren festzustellen.

Unter den letzteren nimmt eine weitaus überragende Bedeutung der pathologische Zustand der Hirnrinde ein, und zwar ist maßgebend hierbei nicht die Ausdehnung, sondern die Lage des corticalen Herdes. In zweiter Linie übt eine hemmende Wirkung aus eine Reihe von objektiven, durch die Versuchsanordnung gegebenen Faktoren. Es wäre da zu nennen Sinnlosigkeit des Reizmaterials, Ablenkung, Verkürzung der Expositionszeit, unter Umständen auch Anwendung eines Fixationspunkts und Ermöglichung der Selbstauslösung der Exposition. Dazu treten endlich negative Faktoren, die aus der individuellen Beschaffenheit des psychischen Gesamtzustandes der Versuchsperson resultieren, nämlich mangelhafte Begabung, fixierender Aufmerksamkeitstypus in 
Verbindung mit einem erhöhten Spannungszustand, große Ermüdbarkeit.

Die den Aufmerksamkeitsumfang fördernden Faktoren haben einen entsprechenden, wenn auch enger gezogenen Wirkungsbereich. Was die Versuchsanordnung betrifft, so sind hier die günstigsten Aufmerksamkeitsbedingungen gegeben bei Zahlen- und Wortversuchen, bei Verlängerung der Expositionszeit und Wiederholung der Exposition, in einer Reihe von Fällen auch bei starrer Fixation des Zentralpunkts und selbständiger Expositionsauslösung. Unter den individuellen, den Aufmerksamkeitsumfang unterstützenden Faktoren wäre zu nennen: Gute Begabung, fluktuierender Aufmerksamkeitstypus mit einem möglichst gleichmäßigen Syannuungszustand, gute Übungsfähigkeit.

Die Resultante aller dieser in entgegengesetzter Richtung und abgestufter Stärke wirkenden Kräfte ist die Umfangsgröße der Aufmerksamkeit. Welche Bedeutung jeder einzelnen Komponente beim Zustandekommen des Aufmerksamkeitsumfangs zufällt, ist individuell sehr verschieden und im allgemeinen wohl kaum exakt festzustellen. So viel haben jedoch die vorliegenden Untersuchungen zeigen können, daß der a usschlaggebende und den ganzen Typus des Aufmerksamkeitsumfangs bestimmende Faktor in jedem Fall die Schädigung der Hirnrinde ist, und zwar nicht die Verletzung an und für sich, sondern die Lage des Rindenherdes.

II.

\section{Untersuchung der Vigilität und Tenazität der Aufmerksamkeit mit der Bourdonschen Probe.}

\section{A. Psychologische Vorbemerkungen.}

Wir gehen nunmehr über zum zweiten Teil unserer Arbeit, die zum Gegenstand hat die Untersuchung der Vigilität und Tenazität der Aufmerksamkeit. Zunächst einige kurze Bemerkungen über den psychologischen Tatbestand. Wir hatten gesehen, daß sich beim Akt des Aufmerkens eine Auswahl unter einer Anzahl gleichzeitig gegebener Empfindungen vollzieht. Nun wissen wir, daß jeder Reiz bzw. die von ihm verursachte Empfindung, unter günstigen Umständen die Aufmerksamkeit wecken kann. Diese Eigenschaft wird von Ziehen als Vigi. lität der Aufmerksamkeit bezeichnet. Eine extrem große Vigilität sowohl der akustischen als auch der optischen Aufmerksamkeit beobachten wir beispielsweise im manischen Zustande. Alle äußeren Reize sind hier imstande, die Aufmerksamkeit auf sich zu lenken. Dabei findet ein fortwährender Wechsel in der Auswahl gleichzeitig gegebener Empfindungen statt. Ist die Aufmerksamkeit nicht auf alle beliebigen Reize eingestellt, sondern haftet sie an einem ganz bestimmten Reiz, ohne daß andere Empfindungen und Vorstellungen sie von der Ausgangsvorstellung abzulenken vermögen, so sprechen wir von Tena zität der Aufmerksamkeit. Wir erinnern uns hier an das Bild des ,zerstreuten" Professors, dessen Aufmerksamkeit so ausschließlich an einem bestimmten Gegenstand haftet, daß die ganze Umwelt mit allen ihren Reizen für ihn versinkt. 
Diese Eigenschaften der Aưfmerksamkeit können nun mit der Bourdonschen Probe auf ihre Leistungstähigkeit untersucht werden. Unter den in großer Anzahl empfohlenen Methoden der Aufmerksamkeitsprüfung wird diese wegen ihrer Einfachheit wohl am meisten angewandt. Indessen gehen die Auffassungen über ihr Wesen und ihre Bedeutung weit auseinander. Bourdon selbst glaubte mit der von ihm angegebenen Probe ein $\mathrm{Ma} B$ für die Unterscheidungsfähigkeit gefunden zu haben. Cattel benutzte sie zur Feststellung der Auffassungsgeschwindigkeit. Erst von Ziehen, Oehrn, Sharp, Binet, Winteler, valtzahn u. a. wurde sie als spezielle dufmerksankeitspróbe ausgebaut.

Die Aufgabe besteht bekanntlich darin, in einem vorgelegten Text ein oder mehrere bestimmte Buchstaben zu durchstreichen. Es handelt sich hierbei offenbar zunächst darum, die gegebenen Buchstabenreize schnell und genau zu erfassen und zu durchstreichen. Ferner muß von der Versuchsperson eine bestimmte Zielvorstellung festgehalten werden, so daß keine Ablenkung durch Empfindungen und Vorstellungen ertolgt die entweder von außen herantreten oder durch die Vielheit der nicht zu durchstreichenden Buchstaben störend in die Ideenassoziation eingreifen. Hieraus folgt, daß die gute Ausführung der Bourdonschen Probe die Intaktheit folgender psychischen Funktionen voraussetzt: 1. Eine exklusive Vigilität, d. h. eine möglichst große Wachsamkeit und Erregbarkeit der Aufmerksamkeit für die zugehörigen Reize. Je besser und schneller es gelingt, die Reizbuchstaben aus den übrigen herauszufinden, desto schneller kann auch die Durchstreichungsarbeit vor sich gehen. 2. Eine gute Tenazität der Aufmerksamkeit, also eine möglichst große Sammlungs- oder Konzentrationsfähigkeit für die Leitvorstellung, die im Durchstreichen eines oder mehrerer ganz bestimmter Buchstaben besteht.

Dementsprechend würden A ufmerksamkeitsstörungen den Ausfall der Bourdonschen Probe nach zwei Richtungen hin beeinflussen. Eine geringe Vigilität für die zu durchstreichenden Buchstaben wird sich besonders in einer Verlangsamung des Durchstreichens äußern, also eine quantitative Herabsetzung der Leistung zur Folge haben. Liegt dagegen eine geringe Tenazität vor, so wird das Festhalten an der Leitvorstellung erschwert und infolgedessen die Qualität der Leistung durch Auslassungen und falsche Durehstreichungen beeinträchtigt sein. Eine Qualitätsherabsetzung würde übrigens auch durch eine krankhaft gesteigerte Vigilität für Nebenreize und Nebenvorstellungen bewirkt werden können.

Der Versuch gliedert sich also in eine Prüfung der sichnelligkeit und in ejne Prüfung der Genauigkeit. Die Zahl der in der Zeiteinheit richtig durchstrichenen Buchstaben liefert uns ein direktes quantitatives Maß für die Vigilität der Aufmerksamkeit, die Fehlerzahl ein reziprokes qualitatives Maß für die Tenazität der Aufmerksamkeit. Mit anderen Worten: Je größer die Vigilität für die zugehörigen Reize, desto größer die Schnelligkeit; je größer die Tenazität für die Leitvorstellung, desto kleiner die Fehlerzahl. Die A uf merksa meitsleistung beim Bourdonschen Versuch ist also der Schnelligkeit direkt und der Fehlerzahl umgekehrt proportional. Die beiden erhaltenen Werte können nun dadurch in Beziehung zueinander gebracht werden, daß die Fehlerzahl in Prozenten der zu durchstreichenden Buchstaben ausgedrückt wird. Damit hätten wir ein einheitliches Maß für die Intensität der Aufmerksamkeit gewonnen.

Die obige Annahme, die in der Zahl der richtig durchstrichenen Buchstaben ein Maß für die quantitative Leistung der Aufmerksamkeit sieht, hedarf jedoch noch einer Einschränkung. Angenommen, dem Bourdonschen Versuch lägen zwei gleichlange Texte zugrunde, die sich nur dadurch unterscheiden, daß der erste eine größere Anzahl der zu durchstreichenden Buchstaben enthält als der zweite. Werden nun in diesen beiden Texten in gleichen Zeiträumen gleichriel 
Buchstaben durchstrichen und ausgelassen, so wäre es falsch, hieraus auf eine Gleichheit der Aufmerksamkeitsleistung zu schließen. Denn je seltener die durchzustreichenden Buchstaben im Text vorkommen, und je mehr Buchstahen zu durchsuchen sind, ehe man auf die Reizbuchstaben trifft, desto größere Anforderungen werden zweifellos an die Tenazität der Aufmerksamkeit gestellt. Das Festhalten der Leitvorstellung wird um so schwieriger sein, je mehr Nebenreize in Gestalt der nicht zu durchstreichenden Buchstaben störend dazwischentreten. Für exakte vergleichende Untersuchungen wäre daher zu fordern, daß das Verhältnis der Reizbuchstabenzahl zur Gesamtbuchstabenzahl vorher genau festgelegt und auch mitgeteilt würde.

\section{B. Versuchsanordnung.}

Auf Grund der vorstehenden Überlegungen gestaltete sich nun die Ausführung des Bourdon-Versuches folgendermaßen: Der Versuchsperson wurde ein in Fraktur gedruckter deutscher Text vorgelegt, dessen Tnhalt - Kant, ,Von der menschlichen Persönlichkeit“ _-, eine Ablenkung der Aufmerksamkeit nach Möglichkeit einschränkte. In diesem Text mußten nun 3 Minuten lang alle kleinen und großen e und $\mathrm{m}$ durchstrichen werden, wobei so schnell und so sorgfältig wie möglich gearbeitet werden sollte. Die Verrechnung erfolgt in der Weise, daß die Zahl der durchstrichenen und der ausgelassenen Reize für jeden Buchstaben gesondert bestimmt wurde. Die Fehlersumme wurde dann umgerechnet in Prozenten der zu durchstreichenden Buchstaben.

Diese auf dem Originalversuch sich aufbauende Versuchsanordnung enthält eine Reihe von Nachteilen und Fehlerquellen, auf die zuerst Ziehen aufmerksam gemacht hat, und die wir in unseren Versuchen an Hirnverletzten vielfach bestätigen konnten. Es stellte sich nämlich heraus, daß die Instruktion, möglichst schnell und möglichst sorgfältig zu arbeiten, in sehr verschiedener Weise befolgt wurde. Während die einen sich in der Hauptsache an den ersten Teil der Vorschrift hielten und sehr schnell, dabei aber teilweise sehr oberflächlich ihre Aufgabe erledigten und viele Fehler machten, waren die anderen bestrebt, möglichst keine Buchstaben zu übersehen. Diese gründliche und sorgfältige Arbeitsmethode konnte jedoch meistens nur auf Kosten der Geschwindigkeit durchgeführt werden. Wir erhielten hier also eine verhältnismäßig geringe quantitative Arbeitsleistung bei relativer Fohlerfreiheit. Im ersteren Fall erwies sich die Quantität teilweise als hervorragend, während die Qualität viel zu wünschen übrig ließ. Aus der Verschiedenheit der individuellen Arbeitsmethode ergeben sich naturgemäß ganz unvergleichbare Resultate.

Dic Nachtejle der ursprünglichen Methode liegen offenbar in der doppelten Instruktion und in der Unmöglichkeit, die Le is tungsges chwind igke it zu regulieren. Es mußte also eine Versuchsanordnung gefunden wercien, die die Wahl des Arbeitstempos der individuellen Willkür enthob. Erst wenn es gelang, die Schnelligkeit des Durchlesens bei jedem Versuch auf konstanter Höhe zu halten, war eine exakte Vergleichung der gewonnenen Resultate möglich. Zu diesem Zweck modifizierte Ziehen den Bourdonschen Versuch in der Weise daB an Stelle des ruhenden Textes ein mit bestimmter Geschwindigkeit rotierender Text dargeboten wurde.

Die Anordnung bei unseren eigenen Versuchen ist nun folgende: Vor der vertikal gestellten Trommel eines Kymographions, auf der ein Papierstreifen mit dem gedruckten Text rotiert, wird ein Gestell angebracht, das die Trommel verdeckt und den Text nur durch einen kleinen rechteckigen Ausschnitt erkennen läßt. Die Versuchsperson sitzt unmittelbar davor und hat mit einem Bleistift die angegebenen Buchstaben in dem langsam rotierenden Text zu durchstreichen. Da dic Breite des Ausschnittes $8 \mathrm{~mm}$ und die Rotationsgeschwindigkeit der 
Trommel ebenfalls $8 \mathrm{~mm}$ pro Sekunde beträgt, so wird jeder einzelne Buchstabe eine Sekunde exponiert. Die Länge der Textzeile entspricht dem Trommelumfang von $620 \mathrm{~mm}$. Eine Umdrehung nimmt also 78 Sekunden in Anspruch. Nach Ablauf der ersten Zeile wird durch schnelles Verschieben des Ausschnitts oder des Textes die zweite Zeile in den Bereich des Expositionsfeldes gebracht. Ein ins Gewicht fallender Zeitvorlust tritt infolge dieser Neueinstellung nicht ein. Der ganze Versuch dauert bei Exposition von 4 Zeilen etwas über 5 Minuten.

Die Versuche wurden an sinnvollen und sinnlosen Texten durchgeführt. Die geringsten Anforderungen an die Aufmerksamkeit werden von einem sinnlosen Text gestellt, da dieser an sich keine Veranlassung zur Ablenkung von der Leitvorstellung bietet. Es würde also bei diesem Versuch nur eine relativ geringe Tenazität in bezug auf die Leitvorstellung erforderlich sein, vorausgesetzt, daß die Vigilität in bezug auf die zugehörigen Reize intakt ist. Liegt dagegen ein sinnvoller Text vor, dessen Inhalt in mehr oder weniger hohem Grade die Aufmerk. samkeit zu fesseln imstande ist, so wird eine gute Leistung nur erzielt werden können bei guter Konzentrationsfähigkeit in Verbindung mit großer Vigilität für die Reizbuchstaben und einer möglichst geringen Vigilität für die aus dem sinnvollen Text zufließenden Nebenvorstellungen. Der quantitative bzw. qualitative Unterschied in den Aufmerksamkeitsleistungen bei sinnlosem und sinnvollem Text wird also ein Maßstab sein für die Sammlungsfähigkeit und den Grad der Empfänglichkeit für ablenkende Reize. Sind z. B. von den zu durchstreichenden Buchstaben bei sinnlosem Text 10, bei sinnvollem Text 20 übersprungen worden, so wird die Minderleistung von 10 Buchstaben im sinnvollen Text aut die mehr oder weniger klare Auffassung des Textinhaltes und die dadurch an. geregten Vorstellungen und Gefühle zurückzuführen sein.

Auf Grund dieser Überlegungen gelangten wir zu folgenden 4 Versuchs. anordnungen, die an die Tenazität der Aufmerksamkeit steigende Anforderungen stellen:

1. Versuchsanordnung: Ununterbrochene sinnlose Buchstaben. folge.

2. Versuchsanordnung: Unterbrochene sinnlose Buchstabenfolge (sinnlose Worte).

3. Versuchsanordnung: Zusammenhanglose sinnvolle Worte.

4. Versuchsanordnung: Zusammenhängender sinnvoller Text.

Jede Versuchsanordnung umfaßt eine Textreihe mit 200 Buchstaben, so daß im ganzen in jedem Versuch 800 Buchstaben zu durchsuchen waren. Unter den Buchstaben kommen in jeder Textreihe $30 \mathrm{e}$ und je $10 \mathrm{~m}$ und $\mathrm{s}$ vor. Es mußten nun beim ersten Versuch alle $\mathbf{e}$ und $\mathbf{m}$, beim zweiten Versuch alle $\mathbf{e}$ und $\mathbf{m}$ und $\mathrm{s}$ durchstrichen werden. Das Verhältnis der Reizbuchstaben zu den übrigen Buch. staben beträgt im ersten Versuch $160 \mathrm{zu} 800$, also $20 \%$, im zweiten Versuch 200 zu 800 , also $25 \%$. Hiermit war eine exakte Grundlage für die Vergleichung des Resultate der 4 Versuchsanordnungen gewonnen.

\section{Versuchspersonen.}

$\mathrm{Da}$ die Versuchspersonen dieselben sind wie bei den tachistoskopischen Ex. perimenten, erübrigt sich hier eine genaue Aufzählung. Leider konnten die Bour. donschen Versuche aus äußeren Gründen nicht in allen Fällen durchgeführt werden. Die Zahl der Versuchspersonen ist hier infolgedessen etwas kleiner als bei Untersuchung des Aufmerksamkeitsumfangs, und zwar handelt es sich um 52 Hirnverletzte una je $8 \mathrm{Kopfverletzte}$ und Normale. In der Regel wurde der Durchstreichversuch unmittelbar vor der tachistoskopischen Prüfung angestellt. 
D. Ergebnisse.

Es sind hier zu besprechen die Ergebnisse von vier Versuchsreihen:

Reihe I: Ruhender sinnvoller Text. o und m durchstrei. vhen. Zeit 3 Minuten. (Bourdonversuch I.)

Reihe II: Wiederholung von Reihe I nach einstündiger geistiger Arbeit. (Bourdonversuch II.)

Reihe III: Rotierender sinnloser und sinnvoller Text in vierfacher Anordnung. e und m durchstreichen. Expositionsdauer des einzelnen Buchstaben 1 Sekunde. Zeit 5 Mi. nuten. (Trommelversuch I.)

Reihe IV: o, m und s durchstreichen. Im ïbrigen wie Reihe IIT. (Trommelversuch II.)

\section{Bourdon-Versuche.}

Einen Ǔberblick über die beiden ersten Versuchsreihen gewährt Tabelle XI.

Tabelle XI. Bourdonversuch an ruhendem, sinnvollem Text vor (I) und nach (II) einstündiger geistiger Arbeit. e und m durchstreichen. Zeit 3 Minuten.

\begin{tabular}{|c|c|c|c|c|c|c|c|c|c|c|}
\hline & \multicolumn{5}{|c|}{ Reihe I } & \multicolumn{5}{|c|}{ Reihe II } \\
\hline & \multicolumn{2}{|c|}{ Gesumtzahl } & \multicolumn{2}{|c|}{$\begin{array}{c}\text { Durchsehnitts- } \\
\text { zahl }\end{array}$} & 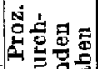 & \multicolumn{2}{|c|}{ Gesamtzahl } & \multicolumn{2}{|c|}{$\begin{array}{c}\text { Durchschnitts- } \\
\text { zahl }\end{array}$} & \multirow{2}{*}{ 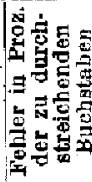 } \\
\hline & $\begin{array}{c}\text { Durch- } \\
\text { strichene } \\
\text { Buchst. }\end{array}$ & 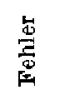 & $\begin{array}{c}\text { Durch- } \\
\text { strichene } \\
\text { Buclsst. }\end{array}$ & 点 & $\mid$ & $\begin{array}{c}\text { Durch- } \\
\text { strichene } \\
\text { Buchst. }\end{array}$ & 绨 & $\begin{array}{l}\text { Durch- } \\
\text { strichene } \\
\text { Buchst. }\end{array}$ & 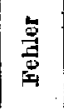 & \\
\hline 8 Normale . . & 1006 & 116 & 126 & 14 & & 1148 & 60 & 143 & 7,5 & $\mathbf{5}$ \\
\hline 8 Kopfverletzte & 956 & 103 & 120 & & 9,8 & 1019 & 88 & 127 & 11 & 8 \\
\hline$\$ 9$ Hirnverletzte & 5393 & 576 & 110 & 12 & 10 & 6069 & 415 & 124 & 8,5 & 6,4 \\
\hline 5 Stirnhimrerletzte & 616 & 28 & $12 \overline{3}$ & 6 & 4,5 & 720 & 26 & 144 & 5 & $\overline{3,4}$ \\
\hline 33 Zentralhirnverletzte & 2735 & 292 & 119 & 13 & 10 & 3039 & 209 & 132 & 9 & 6,4 \\
\hline 13 Scheitelhirnverlctzte & 1318 & 155 & 101 & 12 & 10,6 & 1483 & 113 & 114 & 9 & $7, \vec{z}$ \\
\hline 2 Schlüfenhiruverletzte . & 193 & 21 & 96 & 11 & 10,3 & 287 & 21 & 119 & 11 & 8,5 \\
\hline 6 Hinterhauptshirnverletzte & 531 & 80 & 88 & 13 & 12,8 & 590 & 46 & 98 & 8 & 7,5 \\
\hline 3 hysterische Hirnverletzte & 246 & 138 & 82 & 45 & 35,4 & 264 & 211 & 88 & 70 & 44,3 \\
\hline
\end{tabular}

Wir haben hier die Resultate der Normalen, Kopfuerletzten und Hirnverletzten zusammengestellt. Von den 52 hirnverletzten Versuehspersonen mußten in dieser vergleichenden thersicht ebenso wie bei den tachistoskopischen Versuchen soiche mit hysterischen Symptomen zunächst unberücksichtigt bleiben, weil ihre Aufmerksamkeitsleistungen grund verschieden waren von denen der übrigen Versuohspersonen. Dagegen lag für Ausschaltung der Hirnverletzten mit Sehstörungen hier keine Veranlassing vor. Für jede Gruppe wird nun berechnet: 1. die 
Gesamtzahl der in 3 Minuten durchstrichenen und ausgelassenen e und m; 2. die mittlere Durchschnittszahl für beide Werte; 3. die Zahl der Fehler in Prozenten der zu durchstreichenden Buchstaben.

Was die Natur der gemachten Fehler betrifft, so handelt es sich fast ausschließlich um Auslassungen. Falsche Durchstreichungen infolge Buchstabenverwechslung, wie sie nach v. Maltzahn für Defektpsychosen charakteristisch sind, kommen bei Hirnverletzten in der Bourdonschen Probe so gut wie nicht vor. Auch beim Trommelversuch sind Buchstabenverwechslungen so selten und wenig typisch, daß sie praktisch nicht ins Gewicht fallen und daher im folgenden vernachlässigt werden können.

Die Zahlen der Tabelle XI illustrieren zunächst die Uberlegenkeit der Normalen in der quantitativen Aufmerksamkeitsleistung. Die Hirnverletzten durchstreichen im ersten Versuch durchschnittlich nur 110 Buchstaben in 3 Minuten, die Kopfverletzten 120 und die Normalen 126. Die in der zweiten Versuchsreihe erzielten Werte sind zwar durchweg höher, ihr gegenseitiges Verhältnis wird jedoch durch die Wiederholung des Versuchs kaum beeinflußt. Im Gegensatz hierzu zeigt die qualitative Aufmerksamkeitsleist ung, die umgekehrt proportional ist der Zahl der ausgelassenen Buchstaben, in der ersten Versuchsreihe auffallenderweise nicht bei den Normalen, sondern bei den Hirnverletzten den höchsten Wert. Auch die Kopfverletzten lassen nach dieser Zusammenstellung durchschnittlich etwas weniger Buchstaben aus als die Normalen. Die Unterschiede sind allerdings so gering, daß sie wohl noch innerhalb der Fehlergrenze liegen. Ein Ausgleich findet bereits statt, wenn die Fehlerzahl in Prozenten der zu durchstreichenden Buchstaben ausgedrückt wird. Diese Berechnungsart ergibt eine fast vollständige Übereinstimmung der durchschnittlichen Aufmerksamkeitsintensität.

Die Ursache dieser Erscheinung wird man einerseits in der Verschiedenartigkeit des untersuchten Hirnverletztenmaterials zu suchen haben, anderseits in dem Umstand, daß die Hirn- und Kopfverletzten durch die Wahl eines langsanieren Arbeitstempos sorgfältiger vorgehen können als die Normalen, die bei ihrer schnelleren Arbeitsmethode zwar eine quantitativ bessere Leistung erzielen, dabei aber mehr Buchstaben übersehen als jene. Anders die zweite Versuchsreihe. Hier zeigt sich nicht nur in der Schnelligkeit, sondern auch in der Fxaktheit eine deutliche Utberlegenheit der Normalen gegenüber den Hirnverletzten. Während die Normalen in 3 Minuten durchschnittlich 143 Buchstaben bei einer mittleren Fehlerzahl von nur 7,5 durchstreichen, bringen es die Hirnverletzten nur auf 124 Buchstaben bei 8,5 Fehler. Diese Überlegenheit drückt sich auch in dem aus quantitativer und qualitativer Leistung abgeleiteten Maß der Aufmerksamkeitsintensität aus, das sich bei den 
Normalen auf $5 \%$, bei den Hirnverletzten auf $6,4 \%$, bei den Kopfverletzten auf $8 \%$ beläuft.

Wie gestalten sich nun die Versuchsergebnisse für die 52 hirnverletzten Versuchspersonen im einzelnen? Läßt sich die verschiedene Wertigkeit der Hirnrinde für den Ausfall rler Aufmerksamkeitsleistung auch mit der Bourdonschen Probe nachweisen? Antwort auf diese Fragen gibt ebenfalls Tabelle XI, in deren zweitem Teil die Differenzierung der Hirnverletzten nach dem Ort der corticalen Störung vorgenommen ist. Auf diese Weise erhalten wir 6 Gruppen, und zwar 5 Stirnhirnverletzte, 23 Zentralhirnverletzte, 13 Scheitelhirnverletzte, 2 Schläfenhirnverletzte, 6 Sehhirnverletzte und 3 hysterische Hirnverletzte. Auf den ersten Blick treten uns drei verschiedene Versuchstypen entgegen, nämlich die Stirnhirnverletzten, die hysterischen Hirnverletzten und der übrige Rest. Die charakteristischen Unterscheidungsmerkmale dieser drei Gruppen lassen sich in beiden Versuchsreihen bis ins einzelne verfolgen. Bei weitem an der Spitze stehen die Stirnhirnverletzten mit einer Aufmerksamkeitsintensität von 4,5 resp. $3,4 \%$. Sie überragen damit die Durchschnittsleistung der Hirnverletzten genau um das Doppelte. Eine Mittelstellung nehmen ein die übrigen Hirnverletzten, soweit sie nicht zur Gruppe der Hysteriker gehören. Thre Aufmerksamkeitsleistung entspricht in beiden Versuchsreihen im großen und ganzen dem allgemeinen Durchschnittswert. Diesem kommen am nächsten die Zentralhirnverletzten mit 10 resp. 6,4\%; am weitesten entfernen sich von ihm die Sehhirnverletzten mit 12,8 resp. $7,5 \%$. In einem einschneidenden Gegensatz hierzu stehen die Aufmerksamkeitsresultate der hysterischen Hirnverletzten. Sie arbeiten nicht nur langsamer als selbst die am schwersten geschädigten Hinterhauptsverletzten, sondern übersehen trotz ihrer Langsamkeit weitaus rie meisten Buchstaben. In der ersten Versuchsreihe werden von ihnen viermal mehr Buchstaben ausgelassen als vom Durchschnitt der Hirnverletzten, in der zweiten Versuchsreihe sogar achtmal soviel. Die Aufmerksamkeitsleistung entspricht einem Fehlerprozentsatz von 35,4 resp. $44,3 \%$.

Wenn also auch nach den Ergebnissen der Bourdonschen Probe eine Abhängigkeit der Aufmerksamkeitsintensität von dem Ort der Hirnverletzung nicht in dem Umfange vorzuliegen scheint, wie es nach der tachistoskopischen Methode für den Aufmerksamkeitsumfang der Fall war, so läßt sich doch auch hier eine ähnliche Tendenz keineswegs verkennen. Greifen wir beispielsweise die Stirn-, Scheitel- und Sehhirnverletzten heraus, so drückt sich ihre Aufmerksamkeitsleistung in den Fehlerprozentsätzen 4,5, 10,6 und 12,8 aus, mit anderen Worten: Die Vigilität und Tenazität der A uf merksamkeit ist bei Scheitelhirnverletzten mehr als um das Doppelte, die der Hinterhauptsverletzten fast $u m$ das Dreifache geringer als bei 
Stirnhirnverletzten. In der zweiten Versuchsreihe ist dieses Verhältnis für Stirn- und Scheitelhirnverletzte dasselbe geblieben, es beträgt $3,4 \mathrm{zu} 7,3^{\circ}$; f für die Sehhirnverletzten hat es sich mit $7,5^{\circ}$, etwas günstiger gestaltet.

Aus dem Vergleich der beiden Versuchsreihen ergeben sich weitere bemerkenswerte Folgerungen, wenn wir uns vergegenwärtigen, daß die zweite Versuchsreihe lediglich eine Wiederholung der ersten darstellt. Die Arbeit des Durchstreichens steht also in beiden Fällen nicht unter völlig gleichen Versuchsbedingungen, da sie in der zweiten Versuchs. reihe unterstützt wird durch den Faktor des Utbungszuwachses, der bei der ersten Versuchsreihe fehlt. Mit der Frage, welchen Wandlungen die geistigen Leistungen aus inneren Gründen unterliegen, haben sich Krae pelin und seine Schüler in ihren Untersuchungen über die Arbeits k u rve eingehend beschäftigt. Die beiden Hauptfaktoren, die den Gang der Arbeitskurve bestimmen, sind nach ihnen Ưb ung und Ermüd ung. Es handelt sich hier um einen Kampf entgegengesetzter Einflüsse, von denen der eine oder der andere die Oberhand gewinnen kann. Wir hatten bereits bei den tachistoskopischen Versuchen einen gewissen Grad von Úbungsfähigkeit bei unseren Hirnverletzten beobachten können (vgl. S. 261). Indes war die Zahl der Hirnverletzten mit Ubungszuwachs unverhältnismäßig gering — sie betrug nur $12 \%$ - so daß wir geneigt waren, als Erklärung hierfür das Uberwiegen der Ermüdung über den Ubungsfaktor anzunehmen. Mit der Bourdonschen Probe wurden nun besondere Versuche der Frage gewidmet, welcher der beiden Faktoren bei unserer Versuchsanordnung ausschlaggebend ist. Dies geschah in der Weise, daß etwa eine Stunde nach dem ersten Durchstreichversuch den Versuchspersonen derselbe Text zur Wiederholung der gleichen Arbeit vorgelegt wurde. Die Zwischenpause war ausgefüllt mit ganz bestimmter, in jedem Fall möglichst gleichmäßiger psychischer Arbeits leistung, die in experimenteller Gedïchtnis- und Urteilsprüfung bestand Die Ergebnisse dieses Wiederholungsversuchs wurden bereits in anderen Zusammenhang in Tabelle XI verwertet. Indessen eignet sich die dort gewählte Zusammenstellung für unsern vorliegenden Zweck offenbas nicht. Sie läßt zwar im ganzen einen mehr oder weniger hohen Grac von Utbungszuwachs bei jeder der Versuchsgruppen außer den hyste rischen Hirnverletzten erkennen, gestattet jedoch keinen Einblick ir die individuellen Abweichungen innerhalb der Gruppen selbst. Seher wir uns nämlich die Hirnverletzten in einzelnen an, so können w ir vieı verschiedene Typen unterscheiden:

1. 30 Hirnverletzte mit Zunahme der quantitativen und qualitativer Leistung.

2. 10 Hirnverletzte mit Zunahme der quantitativen und Abnahme der qualitativen Leistung. 
3. 5 Hirnverletzte mit Abnahme der quantitativen und Zunahme der qualitativen Leistung.

4. 4 Hirnverletzte mit Abnabme der quantitativen und qualitativen Leistung.

Bei $61,2 \%$ der Hirnverletzten würde also die ṫbungsfähigkeit größer sein als die Ermüdbarkeit, bei weiteren $30,6 \%$ wäre ein teilweiser Úbungszuwachs festzustellen, und nur bei $8,2 \%$ überwiegt der Ermüdungsfaktor. Unter den letzteren befinden sich 2 Zentralhirnverletzte (Nr. 15 und 35 der Tabelle I) und je ein Scheitelhirnverletzter (Nr. 55) und Occipitalhirnverletzter (Nr.69). Jedoch auch bei diesen 4 Versuchspersonen scheint es sich nicht um einen völligen Mangel, sondern nur um eine Herabsetzung der Übungsfähigkeit zu handeln. Außerdem ist nicht außer acht zu lassen, daß ein geringer Grad von Utbungszuwachs durch den lähmenden Einfluß der Ermüdung unter Umständen vollständig verdeckt werden kann.

Was den Grad der Ubungsfähigkeit bei Hirnverletzten betrifft, so unterrichtet uns hierüber am besten ein Vergleich mit dem thbungszuwachs der Normalen.

Tabelle XII. Übungszuwachsim Bourdon-Versuch vor (I) und nach (II) einstündiger geistiger Arbeit.

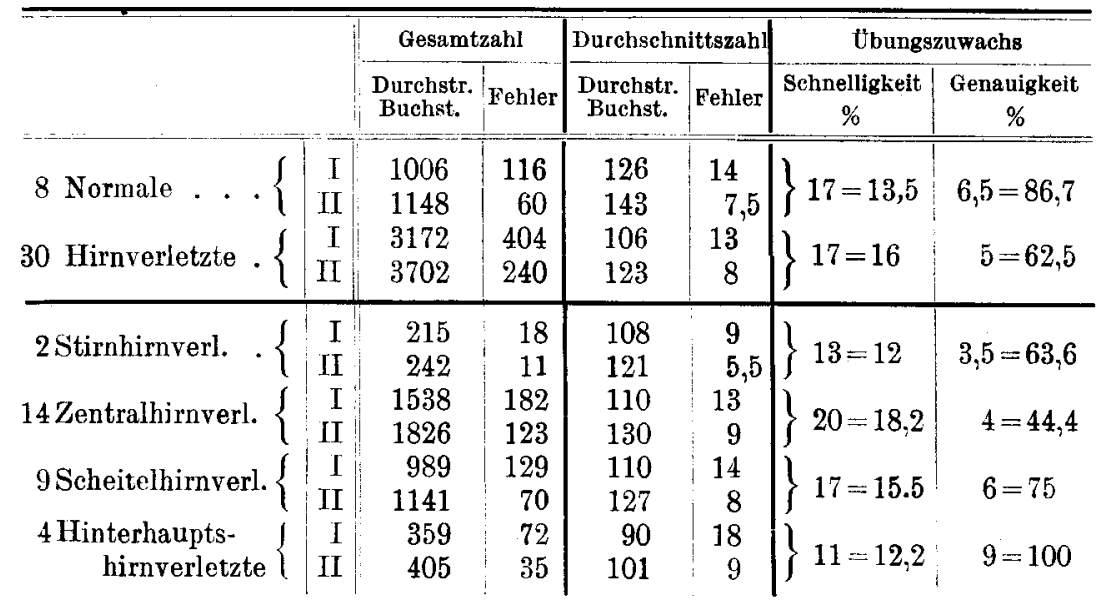

In Tabelle XII ist der Vergleich durchgeführt, und zwar nur für solche Versuchspersonen, bei denen sowohl eine Zunahme der Schnelligkeit als auch der Genauigkeit beim zweiten Bourdon-Versuch vorlag, also sämtliche Normale und 30 Hirnverletzte. Aus der Tabelle geht hervor, daß Normale wie Hirnverletzte im zweiten Versuch durchschnittlich 17 Buchstaken mehr durchstreichen als beim ersten Versuch. Die absolute Schnelligkeitszunahme ist also für beide Gruppen gleich, die relative stellt sich für die Hirnverletzten sogar noch etwas günstiger. Sie

Z. f. d. g. Neur. u. Psych. O: XIVI. 
beträgt bei ihnen $16_{\%}^{\circ}$ gegenüber $13,5 \%$ bei den Normalen. Im Vergleich hiermit ist die qualitative Aufmerksamkeitsleistung dem Übungseinfluß weit zugänglicher. Die Steigerung beträgt bei Normalen $86, \bar{T}$, bei Hirnverletzten $52,5 \%$. Mit anderen Worten:

1. Die Vigilität der optischen Aufmerksamkeit, ausgedrückt durch die Zahl der in der Zeiteinheit durchstrichenen Buchstaben, erfährt durch Ubung sowohl bei Normalen als auch bei Hirnverletzten nur eine unbedeutende Steigerung. Dabei ist der absolute Übungszuwachs in beiden Fällen der gleiche, der relative bei Hirnverletzten etwas größer.

2. Die Tenazität der optischen Aufmerksamkeit, ausgedrückt durch die Zahl der nicht durchstrichenen Buchstaben, kann durch Ubung wesentlich gesteigert werden, und zwar bei den Normalen etwas mehr als bei den Hirnverletzten.

Soweit also eine Übungsfähigkeit bei Hirnverletzten überhaupt vorliegt - - und das ist bei etwa zwei Drittel der Versuchspersonen der Fall -, ist im ganzen genommen der Grad des Ưbungszuwachses bei ihnen durohschnittlich kaum geringer als bei Normalen. Diese Feststellung würle mit einer Erfahrung übereinstimmen, die Busch bei Untorsuchung der geistigen Arbeitsleistung Hirnverletzter mit der Kraepelinschen Additionsmethode gemacht hat. Er konnte nämlich zeigen, daß nur ein geringer Unterschied der Übungsfähigkeit zu Ungunsten der Hirnverletzten vorliegt, und daß 23 von 28 die Normalgrenze erreichen. Mit Recht glaubt Busch aus dieser Beobachtung schließen zu können, daß unsere Bestrebungen nicht aussichtslos sind, durch Wiedereinübung verlorener und Erlernung neuer Kenntnisse und Fähigkeiten den Hirnverletzten eine sozjale Existenz zu verschaffen. Völliger Mangel oder starke Herabsetzung der Übungsfähigkeit würde dagegen die Prognose der Schulung Hirnverletzter recht düster erscheinen lassen.

Schließlich hätten wir uns zu fragen, ob der Grad der Übungsfähigkeit in irgendwelcher Beziehung zum verletzten Rindengebiet steht. Zu diesem Zweck sind in Tabelle XII die 30 Hirnverletzten nach dem Ort der Verletzung in Gruppen getrennt. Ein Schläfenhirnverletzter mußte als Einzelfall in diesem Zusammenhang unberücksichtigt bleiben. Diese Gruppeneinteilung zeigt nur unwesentliche Abweichungen des quantitativen und qualitativen Utbungszuwachses von rem für alle $30 \mathrm{Him}$ verletzten berechneten Durchschnittswert. Wemn auch die Zentralhirnverletzten im quantitativen țbungsfortschritt am besten abschneiden, so stehen sie dafür mit ihrer qualitativen Leistung an letzter Stelle. Die Stirn- und Scheitelhirnverletzten übertreffen zwar den durchschnittlichen qualitativen Ubbungszuwachs der Hirnverletzten, erreichen jedoch nicht die Normalen. Dies ist nur der Fall bei den Sehhirnverletzten, die mit 100\% Ubungsfortschritt am schlechtesten ahschneiden. Trotz- 
dem wird man aus diesen Zahlen eine vorzugsweise Abhängigkeit der Ubungsfähigkeit von dem Ort der corticalen Störung nicht ableiten können. Bestätigt wird diese Auffassung, wenn man für jede einzelne Gruppe das Verhältnis berechnet, in welchem die Versuchspersonen mit Übungszuwachs zu der Gesamtzahl der Versuchspersonen steht. Danach ist bei $40 \%$ sämtlicher Stirnhirnverletzten ein Übungszuwachs festzustellen, bei $61 \%$ Zentralhirnverletzten, bei $69 \%$ Scheitelhirnverletzten und bei $67 \%$ Occipitalhirnverletzten. Also auch hier keine ausgesprochene Bevorzugung eines bestimmten Hirnteils hinsichtlich des Grades der Utbungsfähigkeit. Diese Befunde würden ebenfalls mit den Erfahrungen von $B u s c h$ übereinstimmen, der auch bei seiner Arbeitskurve Beziehungen des Utbungsgrades zu der betroffenen Hirnregion nicht aufdecken konnte.

\section{Trommelversuche.}

Wir gehen nunmehr über zur Besprechung der mit dem Trommelversuch erzielten Aufmerksamkeitsresultate. Die Nachteile und Fehlerquellen, die der Bourdon-Methode anhaften und die Anwendung einer exakteren Probe wünschenswert erscheinen ließen, sind oben eingehend besprochen worden. Um ganz kurz die Vorzüge der neuen Methode zu charakterisieren, so handelt es sich hier um folgendes: Die zeitlich unbestimmte Darbietung des Textes wird hier zu einer zeitlich bestimmten. Ferner ist die Leistungsgeschwindigkeit für alie Versuche einheitlich festgelegt, so daß die Wahl des Arbeitstenıos nicht mehr der Willkür überlassen bleibt. Hierdurch wird erreicht, daß die beim BourdonVersuch als störend empfundene doppelte Instruktion - so gut und so schnell wie möglich zu durchstreichen - wegfällt, so daß die Versuchspersonen ihre ganze Aufmerksamkeit auf die exakte Durchführung der gestellten Aufgabe konzentrieren können. Schließlich hat der im Trommelversuch verwandte Text noch den Vorteil, daß die Zahl der zu durchstreichenden Reize in einem konstanten Verhältnis zu den exponierten Buchstaben steht. Im ersten Trommelversuch kommt 1 Reizbuchstabe auf 5 exponierte Buchstaben, im zweiten Trommelversuch 1 Reizbuchstabe auf 4 exponierte Buchstaben.

Tabelle XIII gibt eine übersichtliche Zusammenstellung der Versuchsergebnisse. Die Rubriken a-d entsprechen den sinnlosen und sinnvollen Textreihen. Der Ubersichtlichkeit wegen mußte hier auf die in den Tabellen XI und XII durchgeführte Trennung in quantitative und qualitative Leistung verzichtet werden. Die Tabelle gibt lediglich das prozentuale Verhältnis dieser beiden Werte, also die durchschnittliche Zahl der ausgelassenen Buchstaben in Prozenten der zu durchstreichenden Buchstaben. Mithin liegt eine um so größere Aufmerksamkeitsleistung vor, je niedriger die berechmete Prozentzahl ist. 
Tabelle XIII. Bourdon-Versuch an rotierenden sinnlosen (a und b) und sinnvollen (c und d) Texten. Reihe III: e und m Reizbuchstaben.

Reihe IV: e, m und s Reizbuchstaben. Zeit 5 Minuten.

\begin{tabular}{|c|c|c|c|c|c|c|c|c|}
\hline & \multicolumn{4}{|c|}{ Reihe III } & \multicolumn{4}{|c|}{ Reihe IV } \\
\hline & a & b & $\mathrm{e}$ & d & a & $\mathrm{b}$ & c & d \\
\hline 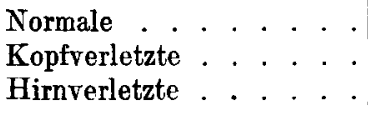 & $\begin{array}{l}1,6 \\
5,6 \\
8,2\end{array}$ & $\begin{array}{r}4,0 \\
8,1 \\
10,2\end{array}$ & $\begin{array}{r}3,1 \\
8,8 \\
11,2\end{array}$ & $\begin{array}{r}2 ; 7 \\
11,8 \\
14,5\end{array}$ & $\begin{array}{r}2,5 \\
12,0 \\
10,8\end{array}$ & $\begin{array}{r}8,2 \\
13,2 \\
13,8\end{array}$ & $\begin{array}{l}12,5 \\
17,0 \\
16,6\end{array}$ & $\begin{array}{r}9,0 \\
15,2 \\
15,6\end{array}$ \\
\hline $\begin{array}{l}\text { Stirnhirnverletzte } \cdot \cdot \cdots \\
\text { Zentralhirnverletzte } \cdot \cdot \cdot \\
\text { Scheitelhirnverletzte . } \\
\text { Hinterhauptshirnverletzte }\end{array}$ & $\begin{array}{r}4,0 \\
5,2 \\
11,8 \\
15,8\end{array}$ & $\begin{array}{r}5,0 \\
5,8 \\
12,8 \\
22,0\end{array}$ & $\begin{array}{r}6,0 \\
7,8 \\
13,8 \\
24,2\end{array}$ & $\begin{array}{r}7,5 \\
10,8 \\
15,0 \\
33,0\end{array}$ & $\begin{array}{r}5,2 \\
8,8 \\
9,4 \\
22,0\end{array}$ & $\begin{array}{r}7,6 \\
9,8 \\
14,0 \\
28,0\end{array}$ & $\begin{array}{l}12,4 \\
12,0 \\
17,0 \\
28,6\end{array}$ & $\begin{array}{l}12,0 \\
11,0 \\
18,4 \\
25,0\end{array}$ \\
\hline Hysterische Hirnverletzte & 48,2 & 49,2 & 49,2 & 48,2 & 47,4 & 52,6 & 55,4 & 52,6 \\
\hline
\end{tabular}

Aus der Tabelle ist nun folgendes zu entnehmen:

a) Ausgesprochene Uberlegenheit der Normalen über die Kopf- und Hirnverletzten in sämtlichen vier Texten beider Versuchsreihen. Die Kopfverletzten nehmen in den meisten Fällen wieder eine Mittelstellung ein. Nur bei Versuchsanordnung IV a und IV c sind sie den Hirnverletzten etwas unterlegen.

b) Deutliche Abhängigkeit der Aufmerksamkeitsintensität von der betroffenen Hirnregion. Durchweg die besten Leistungen weisen die Stimhirnverletzten auf, dann folgen in geringem Abstand die Zentralhirnverletzten. Wesentlich schlechtere Resultate zeigen clie Scheitelhirnverletzten, die schlechtesten die Sehhirnverletzten. Bei den letzteren handelt es sich durchweg um eine im Vergleich mit den Stirnhirnverletzten drei- bis vierfach herabgesetzte Aufmerksamkeitsintensität; bei den Scheitelhirnverletzten sind die erzielten Werte um das Doppelte niedriger. Diese Beziehungen zwischen Aufmerksankeitsleistung und dem Ort der Rindenzerstörung traten zwar auch im Bourdon-Versuch in Erscheinung, jedoch riel weniger deutlich als hier. Eine gute Illustration hierfür gibt die folgende Gegenüberstellung, die sich auf die Versuchsergebnisse der vier Hirnverletztengruppen beim ersten Bourdon-Versuch und beim ersten Trommelversuch mit sinnvollem Text stützt. Die Versuchspersonen sind in beiden Fällen genau die gleichen.

Tabelle XIV.

\begin{tabular}{|c|c|c|c|c|}
\hline & $\begin{array}{l}\text { Stirnhirn- } \\
\text { verletzte }\end{array}$ & $\begin{array}{l}\text { Zentralhirı- } \\
\text { verletzte }\end{array}$ & $\begin{array}{l}\text { Seheitelhirn- } \\
\text { verletzte }\end{array}$ & $\begin{array}{l}\text { Hinterhaupts- } \\
\text { hirnverletzte }\end{array}$ \\
\hline $\begin{array}{l}\text { 1. Bourdon-Versuch (Reihe I) } \\
\text { 1. Trommelversuch (Reilıe IIId) }\end{array}$ & $\begin{array}{l}4,5^{\circ} \\
7,5^{\circ} \%\end{array}$ & $\begin{array}{l}10 \% \\
10,8 \%\end{array}$ & $\begin{array}{l}10,6^{\circ} \% \\
15.0^{\circ}\end{array}$ & $\begin{array}{l}12,8 \% \\
33,0 \%\end{array}$ \\
\hline
\end{tabular}

Also einerseits Chereinstimmung der Ergebnisse beider Untersuchungsmethoden in bezug auf die Uberlegenheit der Stirnhirnver- 
letzten; anderseits geringe Unterschiede in den Aufmerksamkeitsleistungen der Zentral-, Scheitel- und Sehhirnverletzten beim BourdonVersuch gegenüber erheblichen Unterschieden beim Trommelversuch. Was besonders die Versuche bei Sehhirnverletzten betrifft, so konnten sie durch sehr langsame Arbeitsmethode - sie durchstrichen durchschnittlich in 3 Minuten nur 88 Buchstaben, die Stirnhirnverletzten dagegen 123 Buchstaben - einer wesentlichen Herabsetzung der qualitativen Leistung vorbeugen. Beim Bourdon-Versuch erreichen sie also nur deswegen ein verhältnismäßig gutes Resultat, weil die Wahl des Arbeitstempos ihnen überlassen war. Mußten sie dagegen ebenso schnell arbeiten wie die Stirnhirnverletzten, dann ist es nur natürlich, daß sie infolge ihrer mangelhaften Sehkraft nicht mehr konkurrenzfähig sind. Die Herabsetzung der Leistung dürfte hier ebenso wie beim Tachistoskopversuch in erster Linie auf die Sehstörung und nicht auf einen besonders großen Mangel an optischer Aufmerksamkeit zurückzuführen sein.

c) Außerst mangelhafte A ufmerksamkeitsleistungen der hysterischen Hirnverletzten (vgl. Tabelle XIII, S. 274). Die Zahlen fallen vollständig aus dem Rahmen der bei allen ülorigen Hirnverletzten beobachteten Resultate heraus. Während die Normalen unter 100 Reizbuchstaben bei der Versuchsanordnung III a kaum 2 übersehen, die Hirnverletzten durchschnittlich 8 und die Sehhirnverletzten als die schlechtesten Hirnverletzten 16, lassen die Hysteriker fast die Hälfte aller Buchstaben aus. Dabei macht es keinen Unterschied aus, ob sinnvoller oder sinnloser Text exponiert wird.

d) Abhängigkeit der Aufmerksamkeitsintensität vom Ablenkungsfaktor. Sie wird gekennzeichnet durch die Unterschiede in den Versuchsergebnissen bei sinnvollem und sinnlosem Text. Je sinnvoller der Text, desto größer die Ablenkungsmöglichkeit und desto geringer die Aufmerksamkeitsintensität. Diese graduelle Abstufung geht am deutlichsten aus Versuchsreihe III bei Kopf- und Hirnverletzten hervor. Der Fehlerprozentsatz ist am geringsten bei Versuchen mit ununterbrochener sinnloser Buchstabenfolge (Reihe a), am größten bei zusammenhängendem sinnvollem Text (Reihe d). Zwischen diesen beiden Grenzfällen bewegen sich Mittelwerte, die den Versuchsanordnungen bei sinnlosenr und sinnvollen Worten entsprechen. Was clie Unterschiede zwischen den einzelnen Gruppen in bezug auf ihre Empfänglichkeit für ablenkende Reize betrifft, so ist diese relativ am kleinsten bei Scheitelhirnverletzten und relativ am größten bei Zentral- und Sehhirnverletzten. Bei der ersten Gruppe findet bei sinnvollem Text eine Herabsetzung der Aufmerksamkeitsleistung um etwa den vierten Teil des Anfangsbetrages statt, bei den letzteren um mehr als das Doppelte. Auch bei den Normalen ist der Charakter des exponierten Textes nicht bedeutungslos für den Ausfall der Aufmerksamkeitsleistung. Jerloch 
scheint hier der Übungsfaktor eine gewisse Rolle zu spielen, so daß im Verlauf des Versuchs die Sammlungsfähigkeit trotz Steigerung der ablenkenden Momente eher eine Zunahme erfährt. Anders läßt sich die Tatsache wohl kaum erklären, daß im ersten Trommelversuch der Fehlerprozentsatz bei simnlosen Worten (Reihe b) sein Maximum erreicht, um dann bei sinnvollen Worten und zusammenhängendem Text (Reihe $\mathrm{c}$ und d) stufenweise wieder abzusinken. Was hier lediglich für die Normalen gilt, ist im zweiten Trommelversuch auch bei Kopfverletzten und sämtlichen Hirnverletztengruppen zu beobachten. Die Wirksamkeit des Übungsfaktors macht sich hier allerdings nur in der letzten Versuchsanordnung (Reihe d) geltend. Außerdem ist die Steigerung der Aufmierksamkeitsintensität gegenüber der vorausgehenden Reihe so gering, daß für diesen Befund schwerlich eine andere Erklärung in Betracht kommt, als die Annahme einer fast völligen Gleichheit der Ablenkungs. momente in den Versuchsreihen e und d. Mit anderen Worten: Ein zusammenhängender sinnvoller 'Text stellt an die Tenazität der Aufmerksamkeit im allgemeinen keine höheren Anforderungen als ein Text mit sinnvollen, unzusammenhängenden Worten. Mit dieser Einschränkung ist der Satz, daß die Aufmerksamkeitsleistungen beim Trommelversuch umgekehrt proportional dem Ablenkungsfaktor sind, auf Grund des Befunde in den Versuchsreihen III und IV in vollem Umfang aufrechtzuerhalten.

Diese objektiven Befunde werden durch Befragen der Versuchspersonen weitgehend bestätigt. Fast ïbereinstimmend wird von ihnen an. gegeben, daß sie am wenigsten abgelenkt wïrden, wenn die Buchstaben sinnlos und ohne Cnterbrechung einander folgten, und daß die Aufgabe am schwierigsten sei bei sinnvollem Text. Diese Steigerung der Ablenkbarkeit scheint teilweise mit der Neigung zusammenzuhängen, den sinnvollen Stoff in Form von Worten statt von Buchstabenreihen aufzu. fassen. Bei einem solchen Auffassungsvorgang kommen natürlich dit Reizbuchstaben nicht so klar zum Bewußtsein wie beim einfachen Buchstabieren ( $V$ ogt).

e) Abhängigkeit der Aufmerksamkeitsintensität vom Übungsfaktor. Beim Vergleich des ersten und zweiten Trommel. versuchs fällt auf, daß die wesentliche Erschwerung der Versuchsbedin gungen, wie sie durch Einführung eines dritten Reizbuchstabens gegeber ist, nur eine verhältnismäßig geringe Verschlechterung der Aufmerk samkeitsleistung zur Folge hat. Die Differenzen zwischen den entspre chenden Werten der beiden Versuchsreihen sind teilweise minimal: in vereinzelten Fällen werden sogar beim Durchstreichen von 3 Buchstaben bessere Resultate erzielt, als bei 2 Buchstaben, so von den Schejtelhirn verletzten in der Versuchsanordnung IV a und den Sehhirnverletzten in der Versuchsanordıung IVd. Wenn man berlenkt, daß der schwieri. 
geren Versuchsreihe IV in allen Fällen die leichtere Versuchsreihe III vorausging, so liegt es immerhin nahe, als Erklärung für die angedeuteten Verhältnisse einen Ubungsfortschritt in Versuchsreihe IV anzunehmen. In der Tat ließ sich die Berechtigung dieser Anrahme durch eine entsprechende Versuchsanordnung nachweisen. Es wurde nämlich 20 Versuchspersonen ganz unvorbereitet die Durchstreichung der drei Buchstaben $\mathbf{e}, \mathbf{m}$ und $\mathbf{s}$ zur Aufgabe gemacht, ohne daß die beiden BourdonVersuche und der erste Trommelversuch nur mit den beiden Buchstaben e und $\mathbf{m}$ vorausgegangen wären. Das Resultat war ein überraschendes. Die Fehlerprozentsätze der Versuchsanordnungen a-d bei geübten und ungeübten Versuchspersonen zusammengestellt, ergeben folgendes Bild:

Tabelle XV.

\begin{tabular}{c|c|c|c|c}
\hline Reihe IV & a & b & c & d \\
\hline 20 ungeübte Versuchspersonen & 27,0 & 30,0 & 35,4 & 32,0 \\
49 geübte Versuchspersonen & 10,8 & 13,8 & 16,6 & 15,6
\end{tabular}

Also eine Besserung der Aufmerksamkeitsintensität infolge größerer Úbung um das Doppelte bis Dreifache. Dabei ist die Gruppe der ungeübten Versuchspersonen entschieden günstiger zusammengesetzt als die der geübten, denn es fehlen dort die Occipitalhirnverletzten, also die Yersuchspersonen mit den niedrigsten Aufmerksamkeitswerten, während unter den 49 geïhten Versuchspersonen 6 Occipitalhirnverletzte vertreten sind. Im uibrigen ist der Prozentsatz der Stirn-, Zentral- und Scheitelhirnverletzten in beiden Gruppen ungefähr der gleiche.

f) Abhängigkeit der A uf merksamkeitsintensität von der Begabung. Binet hat diese Frage einer eingehenden Prüfung an je 5 intelligenten und unintelligenten Schülern unterzogen. Fr fand, daß die Schnelligkeit unabhängig und die Genauigkeit abhängig sei von der Intelligenz. Zur Nachprüfung dieses Befundes bei Hirnverletzten wurden die Aufmerksamkeitsresultate ebenfalls von je 5 intelligenten und unintelligenten Versuchspersonen zusammengestellt. Außerdem mußte bei der Auswahl darauf geachtet werden, daß die Vergleichspersonen in bezug auf ihre Hirnschädigung möglichst auf gleicher Stufe standen. Dies geschah in der Weise, daß in jeder Gruppe 1 Stirnhirnverletzter und je 2 Zentral- und Scheitelhirnverletzte vertreten waren.

Tabelle XVI.

\begin{tabular}{|c|c|c|c|c|c|c|c|c|c|c|}
\hline & \multicolumn{5}{|c|}{ Reihe I } & \multicolumn{5}{|c|}{ Reihe II } \\
\hline & \multicolumn{2}{|c|}{ Gesamtzahl } & \multicolumn{2}{|c|}{$\begin{array}{c}\text { Durch- } \\
\text { schnittszahl }\end{array}$} & \multirow{2}{*}{ 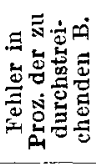 } & \multicolumn{2}{|c|}{ Gesamtzahl } & \multicolumn{2}{|c|}{$\begin{array}{l}\text { Durch- } \\
\text { schnittszahl }\end{array}$} & \multirow{2}{*}{ 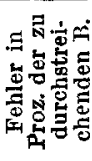 } \\
\hline & 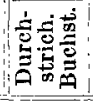 & 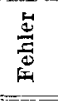 & 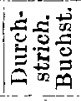 & 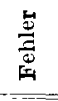 & & 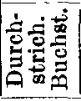 & 岕 & 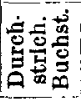 & 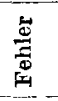 & \\
\hline & 756 & & 151 & 4,2 & & 877 & & 175 & & \\
\hline 5 Tnbegalite & 612 & 50 & 129 & 10 & & 710 & 26 & 142 & 5,2 & $3,6 \%$ \\
\hline
\end{tabular}


Der Einfluß der Begabung tritt also auch hier deutlich in Erscheinung, und zwar nicht nur wie bei Binet in der Qualität, sondern auch in der Quantität der Leistung. Die Unbegabten durchstreichen in $3 \mathrm{Mi}$ nuten sowohl beim ersten als auch beim zweiten Bourdon-Versuch durchschnittlich $23 \%$ Buchstaben weniger als die Begabten und machen beim ersten Versuch etwas mehr als doppelt soviel Fehler. Auch beim zweiten Versuch hat sich das qualitative Verhältnis nur wenig zugunsten der Ungeübten geändert. Es muß allerdings einschränkend bemerkt werden, daß die Abhängigkeit der Aufmerksamkeitsintensität von der Begabung längst nicht bei allen Hirnverletzten nachzuweisen ist, da eben der Begabungsfaktor gegenüber der Rindenläsion beim Durchstreichversuch anscheinend noch mehr in den Hintergrund tritt als bei der tachistoskopischen Prüfung.

\section{E. Schlußfolgerungen.}

Ubersehen wir die Versuchsergebnisse der Bourdon- und Tachistoskopmethode im Zusammenhang, so läßt sich eine weitgehende Utbereinstimmung nicht verkennen. Die Faktoren, von denen die Größe des Aufmerksamkeitsumfangs abhängig war, haben sich auch für die Vigilität und Tenazität der Aufmerksamkeit als ausschlaggebend erwiesen. Der Ausfall sowohl der tachistoskopischen Versuche als auch der Durchstreichmethode richtete sich in erster Linie nach der Lage der Rindenverletzung, in zweiter Linie nach dem Grade der Ùbungsfähigkeit, der Ablenkbarkeit sowie der Begabung. Wir sahen, daß Störungen der optischen Aufmerksamkeit, gleichviel ob es sich um ihren Umfang oder ihre Konzentrationsfähigkeit handelte, in dem Maße zunahmen, als sich der Rindenherd vom Stirnhirn entfernte und sich dem Scheitelhirn näherte.

Diese Beobachtung an Hirnverletzten findet eine interessante Bestätigung in klinischen Erfahrungen, die Pfeifer auf einem ganz anderen Gebiet, nämlich bei Hirntumoren, gemacht hat. Aus seiner Arbeit über psychische Störungen bei Hirntumoren ist zu entnehmen, daß bei 13 Hirntumoren in keinem Fall eine Störung der Aufmerksamkeit vorlag. Ebenso fehlte diese bei 10 Zentralhirnverletzten. Dagegen war unter 8 Fällen von Scheitellappentumoren bei zwei Kranken eine im Verhältnis zu der vorhandenen geringen Bewußtseinstrübung auffällige Herabsetzung der Aufmerksamkeit festzustellen, ohne daß irgendeine Störung der Intelligenz bestand. Ist es nun erlaubt, auf Grund dieser Befunde bei Hirndefekten und Tumoren von einer Lokalisation der A ufinerksamkeit zu sprechen?

Was zunächst das Fehlen jeder Aufmerksamkeitsstörung bei Stirn hirnverletzten betrifft, so soll ohne weiteres zugegeben werden, daß die relativ geringe Versuchszahl - es handelt sich hier vorerst nur 
um 10 Versuchspersonen mit vorwiegender Stirnhirnverletzung Fehlerquellen nicht mit Sicherheit ausschließt. Bei Fortsetzung der Versuche, die zur Klärung der Lokalisationsfrage unbedingt erforderlich ist, muß jedenfalls mit der Möglichkeit gerechnet werden, Stirnhirnverletzten mit Aufmerksamkeitsschädigungen zu begegnen. Immerhin geht doch schon aus den mitgeteilten Aufmerksamkeitsuntersuchungen hervor, daß auch schwere Zertrümmerung des Stimhirns keineswegs wie Monakow u. a. meinen, notwendigerweise mit psychischen Ausfallserscheinungen einhergehen muss. Jedenfalls ist das Bestreben einzelner Autoren, wie Ferrier und Bianchi, gerade im Stirnhirn den Sitz der Aufmerksamkeit anzunehmen, mit unseren Versuchsergebnissen nicht in Einklang zu bringen. Selbst $W$ undt vertrat früher den Standpunkt, daß der Aufmerksamkeitsprozeß mit einer gleichzeitigen Erregung von Elementen der Stirnregion verbunden sei, eine Auffassung, die er allerdings in der neuesten Auflage seiner physiologischen Psychologie hat fallen lassen.

Bei der zweiten Gruppe, den Soldaten mit Rindenherden in der Zentralgegend, scheint die Zahl der Versuchspersonen ausreichend genug, um ein von individuellen Schwankungen unabhängiges Durchschnittsmaß zu gewährleisten. Trotzdem in dieser Gruppe die somatisch am schwersten geschädigten Hirnverletzten vertreten sind, - beispielsweise allein 77\% aller Epileptiker - nähert sich ihre Durchschnittsleistung doch fast noch der Norm. Um so auffallender das Ergebnis bei Schädigung des Scheitellappens. Es ist nicht ohne weiteres einzusehen, weshalb Scheitelhirnverletzte schlechtere Aufmerksamkeitsleistungen darbieten sollten, als Zentrallappenverletzte, zumal sie auf anderen Gebieten durchweg weniger grobe Ausfallserscheinungen zeigen als jene.

Zur Erklärung dieser Tatsache wird man sich zunächst daran erinnern, daß bei Sehhirnverletzten die optische Aufmerksamkeit in hohem Grade geschädigt ist, und zwar infolge der zentralen Sehstörung. Sollten etwa auch bei unseren Scheitelhirnverletzten die Aufmerksamkeitsdefekte lediglich auf Sehstörungen zurückzuführen sein? Dieser Einwand ist sehr wohl berechtigt angesichts der klinischen Erfahrung, da $B$ bei Scheitellappenherden in der Tat Schädigungen des optischen Systems vorkommen können, sei es bedingt durch unmittelbare Läsion der Sehstrahlung, sei es infolge Fernwirkung des Herdes auf die Sehsphäre im Hinterhauptslappen. Nun konnte zwar bei einzelnen Scheitelhirnverletzten eine leichte konzentrische Finengung des Gesichtsfeldes festgestellt werden, die jedoch schwerlich die optischen Aufmerksamkeitsdefekte erklären dürfte. Außerdem waren in der überwiegenden Mehrzahl der Fälle irgendwelche Sehstörungen überhaupt nicht nachzuweisen. Der negative Befund würde natürlich 
die Intaktheit des optischen Systems noch keineswegs beweisen. Wenn wir überhaupt die mangelhaften Aufmerksamkeitsleistungen der Scheitelhirnverletzten auf Sehstörungen zurückführen wollen, so hätten wir es doch hier aller Wahrscheinlichkeit nach nicht mit grobanatomischen Schädigungen der spezifischen Ganglienzellenkomplexe zu tun, sondern mit feinsten strukturellen Veränderungen im Zellaufbau der Sehsphäre, die möglicherweise ebensowenig mit den üblichen Untersuchungsmethoden nachzuweisen sind, wie die durch sie bedingten Funktionsstörungen.

Nun besteht jedoch noch eine zweite Erklärungsmöglichkeit für die Aufmerksamkeitsdefekte bei Scheitellappenherden. Wir wissen, daß jede Empfindung ein Erinnerungsbild hinterläßt, das in ganz bestimmten Rindenelementen niedergelegt wird. Ferner ist mit größter Wahrscheinlichkeit mit einer funktionellen Trennung von Erinnerungsfeldern und Empfindungsfeldern in der Hirnrinde zu rechnen ( $\mathrm{Munk}$, Wilbrand, Ziehen u. a.). Wir sind also keineswegs zu der Annahme genötigt, daß bei Scheitelhirnverletzten die optische Empfind ungs s phäre in Mitleidenschaft gezogen ist, vielmehr würde die Schädigung des optischen Erinnerungszentrums die beobachteten Ausfallserscheinungen genügend erklären können. Die Lage der Erinnerungsfelder für alle Sinnesgebiete exakt festzustellen, ist jedoch noch keineswegs gelungen. Was speziell die Lokalisation der optischen Erinnerungssphäre betrifft, die offenbar in innigem Zusammenhang mit den Funktionen der optischen Aufmerksamkeit steht, so war schon Wilbrand geneigt, die laterale Fläche des Occipitalhirns hierfür in Anspruch zu nehmen. Ferner ist bei 10 unter den von Friedrich Müller zusammengestellten 22 sezierten Fällen von Seelenblindheit die Scheitelhirngegend entweder ausschließlich oder in Verbindung mit benachbarten Rindenterritorien zerstört. Gerade dieser Befund wirft ein Licht auf die schlechten Aufmerksamkeitsleistungen der Scheitelhirnverletzten.

Es lenchtet ohne weiteres ein, daß die angewandten Untersuchungsmethoden, insbesondere die Benutzung des Tachistoskops, nicht nur völlige Intaktheit des optischen Empfindungszentrums, sondern auch schnelle Bereitschaft der optischen Erinnerungsbilder voraussetzt. Bezeichnend ist nun, daß ein großer Teil der Scheitelhirnverletzten auffallende Defekte im Kopfrechnen aufweist. Diejenigen unter ihnen, die intelligent genug sind, um Selbstbeobachtungen zu machen, erklären übereinstimmend, daß sie nur deshalb so schlecht rechnen können. weil es längere Zeit in Anspruch nähme, bis sie sich von den akustisch dargebotenen Zahlen ein visuelles Bild gemacht hätten. Diese schlechten Kopfrechner sind nun dieselben, die beim Tachistoskopversuch in erster Linie versagen. Auch hier geben sie als Erklärung an, daß sie die exponierten Zahlen zwar sehen, daß die Zeit jedoch zu kurz sei, um sich die 
Zahlen in der Erinnerung klar vorstellen und reproduzieren zu können. Objektiv ausgedrückt, findet sich bei ihnen trotz guter Sehschärfe eine Unfähigkeit, kurzdauernde Reize aufzunehmen. Diese Selbstbeobachtungen zusammengehalten mit der experimentell festgestellten Tatsache, daß die schwersten Störungen der optischen Aufmerksamkeit bei Rindenläsion im Scheitellappengebiet vorkommen, scheinen darauf hinzuweisen, da 3 in der Scheitelhirnrinde Zentren gelegen sind, die in funktioneller Verbindung mit dem optischen Aufmerksamkeitsakt stehen. Die alte Flechsigsche Lehre vom hinteren großen Assoziationszentrum, das mit großen Teilen des Scheitellappens zusammenfällt, wird auf Grund unserer experimentellen Aufmerksamkeitsuntersuchungen an Scheitelhirnverletzten in ein neves Licht gerückt.

\section{Zusammenfassung.}

1. Die optisch-sensorielle Aufmerksamkeit von 100 Soldaten davon 80 hirnverletzt und je 10 kopfverletzt und normal - wurde geprüft einerseits auf ihren Umfang mit den Tachistoskopen nach Wundt und Netschajeff, anderseits auf ihre Vigilität (Weckbarkeit) und Tenazität (Konzentrationsfähigkeit) mit der Durchstreichmethode nach Bourdon und Ziehen.

2. Das physiologische Durchschnittsmaß des Aufmerksamkeitsumfangs von 4-6 unverbundenen Einheiten erreichen bei Zahlenversuchen über $2 / 3$ der Normalen und Kopfverletzten, dagegen nur die Hälfte der Hirnverletzten.

3. Für unsere Versuchsbedingungen und Versuchspersonen ist die untere Grenze des normalen Aufmerksamkeitsumfangs nicht bei 4, sondern bei 3 Einheiten anzunehmen. Eine Aufmerksamkeitsstörung liegt also vor, wenn 3 unverbundene Einheiten nicht mehr tachistoskopisch erkannt werden. Unter dieser Voraussetzung haben einen normalen Aufmerksamkeitsumfang sämtliche normalen Soldaten, $80 \%$ der Kopfverletzten und $65 \%$ der Hirnverletzten.

4. Für den Ausfall der tachistoskopischen Aufmerksamkeitsuntersuchung ist der Ort der Rindenläsion von ausschlaggebender Bedeutung, ohne daß die Bevorzugung einer der Hemisphären nachzuweisen wäre. Einen normalen Aufmerksamkeitsumfang haben sämtliche Stirnhirnverletzte, $3 / 4$ der Zentralhirnverletzten und nur $1 / 3$ der Scheitelhirnverletzten. Mit anderen Worten: Substanzdefekte des Stirnhirns sind bedeutungslos für die Größe des Aufmerksamkeitsumfangs. Störungen machen sich erst bemerkbar bei Rindenherden im Gebiet der Zentralwindungen. In dem Maße, als die Verletzung sich vom Stirnhirn entfernt und sich dem Scheitellappen nähert, sinkt der Aufmerksamkeitsumfang von einem Maximum auf ein Minimum. Den Nullpunkt erreicht er bei Verletzung der zentralen Sehregion. Mithin hat das Ge- 
setz von der Konstanz des Aufmerksamkeitsumfangs unter pathologischen Verhältnissen keine Gültigkeit.

5. Die funktionell verschiedene Wertigkeit der Hirnrinde für die Größe des Aufmerksamkeitsumfangs ist mit allen benutzten Versuchsanordnungen übereinstimmend nachzuweisen, nämlich in Zahlen- und sinnlosen Buchstabenversuchen mit und ohne Ablenkung, sowie in Versuchen mit sinnvollen Worten; bei einer Expositionszeit sowohl von $15 \sigma$ als auch von $30 \sigma$; bei einmaliger ebenso wie bei mehrmaliger Exposition. Beispielsweise erkennen die Stirnhirnverletzten als Durch= schnittsleistung Worte mit 17 Buchstaben, die Zentralhirnverletzten Worte mit 14 Buchstaben, die Scheitelhirnverletzten Worte mit 9 Buchstaben.

6. Die Größe des Aufmerksamkeitsumfangs ist die Resultante vieler in entgegengesetzter Richtung und abgestufter Stärke wirkenden Kräfte. $\mathrm{Zu}$ den gü nstige $n$ Versuchsbedingungen gehören : Möglichst sinnvolles Reizmaterial, Verlängerung der Expositionszeit, Wiederholung der Exposition, in einzelnen Fällen selbständige Expositionsauslösung, fluktuierender Aufmerksamkeitstypus, mittlerer Spannungszustand, gute Úbungsfähigkeit und Begabung. Unter den hemmenrlen Faktoren sind zu nennen: Sinnlosigkeit des Reizmaterials, verkürzte Expositionszeit, einmalige Exposition, fixierender Aufmerksamkeitstypus, erhöhter Spannungszustand, große Ablenkbarkeit und Ermüdbarkeit, schlechte Begabung. Der ausschlaggebende und den ganzen Typus des Aufmerksamkeitsumfangs bestimmende Faktor ist in jedem Fall die Sehädigung der Hirnrinde, und zwar nicht die Verletzung an und für sich, sondern die Lage des Rindenherdes.

7. Eine Ausnahme von dieser Regel bilden die hysterischen Hirnverletzten, von denen keiner die untere Grenze des normalen Aufmerksamkeitsumfangs erreicht. Für diese Sondergruppe ist eine Beziehung zwischen Aufmerksamkeitsleistung und Ort der Rindenläsion nicht nachzuweisen. Die psychogene Komponente bei Hirnverletzten führt zu einem in quantitativer und qualitativer Beziehung wohl charakterisierten Aufmerksamkeitstypus, der von differentialdiagnostischer $\mathrm{Be}^{-}$ deutung ist.

8. Das Gesetz von der funktionell verschiedenen Bedeutung der Hirnrinde für die Größe des Aufmerksamkeitsumfangs wird bestätigt durch die Ergebnisse der Vigilitäts- und Tenazitätsuntersuchungen. Die Weckbarkeit und Konzentrationsfähigkeit der optischen Aufmerksamkeit ist bei Scheitelhirnverletzten mehr als um das Doppelte, die der Hinterhauptsverletzten fast um das Dreifache geringer als bei Stirnhimverletzten.

9. Vigilität und Tenazität der Aufmerksamkeit sind ebenso wie ihr Umfang in erster Linie abhängig von der Lage der Rindenverletzung, 
in zweiter Linie vom Grade der Ablenkbarkeit, Ủbungsfähigkeit und Begabung.

10. Die experimentellen Aufmerksamkeitsuntersuchungen an Hirnverletzten scheinen darauf hinzuweisen, daß in der Scheitelhirnrinde Zentren gelegen sind, die in funktioneller Verbindung mit dem optischen Aufmerksamkeitsakt stehen.

Zum Schluß sei mir gestattet, auch an dieser Stelle Herm Geheimrat Ziehen meinen verbindlichsten Dank zu sagen für die Anregung zu den vorliegenden Untersuchungen, sowie besonders für die liebenswürdige Unterstützung bei der Vervollkommnung des Netschajeffschen Tachistoskops.

\section{Literaturverzeichnis.}

1. Bianchi, Revue de psych. clin. thér. 1900.

2. Binet, Attention et Adaptation. Année psych. 6. 1900.

3. Bourdon, Année psych. 1. 1894.

4. - Revue philos. 1895.

5. Busch, Über geistige Arbeitsleistung Hirnverletzter. Zeitschr. f. d. ges. Neur. u. Psych. 40. 1918.

6. Cattel, Über die Träghaut der Netzhaut und des Sehzentrums. Philos. Studien 3. 1886.

7. Deuchler, Pendeltachistoskop. Päd. psych. Arb. 1. 1910.

8. Dürr, Die Lehre von der Aufmerksamkeit. 2. Aufl. 1914.

9. Ebbinghaus, Grundzüge der Psychologie. 1. Aufl. \$. $568 \mathrm{ff}$.

10. Erdmann und Dodge, Psychol. Untersuchungen über das Lesen. Halle 1898.

11. Ferrier, The functions of the brain. London 1886 .

12. Finzi, Zur Untersuchung der Auffassungsfähigkeit und Merkfähigkeit. Kraepelins psych. Arb. III. 1901.

13. Flechsig, Gehirn und Seele. 1896.

11. - Lokalisation geistiger Vorgänge. 1896.

15. Freeman, Untersuchungen über den Aufmerksamkeitsumfang bei Kindern und Erwachsenen. Päd. psych. Arb. 1. 1910.

16. Krae pelin, Die Arbeitskurve. Wundts philos. Studien 19. 1902.

17. Kraskowski, Die Abhängigkeit des Umfangs der Aufmerksamkeit von ihrem Spannungszustande. Psychol. Studien 8. 1913.

18. v. Maltzahn, Untersuchungen über Aufmerksamkeitsstörungen bei Geisteskranken mit Hilfe der Bourdonschen Probe. Diss. Berlin 1911.

19. Messmer, Zur Psychologie des Lesens. Arehiv f. d. ges. Psychol. 2. 1907.

20. Meumann, Vorlesungen I u II.

21. - Intelligenz und Wille.

22. Monakow, Gehimpathologie. 1897.

23. Müller, Ein Beitrag zur Kenntnis der Seelenblindheit. Archiv f. Psych. 24. 1892.

24. Munk, Über die Funktionen der Großhirnrinde. 2. Aufl. Berlin 1890.

25. Netschajeff, Untersuchungen über die Beobachtungsfähigkeit von Schülern. Zeitschr. f. angew. Psych. 4. 1910.

26. Oehrn, Exp. Studien zur Individualpsych. Kraepelins psych. Arb. T. 1899. 
284 F. v. Rohden: Experimentelle Aufmerksamkeitsuntersuchungen usw:

27. Oppenheim, Lehrbuch der Nervenkrankheiten. 6. Aufl.

28. Pfeifer, Psych. Störungen bei Hirntumoren. Archiv f. Psych. 4\%. 1910.

29. Quandt, Bewußtseinsumfang für regelmäßig gegliederte Gesamtvorstellungen. Psychol. Studien 1. 1905.

30. Schumann, Zur Erkennung von Buchstaben und Worten bei momentaner Belichtung. I. Kongreß f. exp. Psychol. 1904.

31. - Psychologie des Lesens. II. Kongreß f. exp. Psychol. 1906.

32. Sharp, Individual Psychology. American. Journ. of Psychol. 1898/99.

33. Vogt, Über Ablenkbarkeit und Gewöhnungsfähigkeit. Kraepelins psych. Arb. 2. 1901.

34. Wilbrand, Die Seelenblindheit als Herderscheinung. Wiesbaden 1887.

35. Winteler, Exp. Beiträge zur Begabungslehre. Zeitschr. f. exp. Pädag. 2. 1906.

36. Wirth, Zur Theorie des Bewußtscinsumfangs und seiner Messung. Philosoph. Studien 20. 1902.

37. - Exp. Analyse der Bewußtseinsphänomene.

38. Wundt, Grundzüge der physiol. Psychologie. 6. Aufl. Bd. III.

39. Zeitler, Tachistoskopische Untersuchungen über das Lesen. Wundts philos. Studien 16. 1900.

40. Ziehen, Ein einfacher Apparat zur Messung der Aufmerksamkeit. Monatsschrift f. Psych. u. Neurol. 14. 1903.

41. - Zur Lehre von der Aufmerksamkeit. Monatsschr. f. Psych. u. Neurol. 24. 1908.

42. - Das Gedächtnis. Festrede. Berlin 1908.

43. - Leitfaden der physiol. Psychologie. 10. Aufl. Jena 1914.

44. - Prinzipien und Methoden der Intelligenzprüfung. 4. Aufl. Berlin 1918.

45. - Über das Wesen der Beanlagung und ihre methodische Erforschung. Päd. Magazin H. 683. Langensalza 1918.

46. - Experimentelle Psychologie. Kolleg und Übungen. W.-s. 1917/18. 